\title{
TITLE: AMORPHOUS ALLOY MEMBRANES FOR HIGH TEMPERATURE HYDROGEN SEPARATION
}

\section{FINALTECHNICAL REPORT}

\author{
REPORTING PERIOD START DATE: 9/30/09 (PROGRAM START) \\ REPORTING PERIOD END DATE: 9/28/13 \\ PRINCIPLE AUTHOR(S): $\quad$ K. COULTER \\ DATE REPORT WAS ISSUED: ～DECEMBER 2013 \\ DOE AWARD NUMBER: DE-FE0001057 \\ SUBMITTING ORGANIZATION: SOUTHWEST RESEARCH INSTITUTE \\ 6220 CULEBRA ROAD (78238-5166) \\ P.O. BOX 28510(78228-0510) \\ SAN ANTONIO, TEXAS \\ OTHER TEAM MEMBERS: \\ GEORGIA TECH UNIVERSITY \\ WESTERN RESEARCH INSTITUTE \\ SUBMIT TO: \\ NETL AAD DOCUMENT CONTROL \\ BLDG. 921 U.S. DEPARTMENT OF ENERGY \\ NATIONAL ENERGY TECHNOLOGY LABORATORY \\ P.O. BOX 10940 \\ PITTSBURGH, PA 15236-0940
}

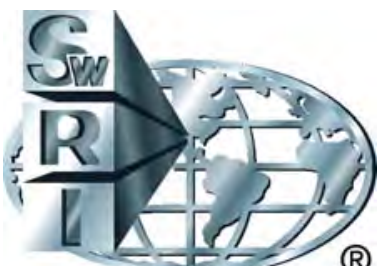




\title{
TITLE: AMORPHOUS ALLOY MEMBRANES FOR HIGH TEMPERATURE HYDROGEN SEPARATION
}

FINAL TECHNICAL REPORT

\author{
REPORTING PERIOD START DATE: 9/30/09 (PROGRAM START) \\ REPORTING PERIOD END DATE: 9/28/13 \\ PRINCIPLE AUTHOR(S): $\quad$ K. COULTER \\ DATE REPORT WAS ISSUED: I DECEMBER 2013 \\ DOE AWARD NUMBER: DE-FE0001057 \\ SUBMITTING ORGANIZATION: SOUTHWEST RESEARCH INSTITUTE \\ 6220 CULEBRA ROAD (78238-5166) \\ P.O. BOX 28510(78228-0510) \\ SAN ANTONIO, TEXAS \\ OTHER TEAM MEMBERS: \\ GEORGIA TECH UNIVERSITY \\ WESTERN RESEARCH INSTITUTE \\ SUBMIT TO: \\ NETL AAD DOCUMENT CONTROL \\ BLDG. 921 U.S. DEPARTMENT OF ENERGY \\ NATIONAL ENERGY TECHNOLOGY LABORATORY \\ P.O. BOX 10940 \\ PITTSBURGH, PA 15236-0940
}

APPROVED:

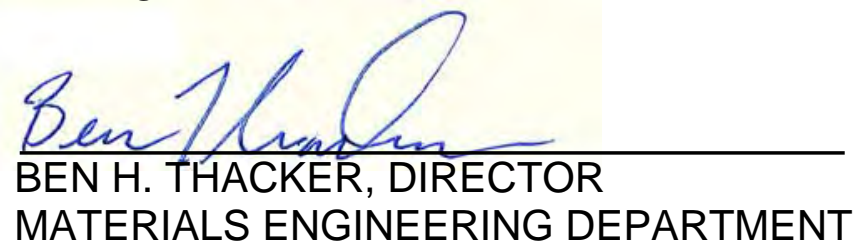




\section{DISCLAIMER}

“This report was prepared as an account of work sponsored by an agency of the United States Government. Neither the United States Government nor any agency thereof, nor any of their employees, makes any warranty, express or implied, or assumes any legal liability or responsibility for the accuracy, completeness, or usefulness or any information, apparatus, product, or process disclose, or represents that its use would not infringe privately owned rights. Reference herein to any specific commercial product, process, or service by trade name, trademark, manufacturer, or otherwise does not necessarily constitute or imply its endorsement, recommendation, or favoring by the United States Government or any agency thereof. The views and opinions of authors expressed herein do not necessarily state or reflect those of the United States Government or any agency thereof.” 


\begin{abstract}
At the beginning of this project, thin film amorphous alloy membranes were considered a nascent but promising new technology for industrial-scale hydrogen gas separations from coalderived syngas. This project used a combination of theoretical modeling, advanced physical vapor deposition fabricating, and laboratory and gasifier testing to develop amorphous alloy membranes that had the potential to meet Department of Energy (DOE) targets in the testing strategies outlined in the NETL Membrane Test Protocol. The project is complete with Southwest Research Institute ${ }^{\circledR}\left(\right.$ SwRI $\left.^{\circledR}\right)$, Georgia Institute of Technology (GT), and Western Research Institute (WRI) having all operated independently and concurrently. GT studied the hydrogen transport properties of several amorphous alloys and found that $\mathrm{ZrCu}$ and $\mathrm{ZrCuTi}$ were the most promising candidates. GT also evaluated the hydrogen transport properties of $\mathrm{V}, \mathrm{Nb}$ and Ta membranes coated with different transition-metal carbides (TMCs) (TM = Ti, Hf, Zr) catalytic layers by employing first-principles calculations together with statistical mechanics methods and determined that $\mathrm{TiC}$ was the most promising material to provide catalytic hydrogen dissociation. SwRI developed magnetron coating techniques to deposit a range of amorphous alloys onto both porous discs and tubular substrates. Unfortunately none of the amorphous alloys could be deposited without pinhole defects that undermined the selectivity of the membranes. WRI tested the thermal properties of the $\mathrm{ZrCu}$ and $\mathrm{ZrNi}$ alloys and found that under reducing environments the upper temperature limit of operation without recrystallization is $\sim 250^{\circ} \mathrm{C}$. There were four publications generated from this project with two additional manuscripts in progress and six presentations were made at national and international technical conferences. The combination of the pinhole defects and the lack of high temperature stability make the theoretically identified most promising candidate amorphous alloys unsuitable for application as hydrogen separation membranes in coal fire systems.
\end{abstract}




\section{TABLE OF CONTENTS}

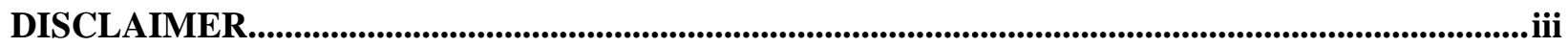

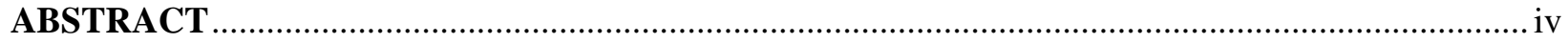

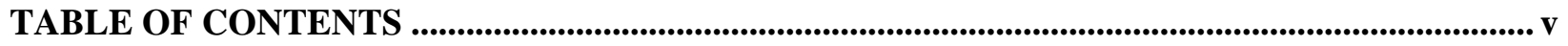

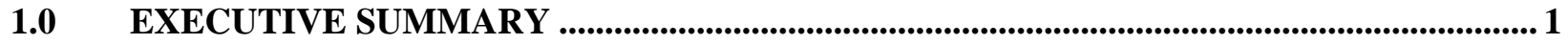

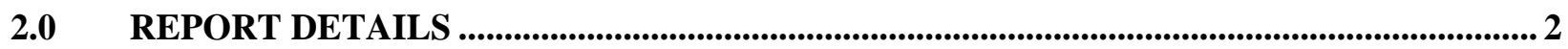

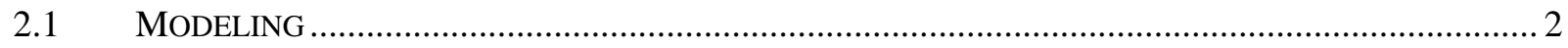

2.2 MEMBRANE DEPOSITION, COMPOSITION AND MiCROSTRUCTURE OPTIMIZATION.................... 29

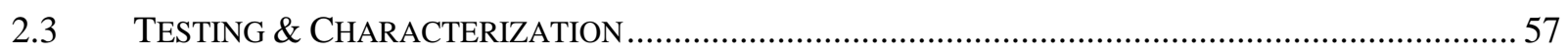

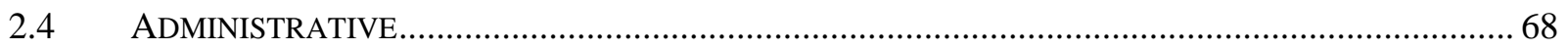

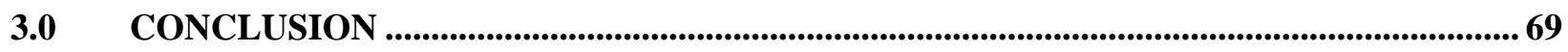

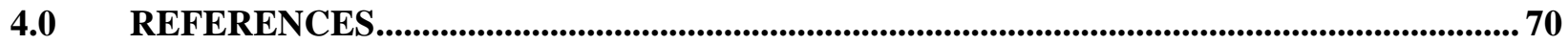

Table 1. Characteristic parameters of magnetron sputtering process ............................................... 30

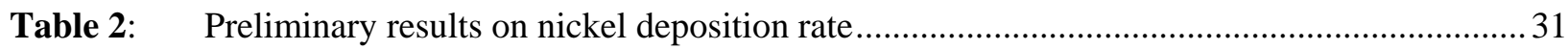

Table 3: Fractional Elemental Concentrations and Deposition Rates of $\mathrm{Ni}_{\mathrm{x}} \mathrm{Zr}_{1-\mathrm{x}}$ Films ...................... 35

Table 4: NiZrNb coating deposition composition vs. process parameters.......................................... 42

Table 5: CuZr coating deposition composition vs. process parameters.............................................. 44

Table 6: CuZrTi and CuZrTa coating deposition composition vs. process parameters........................ 45

Table 7: CuZrTi and CuZrTa coating process parameters, duration and measured thickness............. 48

Table 8: Cr coating process parameters, duration and measured thickness........................................ 52

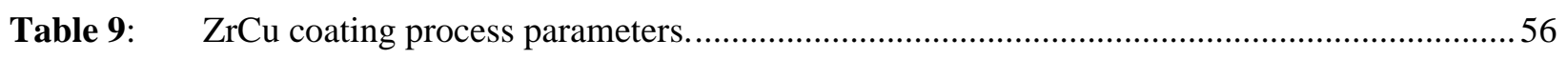

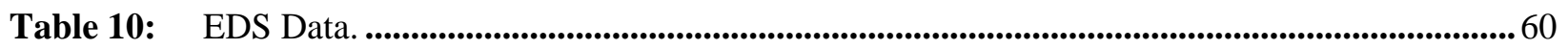

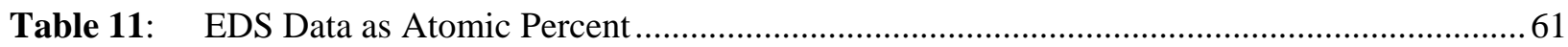

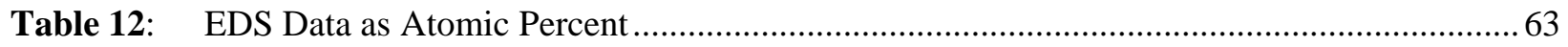

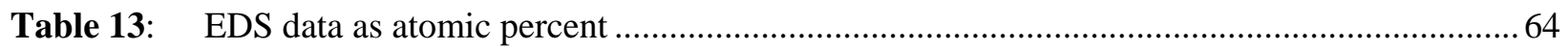

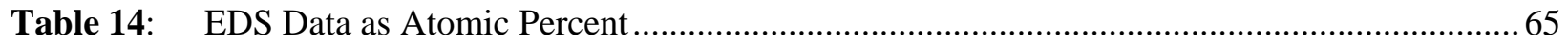

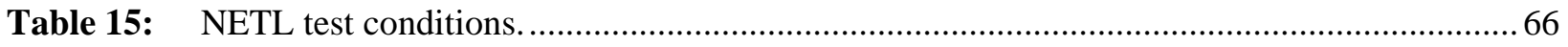




\section{List of Figures}

Figure 1: Comparison of calculated and experimental radial distribution functions for $a$ $\mathrm{Zr}_{30}\left(\mathrm{Ni}_{0.6} \mathrm{Nb}_{0.4}\right)_{70}$ before and after hydrogenation. The curves in the lower (upper) part of the figure are calculated (from experiment). The curve labeled "Host Hydrogenated" shows the results for the hydrogenated material when $\mathrm{H}$ atoms are not included in calculating the radial distribution function.

Figure 2: Comparison of calculated and experimental $\mathrm{H}$ solubility in $a-\mathrm{Zr}_{36} \mathrm{Ni}_{64}$ and $a$ $\mathrm{Zr}_{30}\left(\mathrm{Ni}_{0.6} \mathrm{Nb}_{0.4}\right)_{70}$. Lines are to guide the eye. In all cases, solid curves show the results of our calculations based on a fixed alloy density.

Figure 3: Comparison of calculated and experimental permeability of $\mathrm{H}_{2}$ in $a-\mathrm{Zr}_{36} \mathrm{Ni}_{64}$ and $a$ $\mathrm{Zr}_{30}\left(\mathrm{Ni}_{0.6} \mathrm{Nb}_{0.4}\right)_{70}$ as a function of temperature. The permeation and feed pressure are set as 0.01 and $3 \mathrm{~atm}$. The permeabilities of Pd from two different literature reports are also plotted.

Figure 4: Permeability comparison of different size of $\mathrm{Zr}_{55} \mathrm{Co}_{25} \mathrm{Al}_{20} . \mathrm{P}_{\text {feed }}=3 \mathrm{~atm}, \mathrm{P}_{\text {permeat }}=0.01$ atm

Figure 5: Permeability comparison of nine amorphous metals. $\mathrm{P}_{\text {feed }}=3 \mathrm{~atm}, \mathrm{P}_{\text {permeat }}=0.01 \mathrm{~atm}$. The dotted region is for pure $\mathrm{Pd}$.

Figure 6: Comparison of calculated $\mathrm{H}$ solubility in $\mathrm{Zr}_{20} \mathrm{Cu}_{80}, \mathrm{Zr}_{54} \mathrm{Cu}_{46}$, and $\mathrm{Zr}_{80} \mathrm{Cu}_{20}$. Lines are to guide the eye.

Figure 7: Comparison of calculated $\mathrm{H}$ diffusivity in $\mathrm{Zr}_{20} \mathrm{Cu}_{80}, \mathrm{Zr}_{54} \mathrm{Cu}_{46}$, and $\mathrm{Zr}_{80} \mathrm{Cu}_{20}$. Here, the $\mathrm{H}$ concentration is 0.1 for all three materials.

Figure 8: Comparison of calculated $\mathrm{H}$ permeability in $\mathrm{Zr}_{20} \mathrm{Cu}_{80}, \mathrm{Zr}_{54} \mathrm{Cu}_{46}$, and $\mathrm{Zr}_{80} \mathrm{Cu}_{20}$.................. 7

Figure 9: Permeability dependence upon composition of $\mathrm{Zr}_{\mathrm{x}} \mathrm{Cu}_{100-\mathrm{x}}(\mathrm{x}=20,54$, and 80) at 700 $\mathrm{K}$. The crosses are calculated by our methods and the dashed line is fitted by quadratic polynomial function.

Figure 10: Comparison of normalized solubility of $\mathrm{Zr}_{30} \mathrm{Cu}_{60} \mathrm{~T}_{10}$ to the solubility of $\mathrm{Zr}_{54} \mathrm{Cu}_{46}$ as a function of temperature. Here in $\mathrm{Zr}_{30} \mathrm{Cu}_{60} \mathrm{~T}_{10}$, the ternary elements are $\mathrm{T}=\mathrm{Sc}, \mathrm{Y}, \mathrm{Nb}$, Mo, Tc, Ru, Rh, Ag, Ta, W, Re, Os, Ir, Pt, Au.

Figure 11: Comparison of normalized diffusivity of $\mathrm{Zr}_{30} \mathrm{Cu}_{60} \mathrm{~T}_{10}$ to the diffusivity of $\mathrm{Zr}_{54} \mathrm{Cu}_{46} \ldots \ldots \ldots \ldots . . . .9$

Figure 12: Comparison of calculated permeability of $\mathrm{H}_{2}$ in $\mathrm{Zr}_{30} \mathrm{Cu}_{60} \mathrm{~T}_{10}(\mathrm{~T}=\mathrm{Sc}, \mathrm{Y}, \mathrm{Nb}, \mathrm{Mo}$, Tc, $\mathrm{Ru}, \mathrm{Rh}, \mathrm{Ag}, \mathrm{Ta}, \mathrm{W}, \mathrm{Re}, \mathrm{Os}, \mathrm{Ir}, \mathrm{Pt}, \mathrm{Au})$ as a function of temperature. The permeation and feed pressure are set as 0.01 and $3 \mathrm{~atm}$. The permeabilities of Pd from two different literature reports are also plotted as dotted region.

Figure 13: Permeability comparison of $\mathrm{Zr}_{x} \mathrm{Cu}_{90-\mathrm{x}} \mathrm{Ti}_{10}(\mathrm{x}=30,50$, and 70$)$ and $\mathrm{Zr}_{30} \mathrm{Cu}_{60} \mathrm{Pd}_{10}$. $\mathrm{P}_{\text {feed }}=$ $3 \mathrm{~atm}, \mathrm{P}_{\text {permeat }}=0.01 \mathrm{~atm}$. The dotted region is for pure $\mathrm{Pd}$.

Figure 14: Permeability dependence upon composition of $\mathrm{Zr}_{\mathrm{x}} \mathrm{Cu}_{90-\mathrm{x}} \mathrm{Ti}_{10}(\mathrm{x}=30,50$, and 70) at $500 \mathrm{~K}$. The cross dots are calculated by our methods and the dashed line is fitted by quadratic polynomial function. 


\section{List of Figures (Continued)}

Figure 15: Normalized diffusivity as a function of normalized solubility, where the $\mathrm{Zr}_{54} \mathrm{Cu}_{46}$ is the reference system. The solubility data are calculated at $600 \mathrm{~K}$ and $1 \mathrm{~atm}$. The diffusivity data correspond to the concentration at $600 \mathrm{~K}$ and $\mathrm{P}_{\text {feed }}=3$ atm, $\mathrm{P}_{\text {permeat }}=0.01 \mathrm{~atm}$.

Figure 16: $\quad \mathrm{H}$ binding energy and transition state energy distributions in $\mathrm{Zr}_{30} \mathrm{Cu}_{60} \mathrm{Ti}_{10}$ (a) and $\mathrm{Ta}_{25} \mathrm{Ni}_{60} \mathrm{Ti}_{15}$ (b). $Q_{0}$ and $\sigma$ in two systems are $(0.41,0.15 \mathrm{eV})$ and $(0.46,0.25 \mathrm{eV})$, respectively.

Figure 17: $\quad \mathrm{H}$ binding energy distributions in Gaussian function for $\mathrm{Zr}_{30} \mathrm{Cu}_{60} \mathrm{Ti}_{10}(\mathrm{~T}=\mathrm{Mo}, \mathrm{Ti}, \mathrm{Ru}$, $\mathrm{Rh}$ ) and reference $\mathrm{Zr}_{54} \mathrm{Cu}_{46}$

Figure 18: (a) Gaussian distributions of binding energy in four typical cases, $\mathrm{Zr}_{30} \mathrm{Cu}_{60} \mathrm{Rh}_{10}$, $\mathrm{Zr}_{30} \mathrm{Cu}_{60} \mathrm{Ru}_{10}, \mathrm{Zr}_{30} \mathrm{Cu}_{60} \mathrm{Mo}_{10}$, and $\mathrm{Zr}_{54} \mathrm{Cu}_{46}$. (b) Distribution of $\mathrm{Q}_{0}$ (dashed line) for all available DFT calculated amorphous materials, and fitted Gaussian distribution (solid line) with a mean value of $0.435 \mathrm{eV}$ and a standard deviation of $0.038 \mathrm{eV}$.

Figure 19: Phase diagram of ternary (a) solubility, (b) diffusivity, and (c) permeability of $\mathrm{Zr}_{\mathrm{x}} \mathrm{Cu}_{\mathrm{y}} \mathrm{Ti}_{100-\mathrm{x}-\mathrm{y}}$ at $600 \mathrm{~K}$. The solubilities are averaged by those at 3 and $0.01 \mathrm{~atm}$. The transport diffusivities are at corresponding hydrogen concentrations and the permeabilities are thus related to feed and permeate pressure 3 and $0.01 \mathrm{~atm}$.

Figure 20: Gaussian model parameters for $\mathrm{H}$ binding energy in all DFT results (shown as scattered data) and optimized parameters from fitted samples in $\mathrm{Zr}_{\mathrm{x}} \mathrm{Cu}_{\mathrm{y}} \mathrm{Ti}_{100-\mathrm{x}-\mathrm{y}}$ (black circles). The element labels beside the data indicate the samples of $\mathrm{Zr}_{30} \mathrm{Cu}_{60} \mathrm{~T}_{10}(\mathrm{~T}=$ Sc, Ti, Y, Nb, Mo, Tc, Ru, Rh, Pd, Ag, Ta, W, Re, Os, Ir, Pt, Au). Our previous DFT results for $\mathrm{Zr}_{36} \mathrm{Ni}_{64}$ and $\mathrm{Zr}_{30} \mathrm{Ni}_{42} \mathrm{Nb}_{28}$ are also included as symbol $\mathrm{x}$

Figure 21: (a) Schematic model for hydrogen permeation through metal membrane with catalytic layers and (b) corresponding energy landscape of vanadium membrane with $\mathrm{Mo}_{2} \mathrm{C}$ catalytic coatings. In this model, there are (1) $\mathrm{H}_{2}$ gas dissociative adsorption, (2) $\mathrm{H}$ diffusion within catalyst grain boundary, (3) transition from interface to membrane bulk, (4) diffusion in membrane bulk, (5) transition from bulk to interface, (6) grain boundary diffusion in catalytic layer, and (7) recombination desorption from catalytic layer surface.

Figure 22: $\quad \mathrm{H}_{2}$ adsorption and dissociation energies on $\mathrm{Mo}_{2} \mathrm{C}$ (a) (101), (b) (110), and (c) (100) surfaces. The total energy of free $\mathrm{H}_{2}$ molecule is set as reference.

Figure 23: (a) Comparison of calculated flux as a function of pressure drop with experimental results at $600^{\circ} \mathrm{C}$. (b) Hydrogen flux as a function of temperature for $\mathrm{Mo}_{2} \mathrm{C}$ coated vanadium membranes with different thickness. The feed and permeate pressures are 5 and $10^{-5}$ atm. The desorption processes of $2 \mathrm{H}$ atom forming $\mathrm{H}_{2}$ molecules are simulated on $\mathrm{Mo}_{2} \mathrm{C}(101)$ surface with a desorption energy of $1.36 \mathrm{eV}$. (c) Desorption resistance ratio as a function of temperature for $\mathrm{Mo}_{2} \mathrm{C}$ coated vanadium membranes with different thickness. The feed and permeate pressures are 5 and $10^{-5} \mathrm{~atm}$. 


\section{List of Figures (Continued)}

Figure 24: Surface free energy against $\mu_{C}-\mu_{C}$ (bulk). $\mu_{C}$ is the chemical potential of a $C$ atom and $\mu_{\mathrm{C}}$ (bulk) is the chemical potential in bulk phase of $\mathrm{C}$.

Figure 25: In the above diagrams, the energies shown in I, II and III positions correspond to $\mathrm{H}_{2}$ adsorption energies, dissociation barriers and the dissociated $\mathrm{H}$ adsorption energies on the surfaces (a) TiC(001), (b) HfC (001) and (c) ZrC (001). All energies in eV relative to the related clean surface and a gas phase $\mathrm{H}_{2}$ molecule.

Figure 26: Hydrogen flux as a function of temperature for $\mathrm{TiC}, \mathrm{HfC}$ and $\mathrm{ZrC}$ coat on (a) V, (b) Ta and (c) Nb membranes on both sides. The feed and permeate pressures are 1 and $10^{-5} \mathrm{~atm}$, and the membrane thickness is $75 \mu \mathrm{m}$.

Figure 27: Diffusion resistance ratio as a function of temperature for $\mathrm{TiC}, \mathrm{HfC}$ and $\mathrm{ZrC}$ coat on (a) V, (b) Ta and (c) Nb membranes on both sides. The feed and permeate pressures are 1 and $10^{-5} \mathrm{~atm}$, and the membrane thickness is $75 \mu \mathrm{m}$

Figure 28: (a) Hydrogen flux as a function of temperature for $\mathrm{TiC} / \mathrm{V} / \mathrm{TiC}$, HfC/V/TiC and $\mathrm{ZrC} / \mathrm{V} / \mathrm{TiC}$ composites; (b) Diffusion resistance ratio as a function of temperature for $\mathrm{TiC} / \mathrm{V} / \mathrm{TiC}, \mathrm{HfC} / \mathrm{V} / \mathrm{TiC}$ and $\mathrm{ZrC} / \mathrm{V} / \mathrm{TiC}$. The feed and permeate pressures are 1 and $10^{-5} \mathrm{~atm}$, and the membrane thickness is $75 \mu \mathrm{m}$.

Figure 29: $\quad$ Step profile on masked Ni coating on glass coupon. .......................................................... 32

Figure 30: Deposition rate by right magnetron vs. magnetron power. ............................................... 32

Figure 31: Deposition rate by co-deposition using two magnetron sources vs. magnetron power. ...... 33

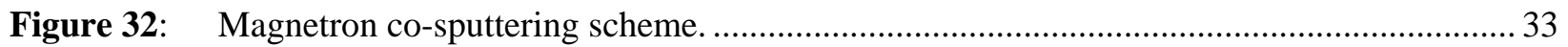

Figure 33: Deposition rates of Ni and Zr vs. magnetron power .......................................................... 35

Figure 34: Deposition rate and Ni concentration in of $\mathrm{Ni}_{\mathrm{x}} \mathrm{Zr}_{1-\mathrm{x}}$ coating vs. Ni magnetron power at Zr magnetron power fixed at 100W.............................................................................. 36

Figure 35: $\quad$ SEM micrograph of the cross-section of $\mathrm{Ni}_{0.93} \mathrm{Zr}_{0.07}$ coating. …...................................... 37

Figure 36: Mechanical properties of as deposited $\mathrm{Ni}_{\mathrm{x}} \mathrm{Zr}_{1-\mathrm{x}}$ coatings vs. coating composition: hardness and elastic modulus (left); H3/E2 toughness parameter (right) ........................... 37

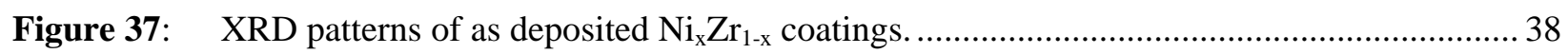

Figure 38: $\quad \mathrm{XRD}$ patterns of $\mathrm{Ni}_{\mathrm{x}} \mathrm{Zr}_{1-\mathrm{x}}$ coatings subjected to 1 hour annealing at $200^{\circ} \mathrm{C} \ldots \ldots \ldots \ldots \ldots \ldots \ldots . . . . . . . . . . . . .39$

Figure 39: $\quad \mathrm{XRD}$ patterns of $\mathrm{Ni}_{\mathrm{x}} \mathrm{Zr}_{1-\mathrm{x}}$ coatings subjected to 1 hour annealing at $250^{\circ} \mathrm{C} \ldots \ldots \ldots \ldots \ldots \ldots \ldots . . . . . . . . . . . .39$

Figure 40: $\quad \mathrm{XRD}$ patterns of $\mathrm{Ni}_{\mathrm{x}} \mathrm{Zr}_{1-\mathrm{x}}$ coatings and $\mathrm{BMG}$ ribbons subjected to 1 hour annealing at $300^{\circ} \mathrm{C}$

Figure 41: $\quad \mathrm{XRD}$ patterns of $\mathrm{Ni}_{\mathrm{x}} \mathrm{Zr}_{1-\mathrm{x}}$ coatings and $\mathrm{BMG}$ ribbon subjected to 24 hours annealing at $300^{\circ} \mathrm{C}$

Figure 42: $\quad$ Electrical conductivity of as deposited $\mathrm{Ni}_{\mathrm{x}} \mathrm{Zr}_{1-\mathrm{x}}$ coatings................................................ 42

Figure 43: Deposition rate for a given magnetron power to establish coating alloy compositions....... 44 


\section{List of Figures (Continued)}

Figure 44: $\quad$ Measured (EDS) atomic concentration of $\mathrm{Cu}, \mathrm{Zr}$ and $\mathrm{Ti}$ for CuZrTi alloys deposited using magnetron sputtering.

Figure 45: Measured (EDS) atomic concentration of $\mathrm{Cu}, \mathrm{Zr}$ and $\mathrm{Ta}$ for CuZrTa alloys deposited using magnetron sputtering.

Figure 46. Optical microscopy images of the surface of a coated porous substrate. In the latter images unfilled pores are magnified.

Figure 47: SEM cross section images of the coated porous substrate ............................................... 50

Figure 48: $\quad$ MicroCT images of $\mathrm{Cr}$ coated porous membranes.......................................................... 51

Figure 49: $\quad$ MicroCT images of $\mathrm{Ru} / \mathrm{V}$ coated porous membranes..................................................... 51

Figure 50: Magnetron sputtering set-up for porous tubes................................................................ 53

Figure 51: Magnetron sputtering of the tubes in operation. ............................................................... 53

Figure 52: A porous stainless steel tube in sputtering fixture.............................................................. 54

Figure 53: A porous stainless steel tube during the sputter cleaning process....................................... 54

Figure 54: Magnetron sputtering of $\mathrm{Cu}$ onto a porous stainless steel tube........................................... 55

Figure 55: SEM Images of zirconia coated Mott porous membranes. ................................................. 56

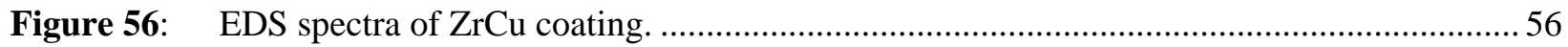

Figure 57: As deposited NiZrNb coatings demonstrated XRD-amorphous patterns. .......................... 58

Figure 58: XRD patterns of NixZr1-x coatings and melt-spun ribbons after $24 \mathrm{Hr}$ annealing in $\mathrm{Ar} / 2 \% \mathrm{H} 2$ at 300 deg $\mathrm{C}$ vs. Zr content.

Figure 59: $\quad \mathrm{XRD}$ patterns of Ni64Zr28Nb8 coating after $24 \mathrm{Hr}$ annealing in $\mathrm{Ar} / 2 \% \mathrm{H}_{2}$ at $300^{\circ} \mathrm{C}$. This coating which has about the same Zr concentration as coating \#11 in Figure 58 has typical amorphous pattern which remains unchanged after 24 annealing. .................... 59

Figure 60: Optical photograph of oxidized NiZr coating after 24 hrs of air annealing at $300^{\circ} \mathrm{C} \ldots \ldots . . . .60$

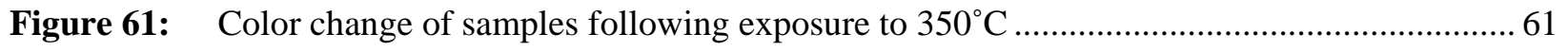

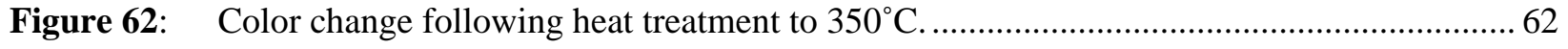

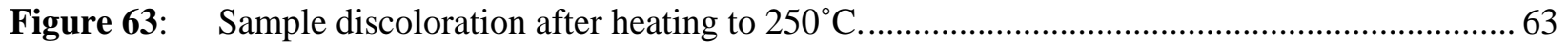

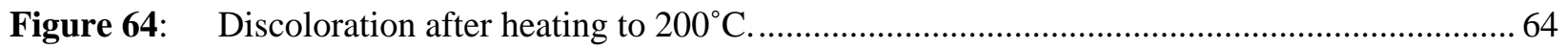

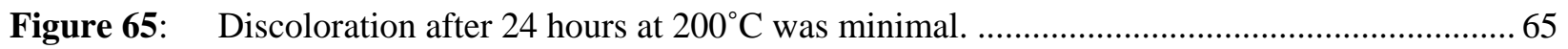

Figure 66: Solid/porous interface on Stainless tube. The tube is coated with $\mathrm{Cu}$.............................. 67 


\subsection{EXECUTIVE SUMMARY}

The approach of the program was to incorporate modeling, fabricating, and testing all operating concurrently to develop thin film amorphous alloy membranes which separate hydrogen from a coal-based system with performance meeting the DOE 2015 targets of flux, selectivity, cost and chemical and mechanical robustness, without the use of platinum group metals (PGMs). This collaborative effort involved work at Southwest Research Institute ${ }^{\circledR}\left(\right.$ SwRI $\left.^{\circledR}\right)$, Georgia Tech (GT) and Western Research Institute (WRI). The project can be summarized in the three primary tasks that were run concurrently:

1) Materials modeling and composition selection.

2) Fabrication of high-performance amorphous alloy membranes.

3) Membrane testing and evaluation.

The following highlights have been completed in support of the program milestones.

- Hydrogen permeability for several amorphous alloys including $\mathrm{Zr}_{36} \mathrm{Ni}_{64}$, $\mathrm{Zr}_{30}\left(\mathrm{Ni}_{0.6} \mathrm{Nb}_{0.4}\right)_{70}, \quad \mathrm{Ta}_{40} \mathrm{Ni}_{60}, \quad \mathrm{Ta}_{25} \mathrm{Ni}_{60} \mathrm{Ti}_{15}, \quad \mathrm{Ti}_{33} \mathrm{Co}_{67}, \quad \mathrm{Hf}_{44} \mathrm{Cu}_{56}, \quad \mathrm{Hf}_{25} \mathrm{Cu}_{60} \mathrm{Ti}_{15}$, $\mathrm{Zr}_{45} \mathrm{Cu}_{45} \mathrm{Al}_{10}, \mathrm{Zr}_{55} \mathrm{Co}_{25} \mathrm{Al}_{20}, \mathrm{Zr}_{30} \mathrm{Cu}_{60} \mathrm{Ti}_{10}, \mathrm{Zr}_{54} \mathrm{Cu}_{46}$, and $\mathrm{Nd}_{60} \mathrm{Fe}_{30} \mathrm{Al}_{10}$ were predicted

- The hydrogen transport properties in $\mathrm{V}, \mathrm{Nb}$ and $\mathrm{Ta}$ membranes coated with different transition-metal carbides (TMCs) $(\mathrm{TM}=\mathrm{Ti}, \mathrm{Hf}, \mathrm{Zr}$ ) catalytic layers were predicted employing first-principles.

- A new technique for depositing separation membrane materials onto tubular porous substrates using magnetron sputtering was developed.

- Thermal stability data for CuZr and NiZr amorphous alloys in hydrogen environments were established.

- Based on the lack of surface catalytic activity predicted, the difficulty in fabricating pinhole free membranes and the low thermal stability, the amorphous alloys investigated in this project were not found experimentally to be viable for separation of hydrogen from a coal based system.

- Two samples were sent to the Southern Research Institute, National Carbon Capture Center for exposure to syngas during gasifier run.

- Four papers were published in refereed journals and two papers are under review.

- Six presentations were made at national and international technical conferences.

- Based on the developments and results of this project collaborations were established with the University of Nevada, TDA Research and Stanford University to explore additional hydrogen separation technologies. 


\subsection{REPORT DETAILS}

\subsection{Modeling}

Georgia Tech's focus within this collaborative project was to use first-principles based modeling to predict the permeability of pure $\mathrm{H}_{2}$ through amorphous metal films. The basic methods for this task have been developed by David Sholl's group and described in several prior publications [1]. This approach requires no experimental input or parameterization, so it is suitable for use in materials screening efforts. The results described in the papers listed above were proof of principle calculations that dealt with a material (amorphous $\mathrm{Fe}_{3} \mathrm{~B}$ ) for which no experimental data is currently available. We have therefore performed extensive calculations for two ZrNi-based amorphous alloys that have been studied in previous experiments with the aim of understanding the accuracy of our theoretical methods. To this end, we examine amorphous $\mathrm{Zr}_{36} \mathrm{Ni}_{64}$ and $\mathrm{Zr}_{30}\left(\mathrm{Ni}_{0.6} \mathrm{Nb}_{0.4}\right)_{70}$, using experimental data on hydrogen solubility and permeation from previous experiments in Japan[2]. Figure 1 compares radial distribution functions for samples of these two materials generated using ab initio Molecular Dynamics and quenching with experimental data. This data indicates that our modeling approach is sufficient to generate realistic samples of these amorphous materials (as characterized by their short-range structure).

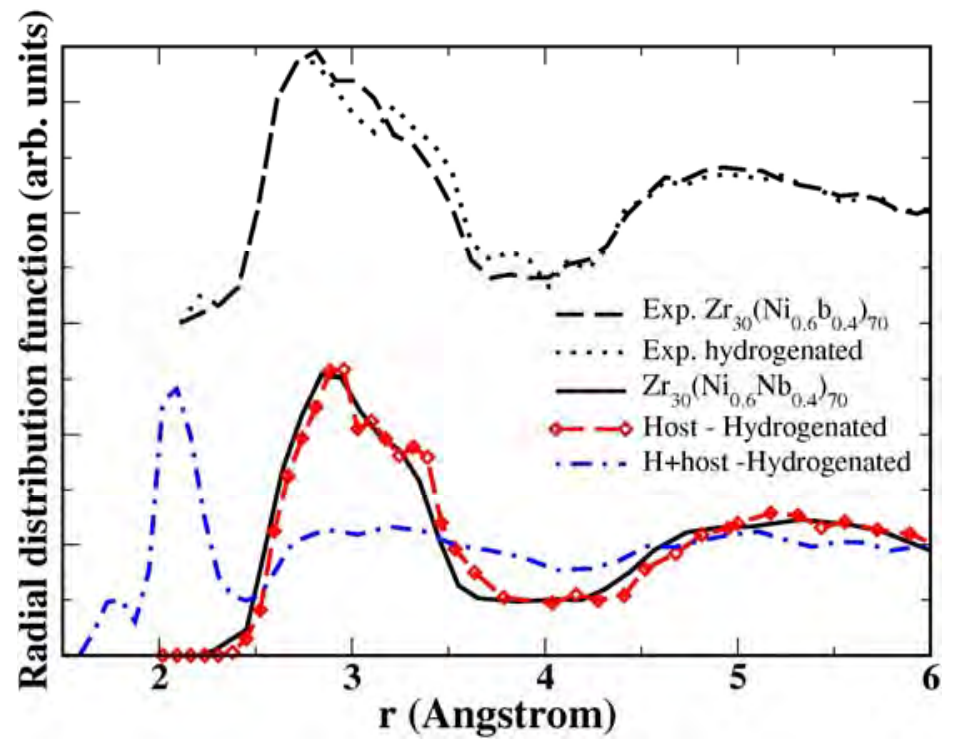

Figure 1: Comparison of calculated and experimental radial distribution functions for $a$ $\mathrm{Zr}_{30}\left(\mathrm{Ni}_{0.6} \mathrm{Nb}_{0.4}\right)_{70}$ before and after hydrogenation. The curves in the lower (upper) part of the figure are calculated (from experiment). The curve labeled "Host - Hydrogenated" shows the results for the hydrogenated material when $\mathrm{H}$ atoms are not included in calculating the radial distribution function.

Figure 2(a) compares the solubility of $\mathrm{H}$ predicted by our first-principles calculations with experimental data from the two $\mathrm{ZrNi}$ alloys. The agreement is good at low and moderate $\mathrm{H}$ loadings, but at high $\mathrm{H}$ loadings the theoretical prediction is smaller than the experimental result. This occurs because of $\mathrm{H}$-induced expansion of the amorphous 
alloy, and we have developed efficient methods that allow us to accurately predict these effects (data not shown).
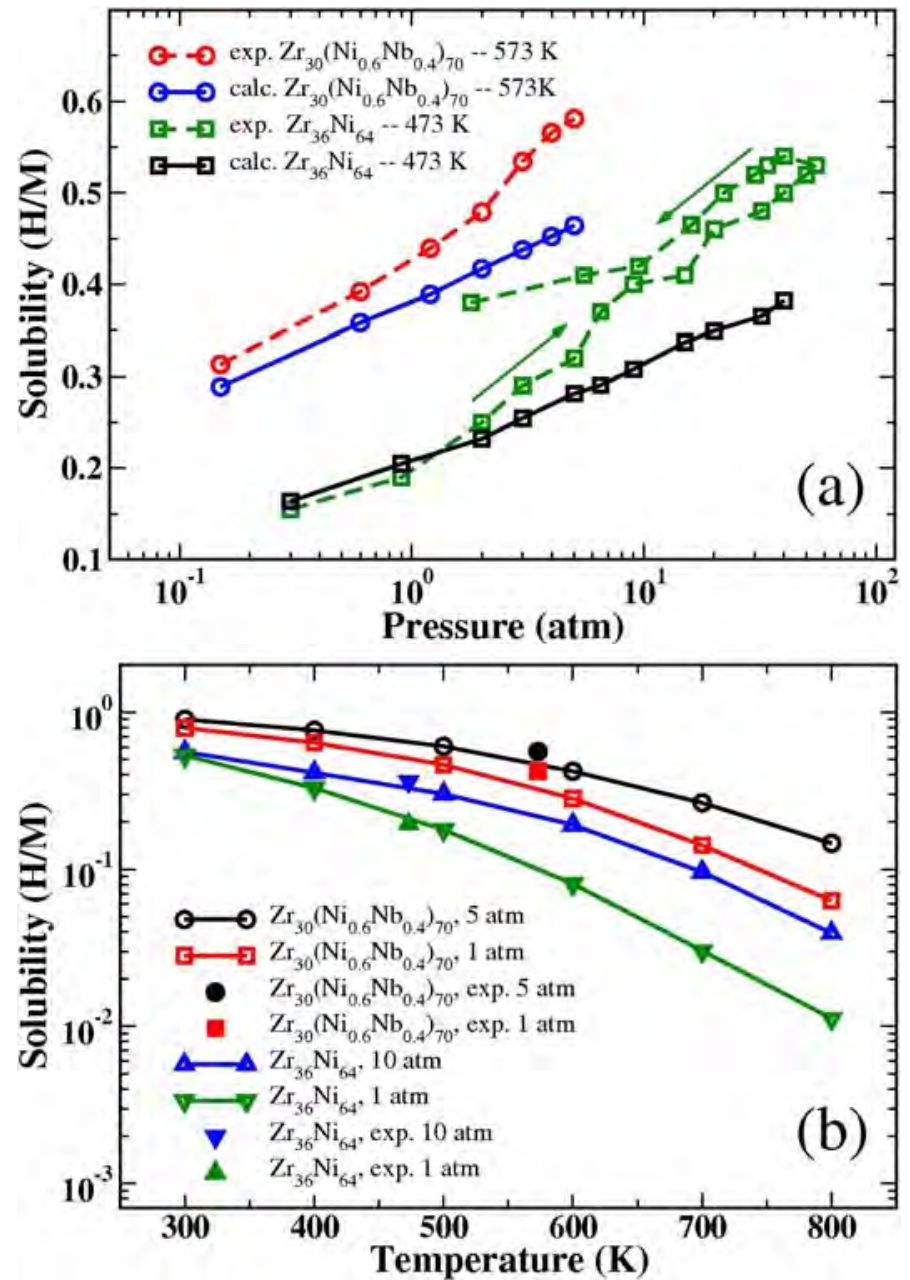

Figure 2: Comparison of calculated and experimental $\mathrm{H}$ solubility in $a-\mathrm{Zr}_{36} \mathrm{Ni}_{64}$ and $a$ $\mathrm{Zr}_{30}\left(\mathrm{Ni}_{0.6} \mathrm{Nb}_{0.4}\right)_{70}$. Lines are to guide the eye. In all cases, solid curves show the results of our calculations based on a fixed alloy density.

Figure 3 compares the $\mathrm{H}$ permeability of the two alloys with experimental data. To make these predictions, first principles methods were used to predict the solubility and net diffusivity of interstitial $\mathrm{H}$ in each amorphous material. The theoretical predictions are 24 times smaller than the experimental data. The experimental data shown on Figure 3 for crystalline Pd emphasizes the variability that exists between different experimental reports of even a material as well characterized as crystalline Pd. We therefore conclude that the quantitative discrepancy between our theoretical predictions and the amorphous film experiments is relatively small and that our methods are capable of making useful predictions about these properties. As emphasized above, our modeling methods do not require any experimental input. A paper that describes the details of the calculations reported here was published in J. Membrane Science in 2011 (381,192-196). 


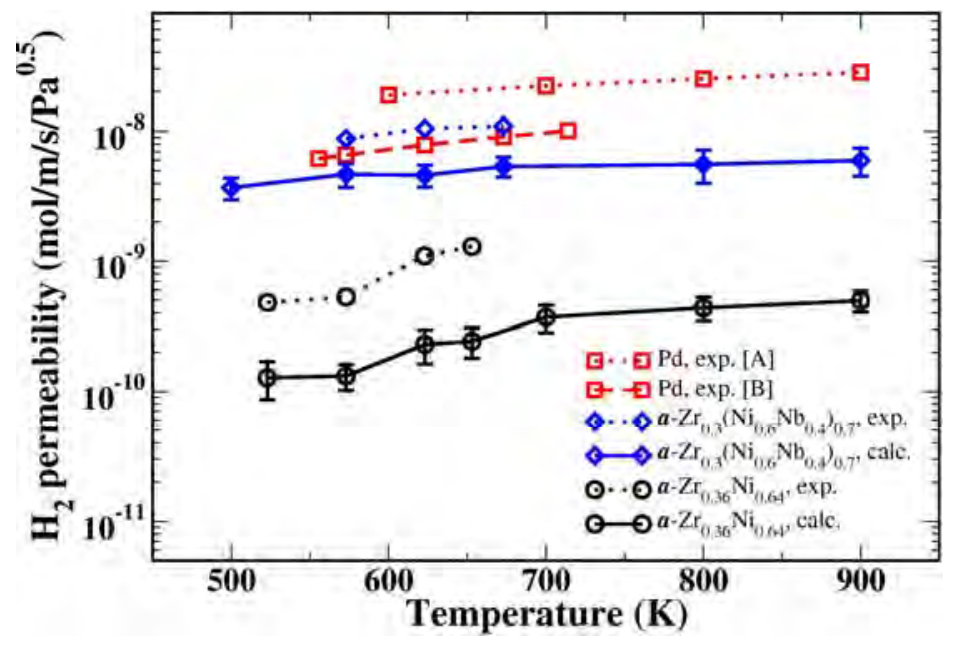

Figure 3: Comparison of calculated and experimental permeability of $\mathrm{H}_{2}$ in $a-\mathrm{Zr}_{36} \mathrm{Ni}_{64}$ and $a-\mathrm{Zr}_{30}\left(\mathrm{Ni}_{0.6} \mathrm{Nb}_{0.4}\right)_{70}$ as a function of temperature. The permeation and feed pressure are set as 0.01 and $3 \mathrm{~atm}$. The permeabilities of Pd from two different literature reports are also plotted.

Georgia Tech's approach requires no experimental input or parameterization, so it is suitable for use in materials screening efforts. However, this method was based on DFT calculations with 108 atom supercells, which requires large amount of calculations and thus time-consuming to perform screening from multiple candidates.

To accelerate the calculation, we used different size supercells to check the convergence of the calculated permeability convergence for $\mathrm{Zr}_{55} \mathrm{Co}_{25} \mathrm{Al}_{20}$. We use 32, 64, 108 atom supercells to calculate solubilities, diffusivities and permeabilities. Figure 4 shows the calculated permeability. Although there is some variation between the calculations with the smaller supercells and the results when using a 108 atom supercell, these differences are small enough that we can use the smaller calculations as a screening tool.

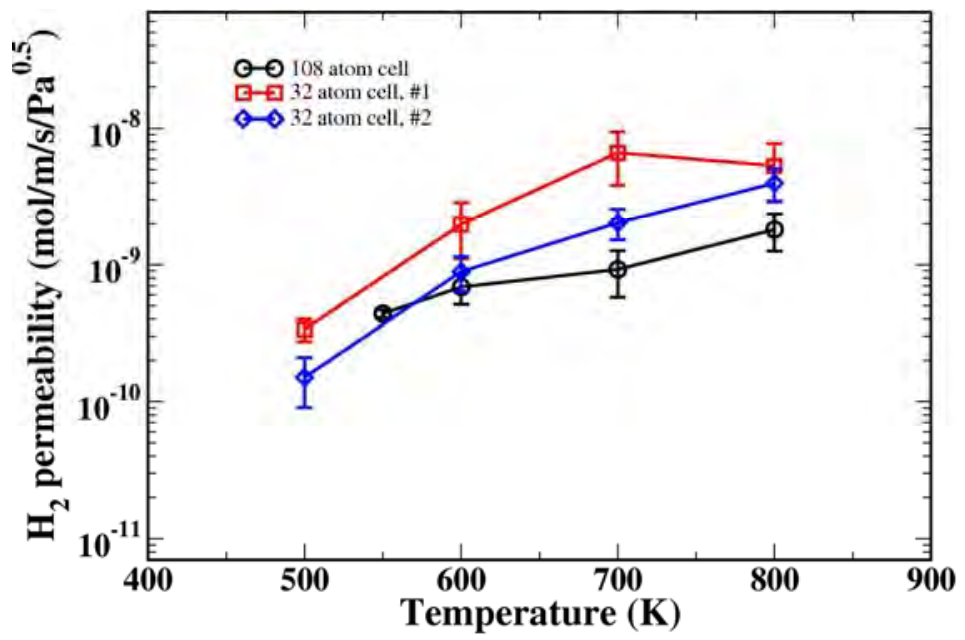

Figure 4: Permeability comparison of different size of $\mathrm{Zr}_{55} \mathrm{Co}_{25} \mathrm{Al}_{20}$. $\mathrm{P}_{\text {feed }}=3 \mathrm{~atm}, \mathrm{P}_{\text {permeat }}$ $=0.01 \mathrm{~atm}$. 
We have therefore performed extensive calculations for amorphous alloys that have not been studied in previous experiments with the aim of novel materials discovery using 32 atom supercells. To this end, we examine amorphous $\mathrm{Ta}_{40} \mathrm{Ni}_{60}, \mathrm{Ta}_{25} \mathrm{Ni}_{60} \mathrm{Ti}_{15}, \mathrm{Ti}_{33} \mathrm{Co}_{67}$, $\mathrm{Hf}_{44} \mathrm{Cu}_{56}, \quad \mathrm{Hf}_{25} \mathrm{Cu}_{60} \mathrm{Ti}_{15}, \quad \mathrm{Zr}_{45} \mathrm{Cu}_{45} \mathrm{Al}_{10}, \quad \mathrm{Zr}_{30} \mathrm{Cu}_{60} \mathrm{Ti}_{10}, \mathrm{Zr}_{54} \mathrm{Cu}_{46}$, and $\mathrm{Nd}_{60} \mathrm{Fe}_{30} \mathrm{Al}_{10}$. Selection of these materials are based on the relative high crystallization temperatures reported experimentally for these materials (at least $>720 \mathrm{~K}$ ). To make permeability predictions, first principles methods were used to predict the solubility and net diffusivity of interstitial $\mathrm{H}$ in each amorphous material.

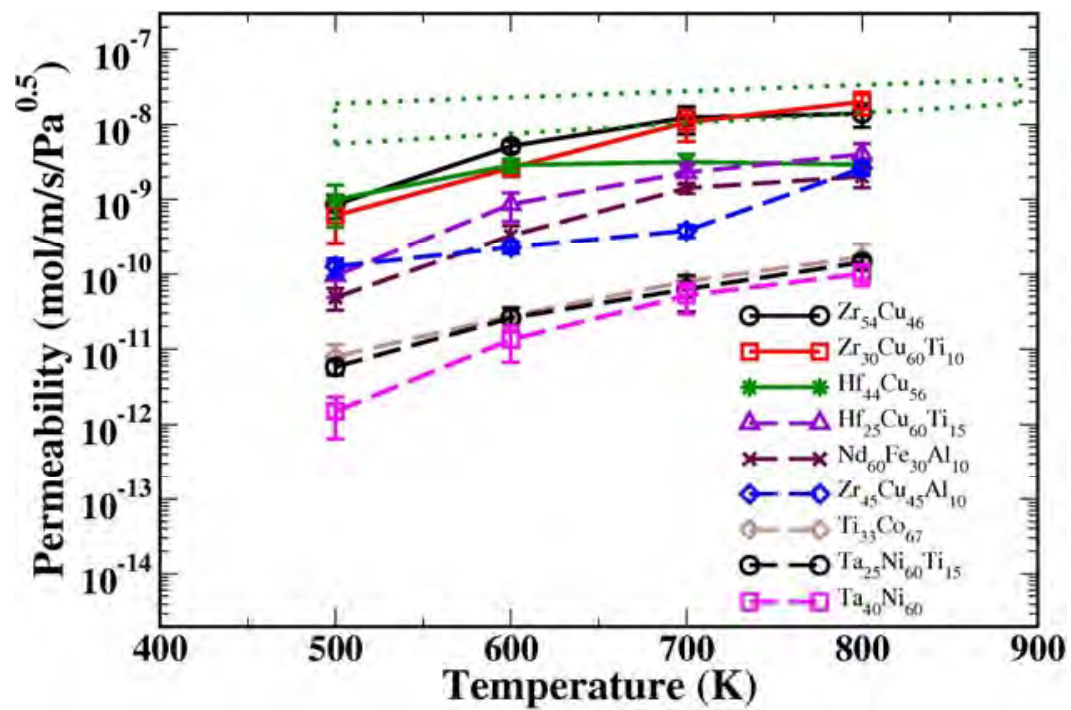

Figure 5: Permeability comparison of nine amorphous metals. $\mathrm{P}_{\text {feed }}=3 \mathrm{~atm}, \mathrm{P}_{\text {permeat }}=$ $0.01 \mathrm{~atm}$. The dotted region is for pure Pd.

Figure 5 plots the predicted $\mathrm{H}$ permeability of the nine alloys. The dotted region in the figure indicates the permeability for pure Pd. The theoretical results of $\mathrm{Zr}_{54} \mathrm{Cu}_{46}$ and $\mathrm{Zr}_{30} \mathrm{Cu}_{60} \mathrm{Ti}_{10}$ are similar to those for pure Pd. The predicted permeability of $\mathrm{Hf}_{44} \mathrm{Cu}_{56}$, and $\mathrm{Hf}_{25} \mathrm{Cu}_{60} \mathrm{Ti}_{15}$ is also relatively high, although lower than pure Pd. The $\mathrm{Ti}_{33} \mathrm{Co}_{67}$, $\mathrm{Ta}_{25} \mathrm{Ni}_{60} \mathrm{Ti}_{15}, \mathrm{Ta}_{40} \mathrm{Ni}_{60}$ permeabilities are very low, which would be not useful for practical application. We are currently refining our computation predictions for the materials in Figure 5 with the highest predicted permeability by performing similar calculations using 108 atom supercells.

Based on the top two candidates, we explored compositions of the form $\mathrm{Zr}_{\mathrm{x}} \mathrm{Cu}_{\mathrm{y}}$ and ternary materials with composition $\mathrm{Zr}_{30} \mathrm{Cu}_{60} \mathrm{~T}_{10}$ for various metals, $\mathrm{T}$. Because the glass forming range of $\mathrm{Zr}_{\mathrm{x}} \mathrm{Cu}_{\mathrm{y}}$ is very wide (95 $>\mathrm{x}>5$ ), we selected $\mathrm{Zr}_{20} \mathrm{Cu}_{80}$ and $\mathrm{Zr}_{80} \mathrm{Cu}_{20}$ as examples to compare with $\mathrm{Zr}_{54} \mathrm{Cu}_{46}$. It can be seen from Figure6 that the $\mathrm{H}$ solubility increases as the $\mathrm{Zr}$ content is increased. However, the favorable binding energies on the other hand induce relative higher diffusion barriers, resulting in lower diffusivity at same concentration. The diffusivity results at $\mathrm{H}$ concentration 0.1 are shown in Figure 7, indicating that the faster diffusion is in $\mathrm{Zr}_{20} \mathrm{Cu}_{80}$, slower in $\mathrm{Zr}_{80} \mathrm{Cu}_{20}$ and $\mathrm{Zr}_{54} \mathrm{Cu}_{46}$ is in the middle. Because of competition effect between solubility and diffusivity, the permeabilities of $\mathrm{Zr}_{54} \mathrm{Cu}_{46}$ are still higher than those of $\mathrm{Zr}_{20} \mathrm{Cu}_{80}$ and $\mathrm{Zr}_{80} \mathrm{Cu}_{20}$ as shown in Figure 8. 


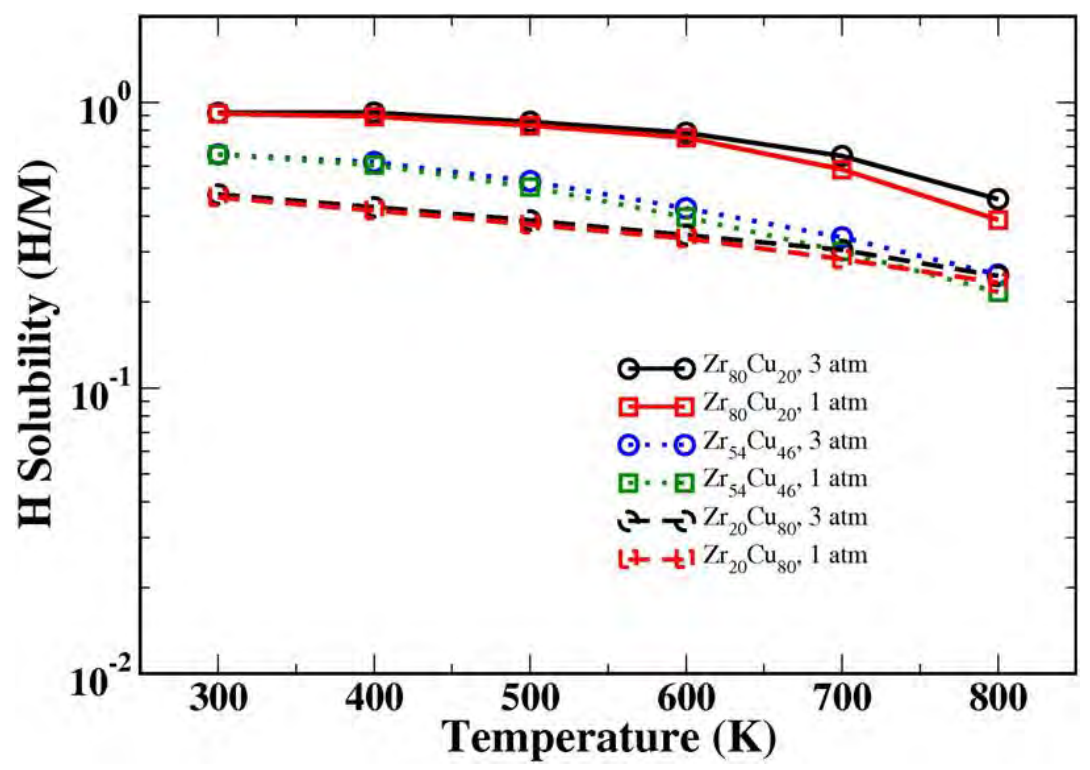

Figure 6: Comparison of calculated $\mathrm{H}$ solubility in $\mathrm{Zr}_{20} \mathrm{Cu}_{80}, \mathrm{Zr}_{54} \mathrm{Cu}_{46}$, and $\mathrm{Zr}_{80} \mathrm{Cu}_{20}$. Lines are to guide the eye.

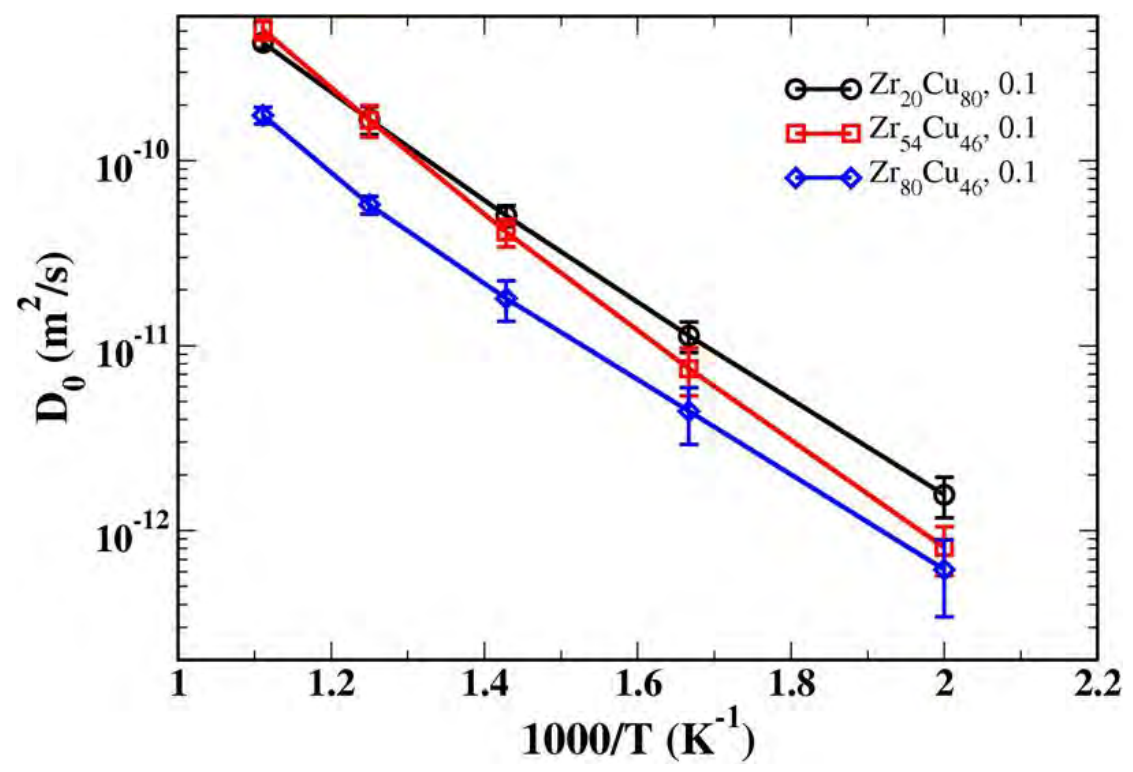

Figure 7: Comparison of calculated $\mathrm{H}$ diffusivity in $\mathrm{Zr}_{20} \mathrm{Cu}_{80}, \mathrm{Zr}_{54} \mathrm{Cu}_{46}$, and $\mathrm{Zr}_{80} \mathrm{Cu}_{20}$. Here, the $\mathrm{H}$ concentration is 0.1 for all three materials. 


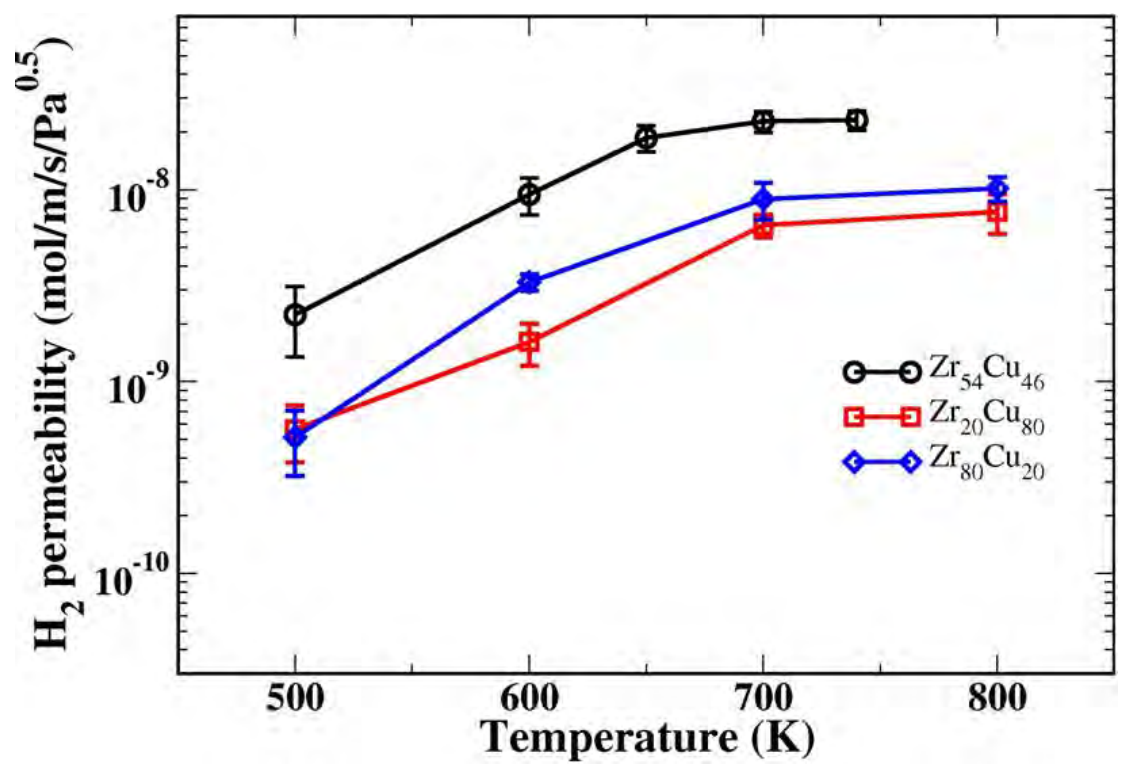

Figure 8: Comparison of calculated $\mathrm{H}$ permeability in $\mathrm{Zr}_{20} \mathrm{Cu}_{80}, \mathrm{Zr}_{54} \mathrm{Cu}_{46}$, and $\mathrm{Zr}_{80} \mathrm{Cu}_{20}$.

Based on the permeability of three compositions, we made the simplistic assumption of using the data at $700 \mathrm{~K}$ to fit a quadratic polynomial function to search for best $\mathrm{ZrCu}$ composition. The results in Figure 9 predict based on the rough approximation that the permeability reaches the maximum in the middle of the composition range. This result reflects a competition behavior between solubility and diffusivity for overall permeability, since the solubility of $\mathrm{H}$ increases with increased $\mathrm{Zr}$ content but the diffusivity decreases correspondingly.

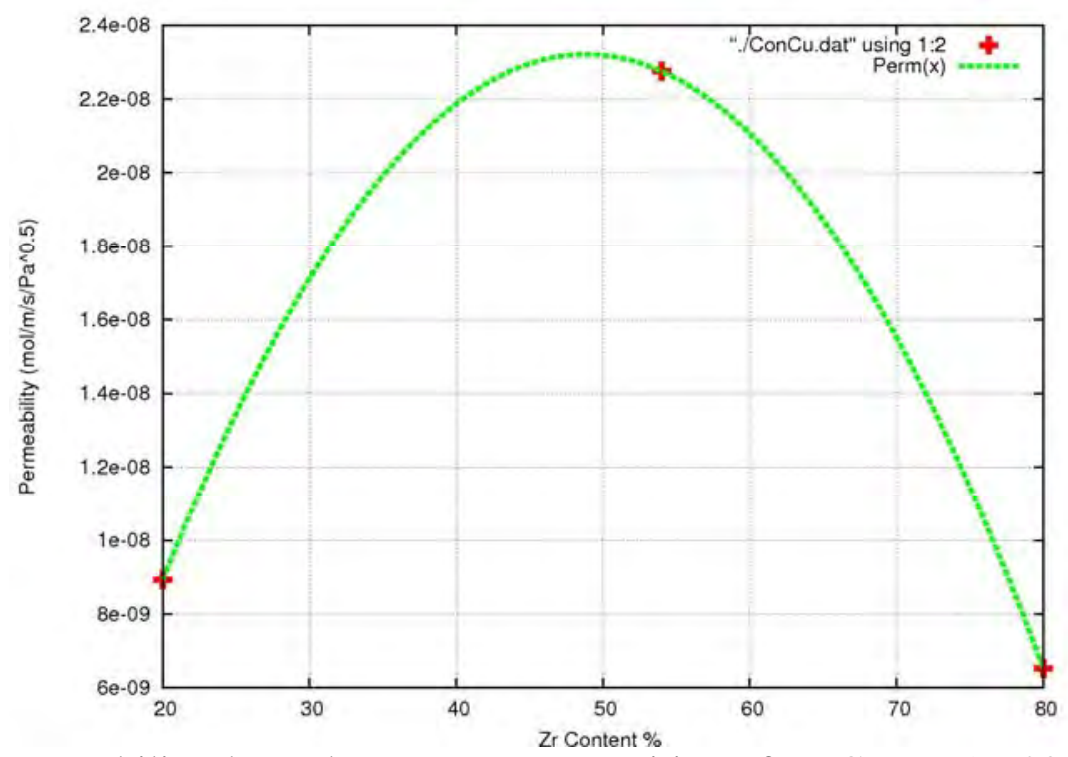

Figure 9: Permeability dependence upon composition of $\mathrm{Zr}_{\mathrm{x}} \mathrm{Cu}_{100-\mathrm{x}}(\mathrm{x}=20,54$, and 80) at $700 \mathrm{~K}$. The crosses are calculated by our methods and the dashed line is fitted by quadratic polynomial function. 
For the ternary optimization in $\mathrm{Zr}_{30} \mathrm{Cu}_{60} \mathrm{~T}_{10}$, we selected $\mathrm{T}=\mathrm{Sc}, \mathrm{Y}, \mathrm{Nb}, \mathrm{Mo}, \mathrm{Tc}, \mathrm{Ru}, \mathrm{Rh}$, Ag, Ta, W, Re, Os, Ir, Pt, and Au as ternary elements. We selected these elements because on the one hand to keep good glass forming ability and on the other hand not to decrease crystallization temperatures. For each above materials, we used ab initio Molecular Dynamics to get amorphous structures using, grand canonical Monte Carlo for solubilities, kinetic Monte Carlo for diffusivities and permeabilities. The solubility, diffusivity and permeability results are respectively shown in Figure 10, 11 and 12. To make an easy comparison, we normalize the ternary solubilities to that of $\mathrm{Zr}_{54} \mathrm{Cu}_{46}$. Even though selection of $\mathrm{Zr}_{54} \mathrm{Cu}_{46}$ is a little arbitrary, this normalization still gives a clear ranking list on their performance. We found that most solubilities in the range of 300$800 \mathrm{~K}$ are lower than those of $\mathrm{Zr}_{54} \mathrm{Cu}_{46}$. An exception is $\mathrm{Rh}$, which has higher solubility possibly because of chemical affinity of $\mathrm{Rh}$ and $\mathrm{H}$. The next three candidates are $\mathrm{Y}, \mathrm{Ta}$ and Sc with solubilities very close to $\mathrm{Zr}_{54} \mathrm{Cu}_{46}$. We also normalize the ternary diffusivities to that of $\mathrm{Zr}_{54} \mathrm{Cu}_{46}$ to make a clear comparison. The top candidates are $\mathrm{Ru}, \mathrm{W}, \mathrm{Tc}, \mathrm{Ta}$, and Sc. We found that the species with faster diffusivities are interestingly those with lower solubilities. Finally, we calculate permeability based on solubility and diffusivity and plot the results directly in Figure12. It is clear that the Sc, Ta and Y are also promising ternary additives for $\mathrm{Zr}_{30} \mathrm{Cu}_{60} \mathrm{~T}_{10}$ because of both favorable quantities for their solubilities and diffusivities.

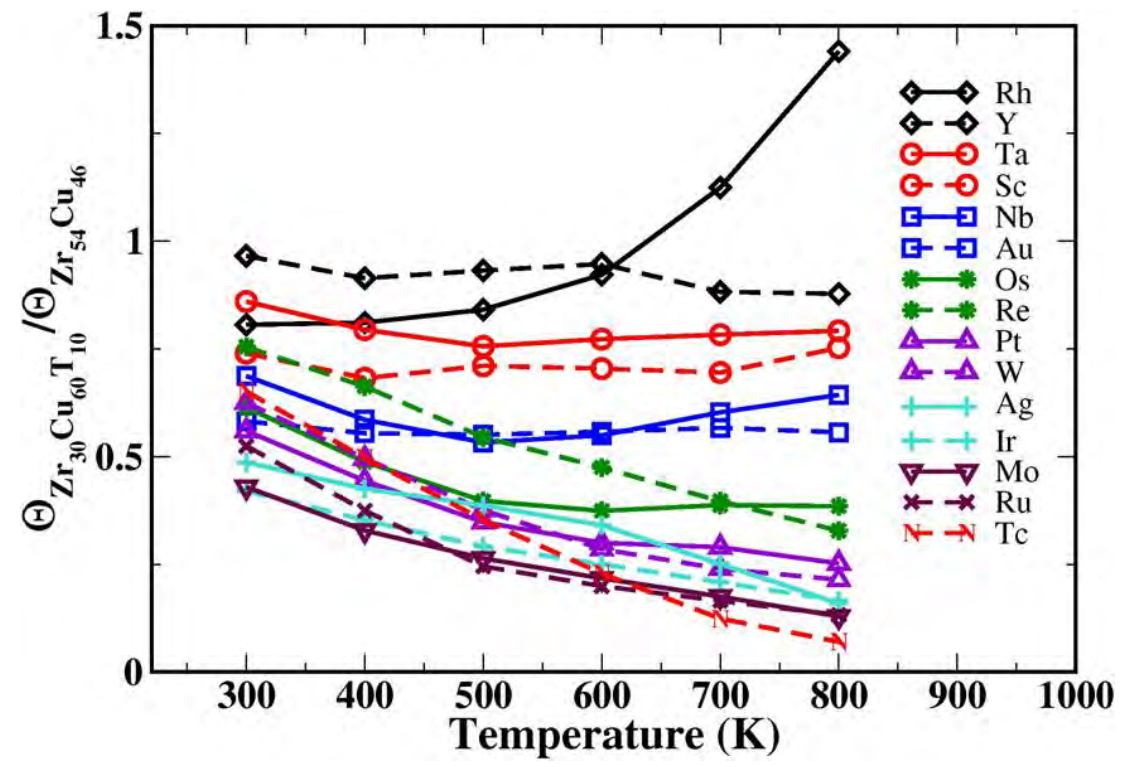

Figure 10: Comparison of normalized solubility of $\mathrm{Zr}_{30} \mathrm{Cu}_{60} \mathrm{~T}_{10}$ to the solubility of $\mathrm{Zr}_{54} \mathrm{Cu}_{46}$ as a function of temperature. Here in $\mathrm{Zr}_{30} \mathrm{Cu}_{60} \mathrm{~T}_{10}$, the ternary elements are $\mathrm{T}=$ Sc, Y, Nb, Mo, Tc, Ru, Rh, Ag, Ta, W, Re, Os, Ir, Pt, Au. 


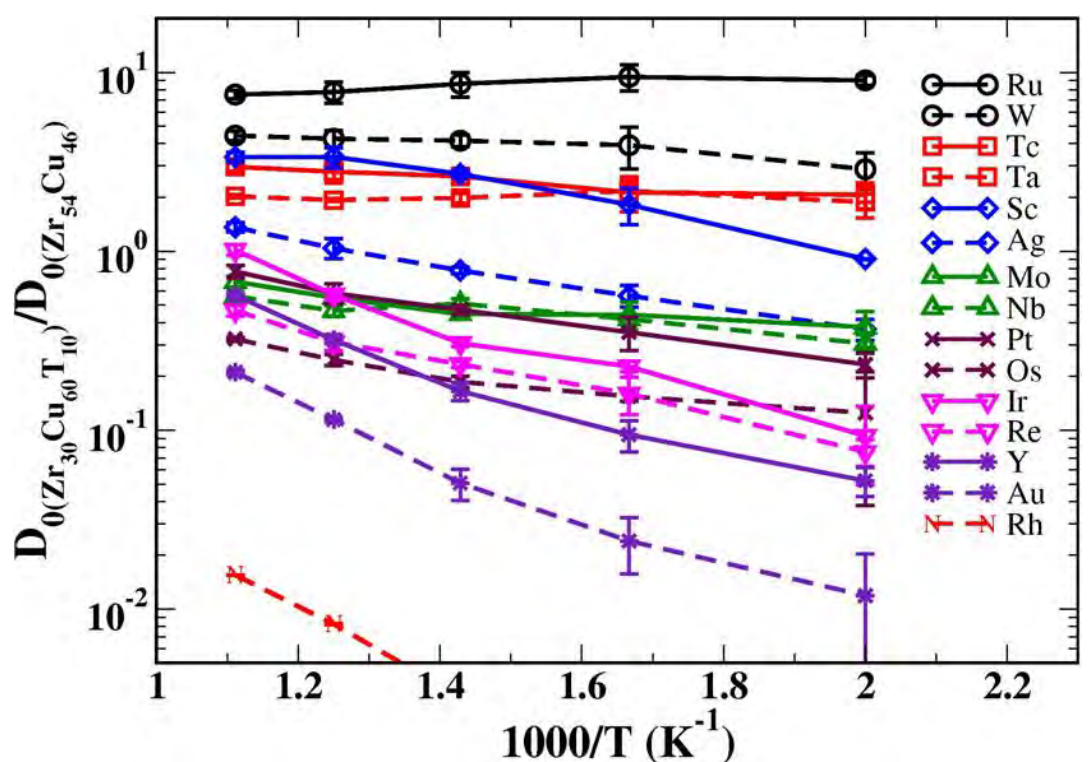

Figure 11: Comparison of normalized diffusivity of $\mathrm{Zr}_{30} \mathrm{Cu}_{60} \mathrm{~T}_{10}$ to the diffusivity of $\mathrm{Zr}_{54} \mathrm{Cu}_{46}$

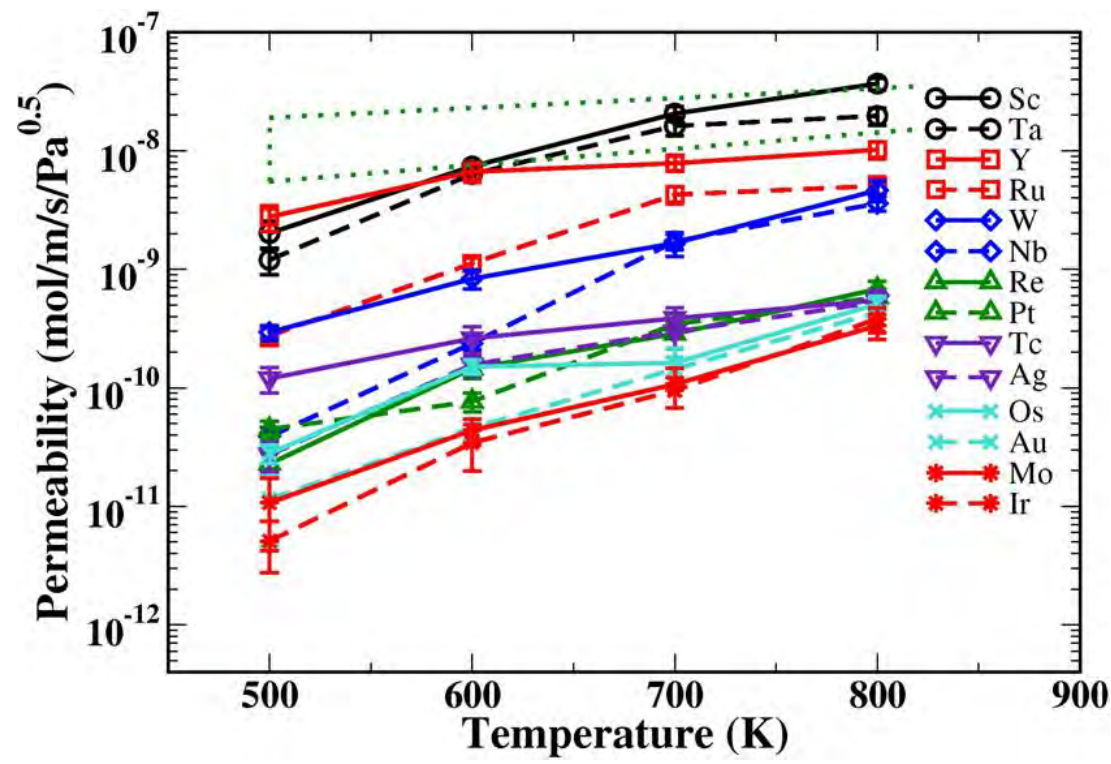

Figure 12: Comparison of calculated permeability of $\mathrm{H}_{2}$ in $\mathrm{Zr}_{30} \mathrm{Cu}_{60} \mathrm{~T}_{10}(\mathrm{~T}=\mathrm{Sc}, \mathrm{Y}, \mathrm{Nb}$, Mo, Tc, Ru, Rh, Ag, Ta, W, Re, Os, Ir, Pt, Au) as a function of temperature. The permeation and feed pressure are set as 0.01 and $3 \mathrm{~atm}$. The permeabilities of Pd from two different literature reports are also plotted as dotted region.

To achieve fast surface $\mathrm{H}_{2}$ dissociation process, a thin layer of Pd is normally added on the film's surface as a catalytic layer in experiments with amorphous films. It is thus interesting to see the $\mathrm{H}$ properties in $\mathrm{Zr}_{30} \mathrm{Cu}_{60} \mathrm{Pd}_{10}$ due to $\mathrm{Pd}$ diffusion into host lattice. As shown in Figure 13, $\mathrm{H}$ permeability through $\mathrm{Zr}_{30} \mathrm{Cu}_{60} \mathrm{Pd}_{10}$ is not favorable compared to either $\mathrm{Pd}, \mathrm{Zr}_{54} \mathrm{Cu}_{46}$, or $\mathrm{Zr}_{30} \mathrm{Cu}_{60} \mathrm{Ti}_{10}$. 


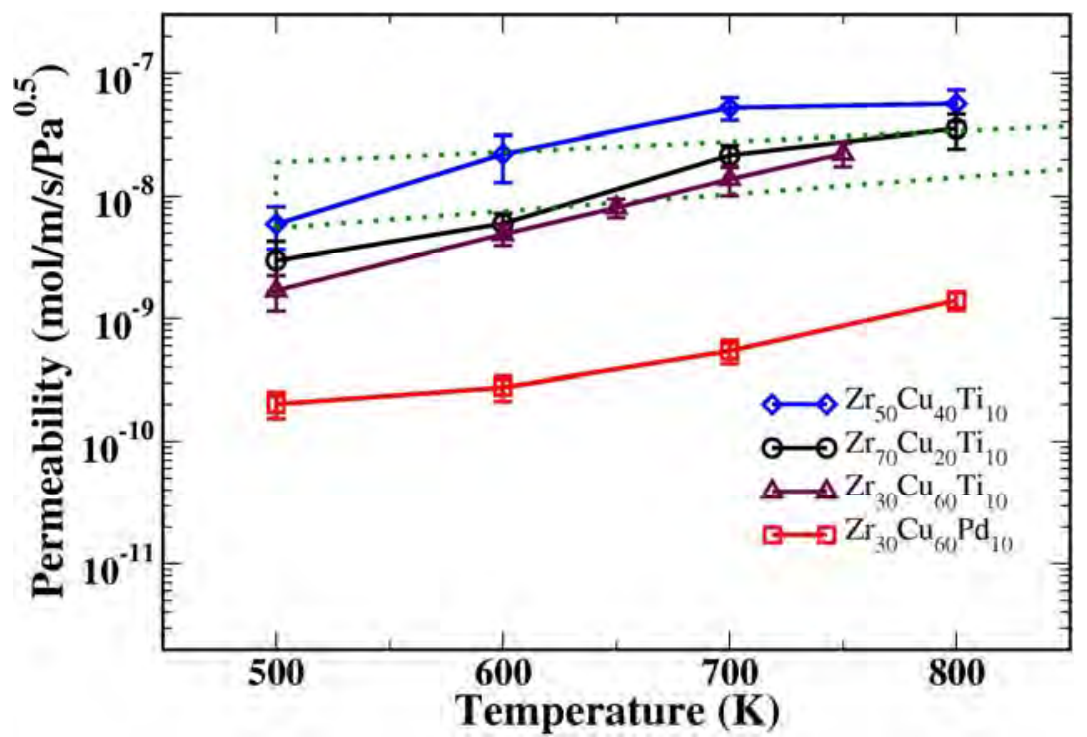

Figure 13: Permeability comparison of $\mathrm{Zr}_{x} \mathrm{Cu}_{90-\mathrm{x}} \mathrm{Ti}_{10}(\mathrm{x}=30,50$, and 70) and $\mathrm{Zr}_{30} \mathrm{Cu}_{60} \mathrm{Pd}_{10}$. $\mathrm{P}_{\text {feed }}=3 \mathrm{~atm}, \mathrm{P}_{\text {permeat }}=0.01 \mathrm{~atm}$. The dotted region is for pure $\mathrm{Pd}$.

Figure 13 also plots the $\mathrm{H}$ permeability of $\mathrm{Zr}_{\mathrm{x}} \mathrm{Cu}_{90-\mathrm{x}} \mathrm{Ti}_{10}(\mathrm{x}=30,50$, and 70$)$. As can be seen, the dotted region is for pure Pd. The results of $\mathrm{Zr}_{\mathrm{x}} \mathrm{Cu}_{90-\mathrm{x}} \mathrm{Ti}_{10}(\mathrm{x}=30,50$, and 70) are approaching the pure $\mathrm{Pd}$ and $\mathrm{Zr}_{50} \mathrm{Cu}_{40} \mathrm{Ti}_{10}$ is better than both of $\mathrm{Zr}_{30} \mathrm{Cu}_{60} \mathrm{Ti}_{10}$ and $\mathrm{Zr}_{70} \mathrm{Cu}_{20} \mathrm{Ti}_{10}$. The $500 \mathrm{~K}$ permeability data fitted by quadratic polynomial function shown in Figure 14 indicate a similar trend as composition optimization of $\mathrm{Zr}_{\mathrm{x}} \mathrm{Cu}_{100-\mathrm{x}}(\mathrm{x}=20,54$, and 80 ). That is, the best performance occurs in the middle range of $\mathrm{Zr}$ content. We therefore recommended experimental investigation on the top two candidates, $\mathrm{Zr}_{54} \mathrm{Cu}_{46}$ and $\mathrm{Zr}_{50} \mathrm{Cu}_{40} \mathrm{Ti}_{10}$ to examine our predication.

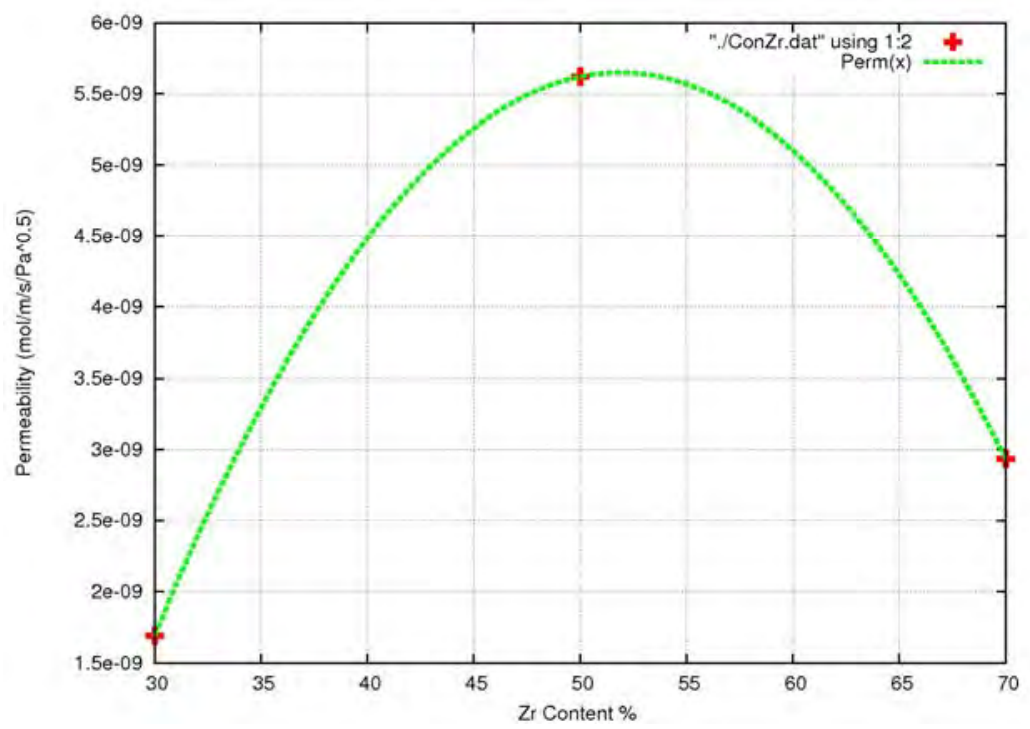

Figure 14: Permeability dependence upon composition of $\mathrm{Zr}_{\mathrm{x}} \mathrm{Cu}_{90-\mathrm{x}} \mathrm{Ti}_{10}(\mathrm{x}=30$, 50, and 70 ) at $500 \mathrm{~K}$. The cross dots are calculated by our methods and the dashed line is fitted by quadratic polynomial function. 
Based on the above results, we also optimized permeability performance of the amorphous $\mathrm{Zr}_{\mathrm{x}} \mathrm{Cu}_{100-\mathrm{x}}$ based alloy with different composition due to the wide glass forming range, $95>x>5$. We also performed extensive calculations for ternary element screening for $\mathrm{Zr}_{30} \mathrm{Cu}_{60} \mathrm{~T}_{10}$ (T= Sc, Y, Nb, Mo, Tc, Ru, Rh, Ag, Ta, W, Re, Os, Ir, Pt, Au). We found that the permeability of above materials are ranging from $10^{-11}$ to $10^{-8}$ $\mathrm{mol} / \mathrm{m} / \mathrm{s} / \mathrm{Pa}^{0.5}$ at $600 \mathrm{~K}$ with feed and permeate pressure 3 and $0.01 \mathrm{~atm}$ respectively. The ratio of diffusivity as a function of the ratio of solubility would be an easy way to help us to identify that the promising materials. As shown in Figure 15, high solubility and high diffusivity materials should locate at upright corner region.
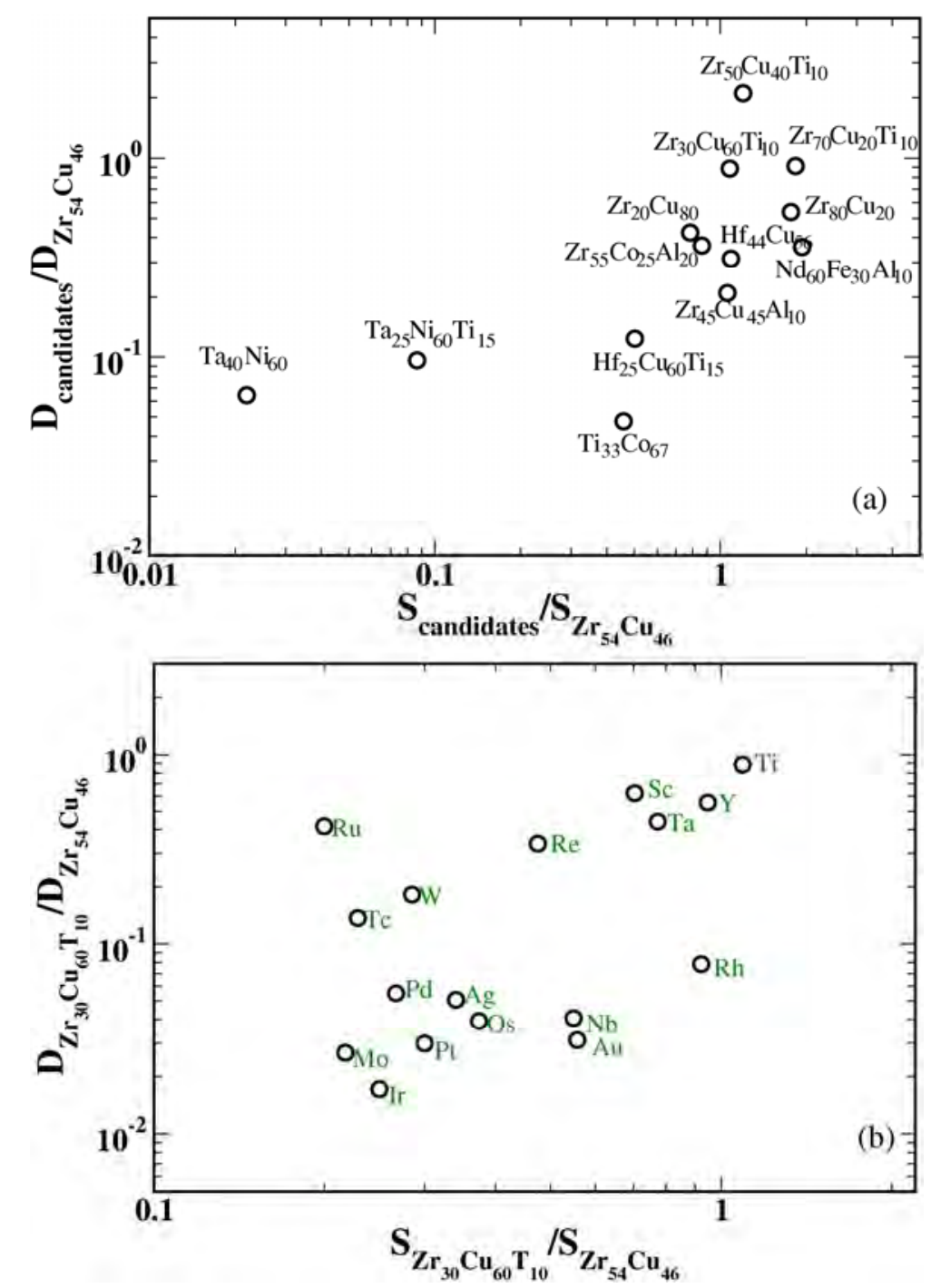

Figure 15: Normalized diffusivity as a function of normalized solubility, where the $\mathrm{Zr}_{54} \mathrm{Cu}_{46}$ is the reference system. The solubility data are calculated at $600 \mathrm{~K}$ and $1 \mathrm{~atm}$. The diffusivity data correspond to the concentration at $600 \mathrm{~K}$ and $\mathrm{P}_{\text {feed }}=3 \mathrm{~atm}$, $\mathrm{P}_{\text {permeat }}=0.01 \mathrm{~atm}$.

We use correlated saddle point model to understand why those materials have good performance. The correlated saddle point model stresses that the saddle point energy is related to the energies of the two adjacent sites $\left(E_{i}\right.$ and $\left.E_{k}\right)$ and a constant values $Q_{0}$ by 
the equation $Q_{i k}=Q_{0}+0.5\left(E_{i}+E_{k}\right)$. If the $\mathrm{H}$ binding energy distribution and $\mathrm{H}$ diffusion saddle point energy distribution can be described by simple Gaussian functions, the mean value difference in a specific system would be $Q_{0}$. Since we have all the Density Functional Theory (DFT) calculation data, we thus can analyze any interested cases using this model. For example, to understand the low solubility and high diffusivity behavior in $\mathrm{Zr}_{30} \mathrm{Cu}_{60} \mathrm{Ru}_{10}$ system as shown in Figure 15(b), we can refer the corresponding energy distributions. Figure 16(a) shows the $\mathrm{H}$ binding energy distribution (black solid line), saddle point energy distribution (red dashed line), and the mean value difference $Q_{0}=0.41$ $\mathrm{eV}$. Because the mean value of binding energy distribution is close to zero indicating unfavorable binding energy, thus it is clear to see the low $\mathrm{H}$ solubility. If we check the $\mathrm{H}$ binding configuration at $600 \mathrm{~K}$ and $1 \mathrm{~atm}$, only the sites with binding energy smaller than $-0.33 \mathrm{eV}$ are occupied. Starting from these sites, the $\mathrm{H}$ atoms jump to neighboring sites with the highest probability of mean value, thus the average diffusion barrier would be $Q_{i k}=Q_{0}+0.5\left(E_{i}+E_{k}\right)=0.41+0.15=0.56 \mathrm{eV}$. With the relative low average diffusion barrier, it is easy to conclude a relatively high diffusivity in $\mathrm{Zr}_{30} \mathrm{Cu}_{60} \mathrm{Ru}_{10}$ system. Similarly, for the case of $\mathrm{Ta}_{25} \mathrm{Ni}_{60} \mathrm{Ti}_{15}$ as shown in Figure 16(b), only the sites with binding energy $<-0.4 \mathrm{eV}$ are occupied at $600 \mathrm{~K}$ and $1 \mathrm{~atm}$. Due to the unfavorable binding energy mean value, the low solubility can be easily concluded. Another aspect is that a large standard deviation $\sigma=0.25 \mathrm{eV}$ and a large mean value difference $Q_{0}=0.46 \mathrm{eV}$ induces a large average diffusion barrier $Q_{i k}=0.46+0.25=0.71 \mathrm{eV}$, thus $\mathrm{Ta}_{25} \mathrm{Ni}_{60} \mathrm{Ti}_{15}$ can be attributed into low solubility and low diffusivity. Based on these examples, we can conclude that the performance depends on not only the binding energy standard deviation but also the mean value position and difference $Q_{0}$. 

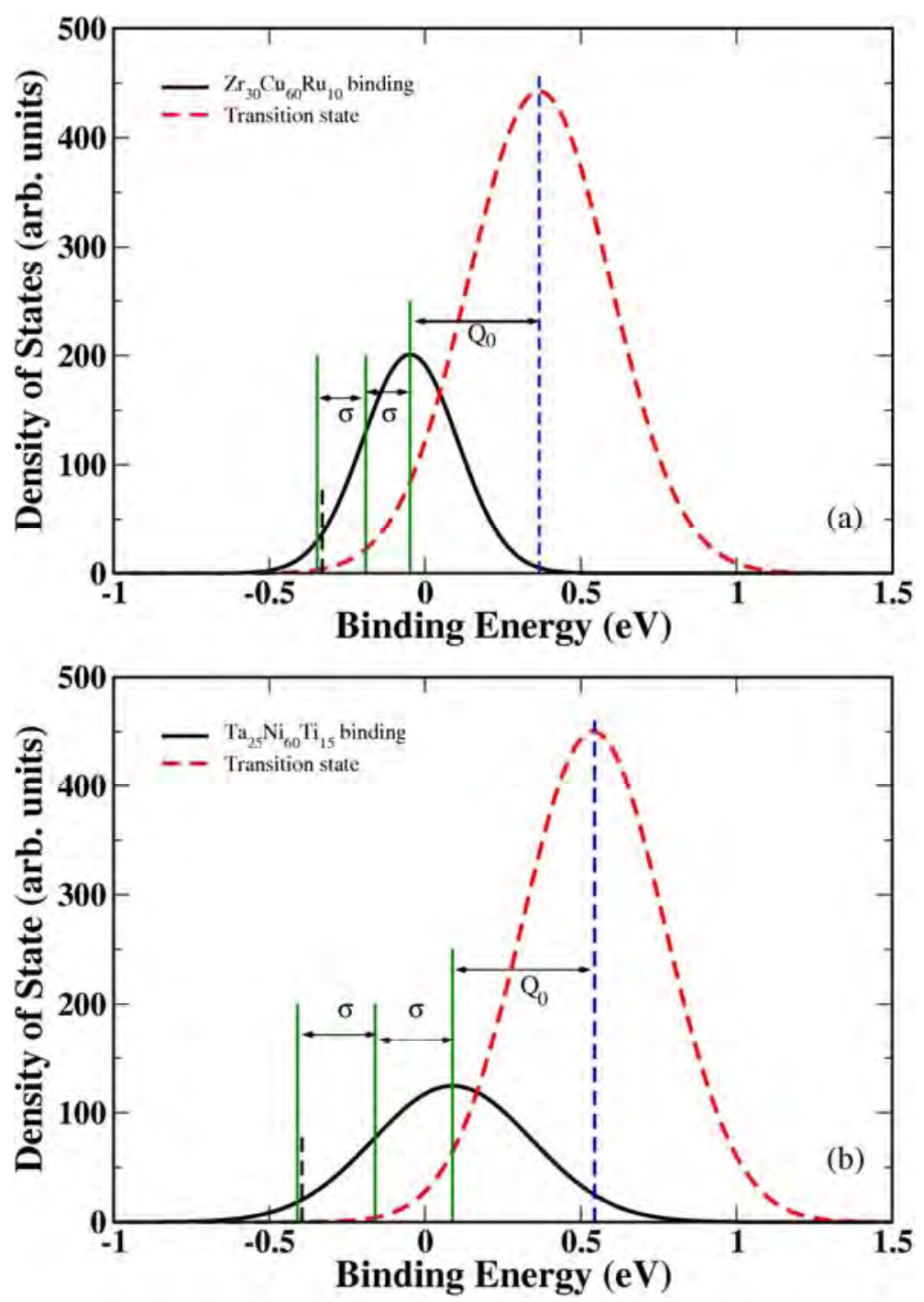

Figure 16: $\mathrm{H}$ binding energy and transition state energy distributions in $\mathrm{Zr}_{30} \mathrm{Cu}_{60} \mathrm{Ti}_{10}$ (a) and $\mathrm{Ta}_{25} \mathrm{Ni}_{60} \mathrm{Ti}_{15}$ (b). $Q_{0}$ and $\sigma$ in two systems are $(0.41,0.15 \mathrm{eV})$ and $(0.46,0.25 \mathrm{eV})$, respectively.

Even though the correlated saddle point model can explain the complex solubility and diffusivity properties of amorphous materials, it can only explain the behaviors after detail calculations and the model is not predictive. Interestingly, if a simple Gaussian distribution model for only $\mathrm{H}$ binding energy is applied, the material behavior can also be explained and even predicted.

Figure 17 shows the $\mathrm{H}$ binding energy distributions in $\mathrm{Zr}_{30} \mathrm{Cu}_{60} \mathrm{~T}_{10}(\mathrm{~T}=\mathrm{Ru}, \mathrm{Rh}, \mathrm{Mo}$, and Ti) and the reference system $\mathrm{Zr}_{54} \mathrm{Cu}_{46}$. From the mean value position and standard deviation shape, we can analyze the behavior of the each limiting case including low solubility/ low diffusivity $\left(\mathrm{Zr}_{30} \mathrm{Cu}_{60} \mathrm{Mo}_{10}\right)$, low solubility/ high diffusivity $\left(\mathrm{Zr}_{30} \mathrm{Cu}_{60} \mathrm{Ru}_{10}\right)$, high solubility/ low diffusivity $\left(\mathrm{Zr}_{30} \mathrm{Cu}_{60} \mathrm{Rh}_{10}\right)$ and high solubility/ high diffusivity $\left(\mathrm{Zr}_{30} \mathrm{Cu}_{60} \mathrm{Ti}_{10}\right)$. For example, the unfavorable mean value position and the narrow standard deviation imply that $\mathrm{Zr}_{30} \mathrm{Cu}_{60} \mathrm{Ru}_{10}$ will have low solubility and high diffusivity. 
While keeping almost the same mean value position, the wider standard deviation in $\mathrm{Zr}_{30} \mathrm{Cu}_{60} \mathrm{Mo}_{10}$ gives relative large average diffusion barrier and thus low diffusivity. The opposite $\mathrm{H}$ binding energy shape is in $\mathrm{Zr}_{30} \mathrm{Cu}_{60} \mathrm{Rh}_{10}$, where the favorable mean value and very wide standard deviation suggest high solubility and low diffusivity. Similarly, we can analyze the $\mathrm{Zr}_{30} \mathrm{Cu}_{60} \mathrm{Ti}_{10}$ and $\mathrm{Zr}_{54} \mathrm{Cu}_{46}$. Thus using the simple Gaussian model, from the $\mathrm{H}$ binding energy distribution shape and position we can qualitatively predict solubility and diffusivity and thus permeability.

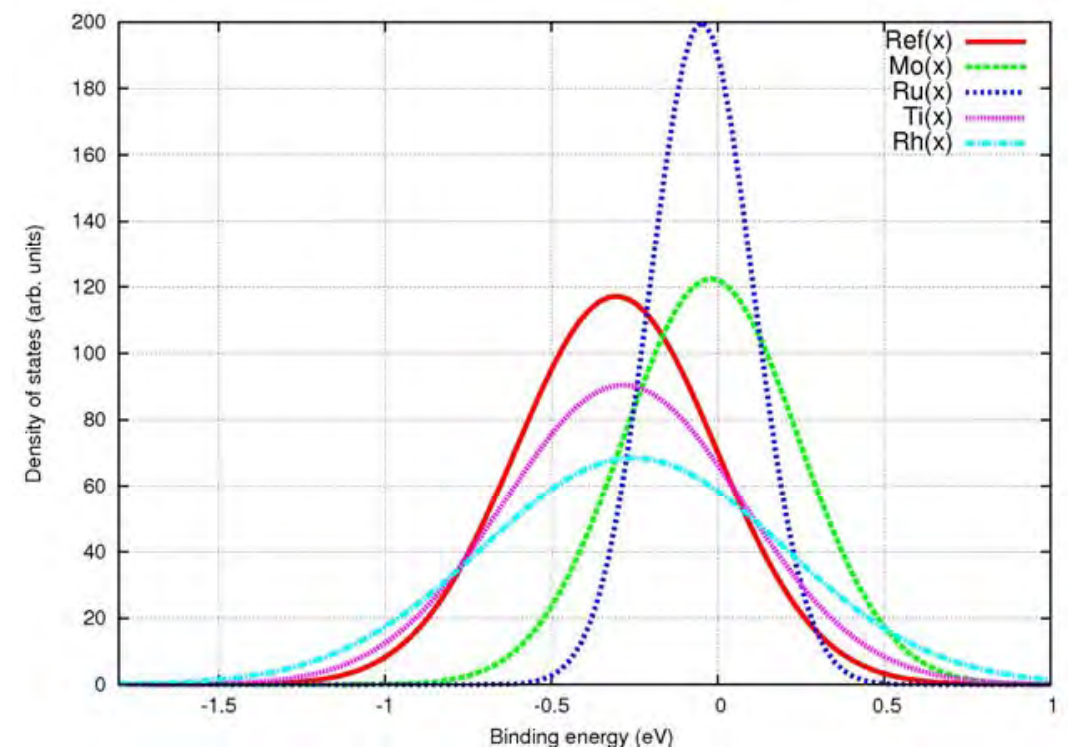

Figure 17: $\mathrm{H}$ binding energy distributions in Gaussian function for $\mathrm{Zr}_{30} \mathrm{Cu}_{60} \mathrm{Ti}_{10}(\mathrm{~T}=$ $\mathrm{Mo}, \mathrm{Ti}, \mathrm{Ru}, \mathrm{Rh}$ ) and reference $\mathrm{Zr}_{54} \mathrm{Cu}_{46}$.

As we have seen, both the correlated saddle point model and the Gaussian model can explain solubility and diffusivity very well. The correlated saddle point model, however, needs thorough DFT calculations to understand interesting properties and is not predictive. The Gaussian model, in contrast, only needs binding energy calculations to qualitatively explain solubility and diffusivity. Since the solubility and diffusivity of all DFT calculated amorphous samples can be explained by both the correlated saddle point model and the Gaussian model, a natural question is that if there is an intrinsic relation between the two models.

To test whether the correlated saddle point model is consistent with the simple Gaussian model, we analyzed $\mathrm{Q}_{0}$, the mean value difference of binding energy distribution and $\mathrm{H}$ diffusion saddle point energy distribution. We collected the $\mathrm{Q}_{0}$ values from all of our DFT results $\left(\mathrm{Zr}_{30} \mathrm{Cu}_{60} \mathrm{~T}, \mathrm{~T}=\mathrm{Sc}, \mathrm{Ti}, \mathrm{Y}, \mathrm{Nb}, \mathrm{Mo}, \mathrm{Tc}, \mathrm{Ru}, \mathrm{Rh}, \mathrm{Pd}, \mathrm{Ag}, \mathrm{Ta}, \mathrm{W}, \mathrm{Re}, \mathrm{Os}\right.$, Ir, Pt, Au) and fitted them with a simple Gaussian function. As shown in Figure 18(b), for different materials $\mathrm{Q}_{0}$ is different and those values can be distributed in a Gaussian function with a mean value of $0.435 \mathrm{eV}$ and a standard deviation of $0.038 \mathrm{eV}$. Comparing with any specified systems shown in Figure 18(a), e.g. $\mathrm{Zr}_{54} \mathrm{Cu}_{46}$, the $\mathrm{Q}_{0}$ peak is very narrow, implying that the correlated saddle point model always contain a nearly constant $\mathrm{Q}_{0}$ for any system. Therefore, the $\mathrm{H}$ diffusion processes between nearby binding sites will 
strongly depend on the initial and final energies. The Gaussian model describes only the initial and final energies, thus the correlated saddle point model is consistent with the
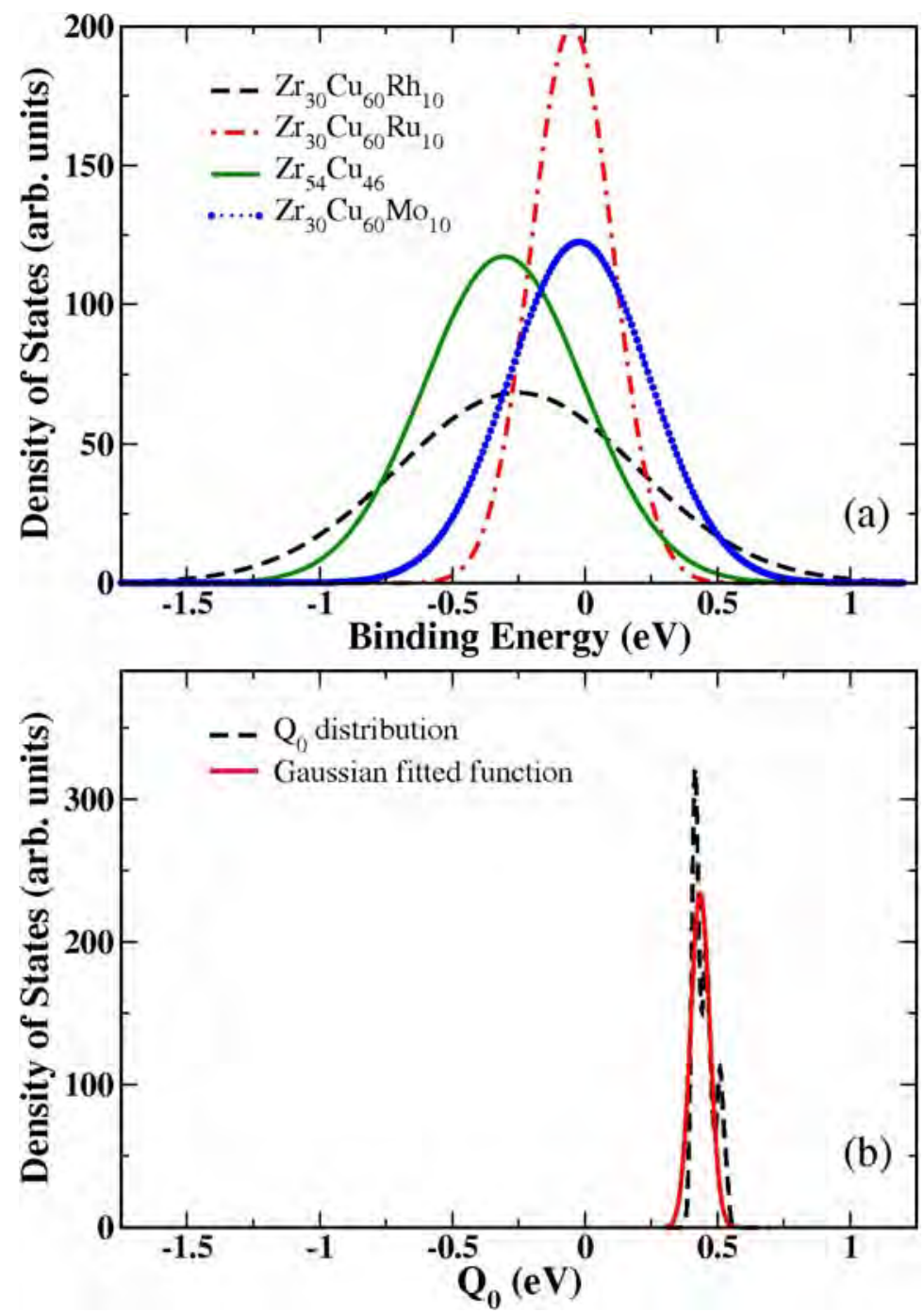

Figure 18: (a) Gaussian distributions of binding energy in four typical cases, $\mathrm{Zr}_{30} \mathrm{Cu}_{60} \mathrm{Rh}_{10}, \mathrm{Zr}_{30} \mathrm{Cu}_{60} \mathrm{Ru}_{10}, \mathrm{Zr}_{30} \mathrm{Cu}_{60} \mathrm{Mo}_{10}$, and $\mathrm{Zr}_{54} \mathrm{Cu}_{46}$. (b) Distribution of $\mathrm{Q}_{0}$ (dashed line) for all available DFT calculated amorphous materials, and fitted Gaussian distribution (solid line) with a mean value of $0.435 \mathrm{eV}$ and a standard deviation of 0.038 $\mathrm{eV}$.

It is of great interest for experimental researchers to know the corresponding properties at any compositions for a ternary and even multiple component systems. Here we take $\mathrm{Zr}_{\mathrm{x}} \mathrm{Cu}_{\mathrm{y}} \mathrm{Ti}_{100-\mathrm{x}-\mathrm{y}}$ as an example to show how we predict those properties based on the DFT data. We use one dimensional polynomial interpolation and extrapolation techniques followed by a two dimensional least square surface fitting method to construct solubility and diffusivity data. The polynomial function used in this fitting is $f(x, y)=\sum_{i}{ }^{p} \Sigma_{j}{ }^{q_{i j}} a_{i}\left(x-x_{0}\right)^{i-}$ ${ }^{1}\left(\mathrm{y}-\mathrm{y}_{0}\right)^{\mathrm{j}-1}$, where $\mathrm{a}_{\mathrm{ij}}$ are parameters and $\mathrm{x}_{0}, \mathrm{y}_{0}$ are average values of known data in $\mathrm{x}$ and $\mathrm{y}$ directions. In these calculations, we assume $\mathrm{Zr}_{\mathrm{x}} \mathrm{Cu}_{\mathrm{y}} \mathrm{Ti}_{100-\mathrm{x}-\mathrm{y}}$ is still in amorphous phase at 
any compositions even at the limiting compositions $\mathrm{Zr}_{100}, \mathrm{Cu}_{100}$, and $\mathrm{Ti}_{100}$. In other words, during $\mathrm{H}$ permeation processes, precipitate phenomena are not considered. Moreover, we don't consider the $\mathrm{H}$ reactions with the host lattice forming metal hydrides at corresponding conditions.

The fitted solubility and diffusivity normalized with respect to $\mathrm{Zr}_{54} \mathrm{Cu}_{46}$ at any composition are plotted in Figure 19(a) and (b). The solubility monotonically increases with increasing $\mathrm{Zr}$ or Ti composition and decreases with $\mathrm{Cu}$ content. The more complex situation of diffusivity is that their higher diffusivity centered in the middle composition region. At higher $\mathrm{Zr}$ and/or Ti compositions, the diffusivity decrease would be governed by the blocking effect at the high hydrogen concentration. By comparing with solubility and diffusivity data, we find that the fitting results are in good agreement with the DFT data. Based on the fitted phase diagram of solubility and diffusivity, we can calculate corresponding permeability at any compositions at the same conditions by the Fick's law. Note that the fitted solubility is based on the averaged solubility at 3 and 0.01 atm at 600 $\mathrm{K}$, and diffusivity is the transport diffusivity at corresponding concentration, the permeability is thus simply multiplied by these two quantities. 

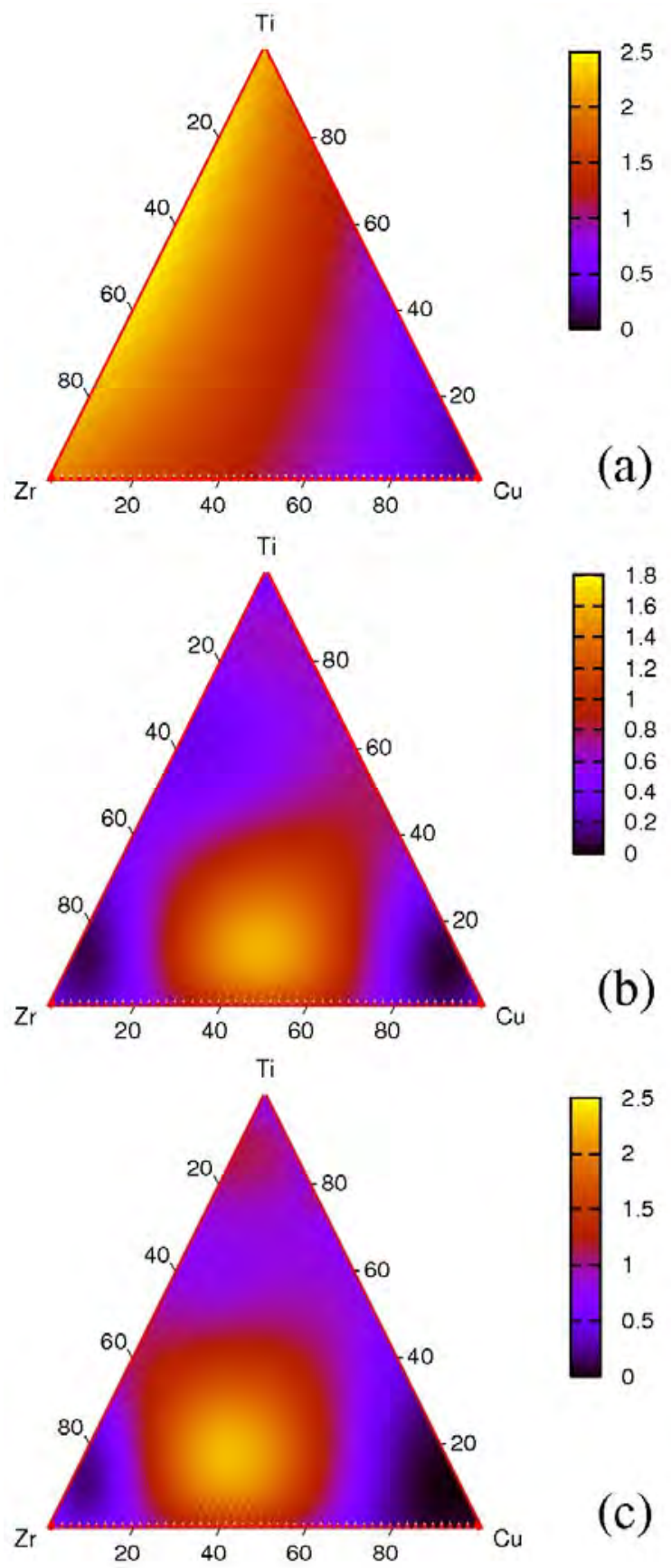

(b)
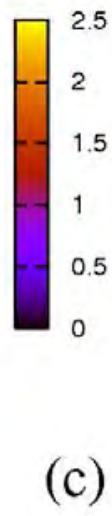

Figure 19: Phase diagram of ternary (a) solubility, (b) diffusivity, and (c) permeability of $\mathrm{Zr}_{\mathrm{x}} \mathrm{Cu}_{\mathrm{y}} \mathrm{Ti}_{100-\mathrm{x}-\mathrm{y}}$ at $600 \mathrm{~K}$. The solubilities are averaged by those at 3 and $0.01 \mathrm{~atm}$. The transport diffusivities are at corresponding hydrogen concentrations and the permeabilities are thus related to feed and permeate pressure 3 and $0.01 \mathrm{~atm}$.

The membrane performance can be qualitatively estimated by the shape and position of the simple Gaussian model as can be seen in previous report and above section. More precisely, if we can quantitatively optimize the parameters $(\mu, \sigma)$ of Gaussian distribution functions, we then can exclude a large amount of amorphous materials with large deviation from these optimal parameters for future theoretical investigations. Starting 
from our DFT-based results including binding energy, solubility, and diffusivity, we can get the permeability at any composition of $\mathrm{Zr}_{\mathrm{x}} \mathrm{Cu}_{\mathrm{y}} \mathrm{Ti}_{100-\mathrm{x}-\mathrm{y}}$ by the fitting technique described above. Alternatively, we can also fit the Gaussian model parameters mean value $\mu$ and standard deviation $\sigma$ as a function of $\mathrm{Zr}_{\mathrm{x}} \mathrm{Cu}_{\mathrm{y}} \mathrm{Ti}_{100-\mathrm{x}-\mathrm{y}}$ composition. Once we get diagrams of permeability, $\mu$, and $\sigma$ as a function of $\mathrm{ZrCuTi}$ composition, we can determine what good values of the Gaussian parameters are by restricting our attention to materials with desirable permeability. In Figure 20, the black circles are good parameters under which the permeabilities are about 2 times higher than $\mathrm{Zr}_{54} \mathrm{Cu}_{46}$ at $600 \mathrm{~K}$ with 3 and $0.01 \mathrm{~atm}$ feed and permeate pressure respectively. We also show the resulting parameters from our available DFT results into Figure 20, where $\mathrm{Zr}_{50} \mathrm{Cu}_{40} \mathrm{Ti}_{10}$, $\mathrm{Zr}_{30} \mathrm{Cu}_{60} \mathrm{~T}_{10}(\mathrm{~T}=\mathrm{Sc}, \mathrm{Ta}, \mathrm{Y}$, and Ti) are much closer than other materials indicating good permeability performance. This is in good agreement with our DFT results. This suggests that for any material to have high permeability, it should have Gaussian parameters within the region denoted in the figure. Thus we only need to do DFT for $\mathrm{H}$ binding energy as a first iteration screening step and only do diffusivity for those materials in short list.

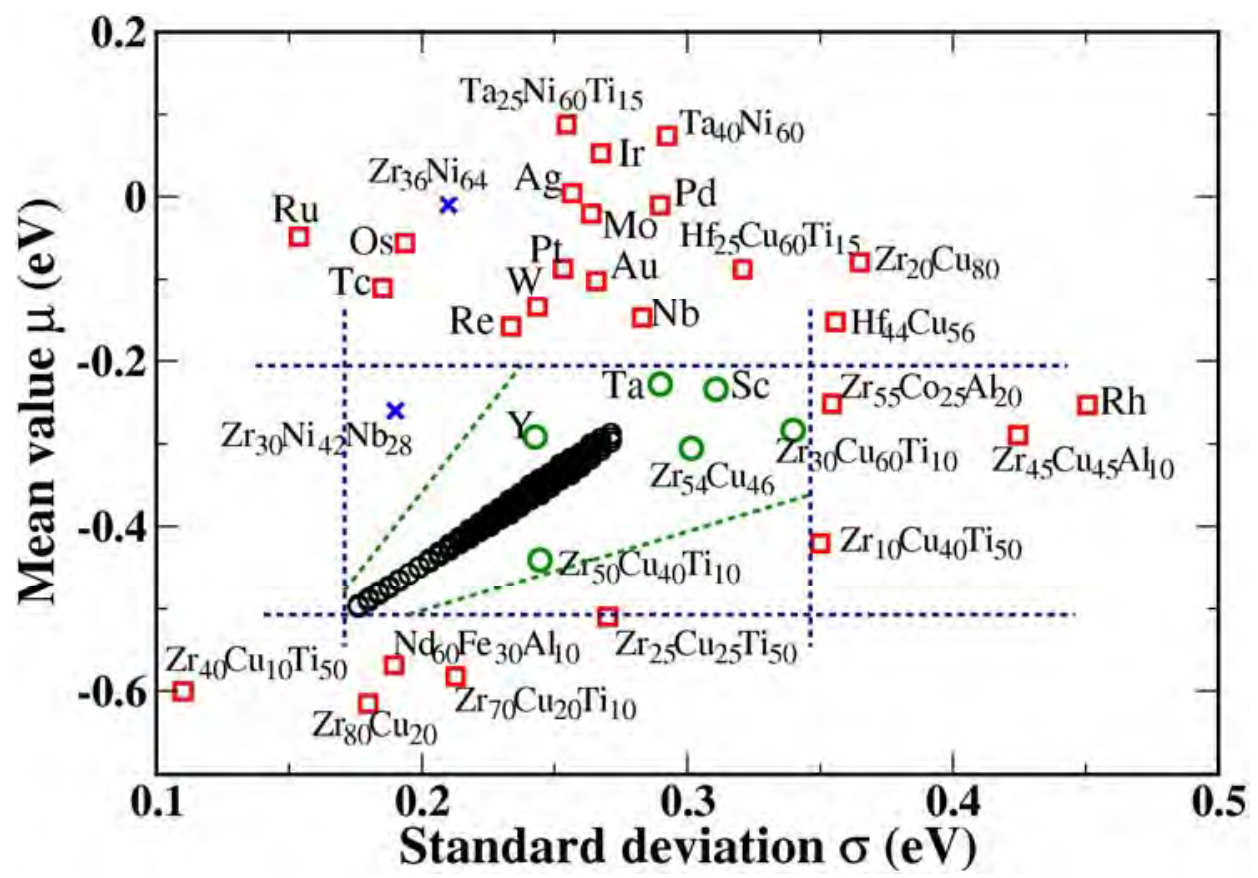

Figure 20: Gaussian model parameters for $\mathrm{H}$ binding energy in all DFT results (shown as scattered data) and optimized parameters from fitted samples in $\mathrm{Zr}_{\mathrm{x}} \mathrm{Cu}_{\mathrm{y}} \mathrm{Ti}_{100-\mathrm{x}-\mathrm{y}}$ (black circles). The element labels beside the data indicate the samples of $\mathrm{Zr}_{30} \mathrm{Cu}_{60} \mathrm{~T}_{10}(\mathrm{~T}=\mathrm{Sc}$, $\mathrm{Ti}, \mathrm{Y}, \mathrm{Nb}, \mathrm{Mo}, \mathrm{Tc}, \mathrm{Ru}, \mathrm{Rh}, \mathrm{Pd}, \mathrm{Ag}, \mathrm{Ta}, \mathrm{W}$, Re, Os, Ir, Pt, Au). Our previous DFT results for $\mathrm{Zr}_{36} \mathrm{Ni}_{64}$ and $\mathrm{Zr}_{30} \mathrm{Ni}_{42} \mathrm{Nb}_{28}$ are also included as symbol $\mathrm{x}$.

A problem coming with non-Pd based high permeability membranes is the low catalytic activity for hydrogen dissociation. To search for a good catalytic material that is added to a membrane, besides some associated properties such as high temperature phase stability and low intermetallic diffusion between membrane and catalyst, the ability to dissociate hydrogen molecule is the most important. Recently, dense vanadium (V) membranes 
coated with molybdenum carbides $\left(\mathrm{Mo}_{2} \mathrm{C}\right)$ have been tested experimentally and exhibited promising hydrogen permeabilities, where the carbides are potentially assessed to serve as stable catalysts for $\mathrm{H}_{2}$ dissociation. The molybdenum carbides with extremely high melting points are mechanically durable, making them less prone to alloying with the membrane materials and enable stable operation at high temperature. Although the carbide materials are not necessarily intrinsically hydrogen permeable, the proven hypothesis was that thin layers of carbides may allow for the transport of dissociated hydrogen to the underlying metal along grain boundaries or micro-scaled defects. Interestingly, all the carbide-coated vanadium composites showed poor correspondence to Sievert's law at $600^{\circ} \mathrm{C}$, suggesting that the $\mathrm{Mo}_{2} \mathrm{C}$ catalytic layer is limiting the rate of hydrogen transport in these membranes.

In this work, by taking the $\mathrm{Mo}_{2} \mathrm{C} / \mathrm{V}$ as an example, we use a microkinetic model based on density functional theory (DFT) calculations to explain the experimental observations and illustrate a rule of principle to search for catalytic materials for spillover governed hydrogen purification.

\section{Microkinetic model of $\mathrm{H}_{2}$ permeation through metal membranes with catalytic layers}

Our model for the permeation of $\mathrm{H}_{2}$ through catalytic layer and metal membrane is extracted from experimental conditions and closely follows the previous simple model. In this model, we describe a dissociative adsorption of $\mathrm{H}_{2}$ molecules onto the catalytic layer surface as shown the process 1 in Figure 21(a). According to the assumption explained above, the dissociated $\mathrm{H}$ on the catalytic surface will easily diffuse along the grain boundary to the interface of catalytic layer and metal membrane. The following steps include transition of atomic $\mathrm{H}$ from the interface into the bulk membrane, diffusion within the bulk membrane, and transport from bulk membrane to the downstream interface as depicted processes 3, 4, and 5 respectively in Figure 21(a). The other steps 6 and 7 are reverse processes of 1 and 2 noted as diffusion through the catalytic layer and recombinative desorption from the catalytic layer. Obviously, we treat the membrane as an unsupported, defect-free metal film. We assume that both the feed and permeate gases around the membrane are pure $\mathrm{H}_{2}$, implying that chemical contamination of the membrane surfaces is not considered. 

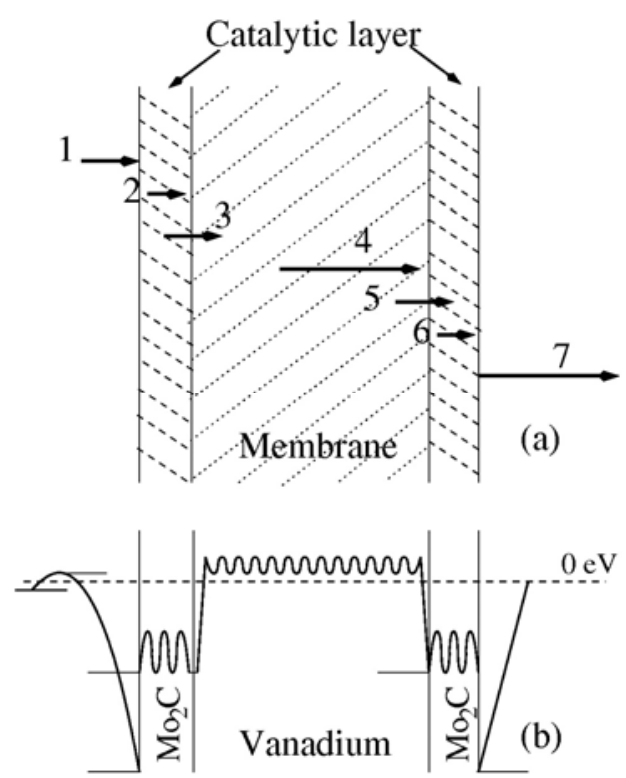

Figure 21: (a) Schematic model for hydrogen permeation through metal membrane with catalytic layers and (b) corresponding energy landscape of vanadium membrane with $\mathrm{Mo}_{2} \mathrm{C}$ catalytic coatings. In this model, there are (1) $\mathrm{H}_{2}$ gas dissociative adsorption, (2) $\mathrm{H}$ diffusion within catalyst grain boundary, (3) transition from interface to membrane bulk, (4) diffusion in membrane bulk, (5) transition from bulk to interface, (6) grain boundary diffusion in catalytic layer, and (7) recombination desorption from catalytic layer surface.

With this model, we can define the fluxes associated with each of these transport processes. The net flux due to diffusion through the bulk membrane is defined via Fick's law. In the case of crystalline vanadium, the dilute $\mathrm{H}$ concentration is perfect because of the relative unfavorable $\mathrm{H}$ binding energy. Here for the $\mathrm{H}$ transport through the vanadium membrane, we didn't consider diffusion along the grain boundary because the relative large thickness in several or tens micrometers. While for the catalytic layer, we consider $\mathrm{H}$ transport through grain boundary due to a significantly thinner thickness.

The atomic adsorption flux at the surface can be defined by external hydrogen partial pressure in the gas just near the surface, temperature, and sticking coefficient. The sticking coefficient can be modeled by the quasi-chemical equilibrium approximation (QCA). The QCA is based on the idea that pairs of adsorbates rather than individual adsorbates are distributed randomly on the surface. Thus it is intrinsically better than mean-field approximation, which ignores the interaction between adsorbates and disperses the adsorbates randomly on the surface. Correspondingly, the flux of $\mathrm{H}_{2}$ molecules leaving a surface by recombinative desorption is determined by desorption energy for a pair of $\mathrm{H}$ atoms from neighboring adsorption sites on the surface, and the probability of finding two adjacent occupied binding sites.

To describe the net flux of $\mathrm{H}$ atoms from the catalytic layer and membrane interface on the feed side to adjacent subsurface interstitial sites, the activation energy barrier for hopping from an interface site to a subsurface interstitial site, $\mathrm{H}$ coverage and the probability that the subsurface site is occupied must be known. Similarly, the net flux of $\mathrm{H}$ atoms from subsurface interstitial sites to interface sites on the permeate side of the membrane must also be known. 
Once all the rate parameters in the individual fluxes defined above are known, the overall permeance of $\mathrm{H}_{2}$ through a membrane can be calculated as a function of the feed pressure, transmembrane pressure drop, and temperature. Our approach to this calculation is similar to the method used by Ward and Dao. By fixing the feed pressure, we choose an arbitrary flux and calculate the corresponding permeate pressure. If the calculated permeate pressure does not match the desired permeate pressure, the flux value is updated to achieve a closer match between the calculated and desired value. This iterative process is continued until the difference between the calculated and target permeate pressure was less than $10^{-5} \mathrm{~atm}$.

\section{Mo $\mathbf{C}$ surfaces and $\mathrm{H}_{2}$ dissociation}

To address kinetic properties, a series of parameters about hydrogen adsorption on $\mathrm{Mo}_{2} \mathrm{C}$ must be identified. As the experimental results suggested that the orthorhombic $\mathrm{Mo}_{2} \mathrm{C}$ is favorable around $600^{\circ} \mathrm{C}$ temperature, our calculations focused on the orthorhombic structure in the Pbcn space group. Based on the DFT optimized structure, a series of surface configurations are created including (101), (110), (100), (010), (001), and (011) surfaces. The surface energy calculations suggest that (101), (110), and (100) are 2.82, 2.93, and $3.18 \mathrm{~J} / \mathrm{m}^{2}$ respectively. The other surface energies are unfavorable and not shown here.

The $\mathrm{H}_{2}$ adsorption and dissociation on the three relatively favorable surfaces are then investigated by multiple DFT calculations. The calculation results are plotted as dashed lines in Figure 22. We also include van der Waals interactions for hydrogen adsorption via a simple pair-wise force field known as the DFT- $\mathrm{D}_{2}$ method of Grimme. The adsorption energies and dissociation barriers are shown as solid lines in Figure 22(a)(c). A similar feature of the energy profile for all three cases is that the adsorption energies with $\mathrm{D}_{2}$ correction are lower than those cases without correction. The low dissociation barriers in all cases imply fast dissociation kinetics on $\mathrm{Mo}_{2} \mathrm{C}$ surfaces. Moreover, the binding energies of dissociated $\mathrm{H}$ are clearly very favorable as $-1.49,-1.13$ and $-1.74 \mathrm{eV}$ on the three surfaces. 


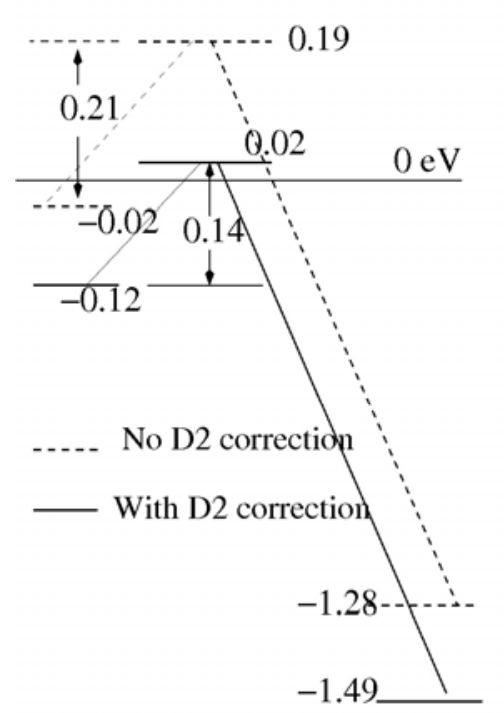

(a)

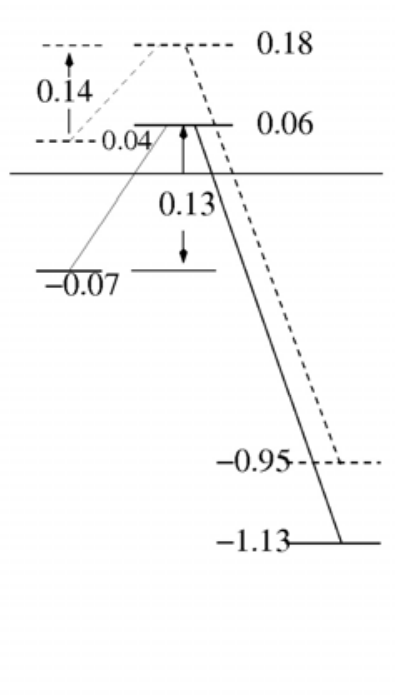

(b)

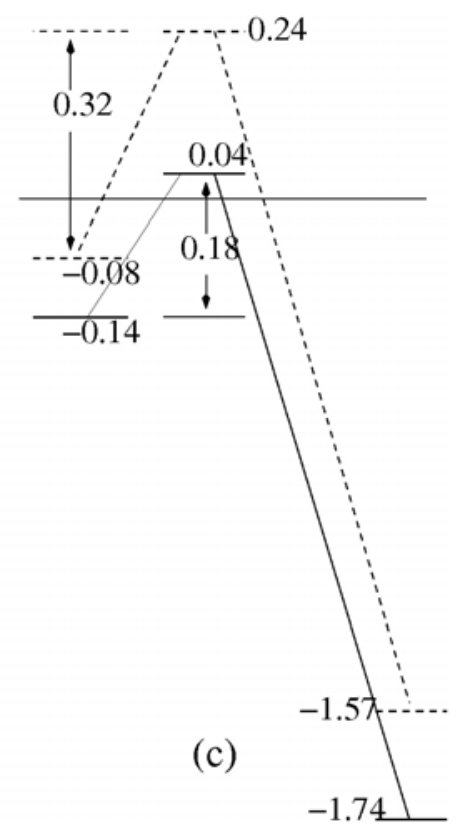

Figure 22: $\mathrm{H}_{2}$ adsorption and dissociation energies on $\mathrm{Mo}_{2} \mathrm{C}$ (a) (101), (b) (110), and (c) (100) surfaces. The total energy of free $\mathrm{H}_{2}$ molecule is set as reference.

\section{Flux of Vanadium membrane with $\mathrm{Mo}_{2} \mathrm{C}$ layer and resistance analysis}

Due to the similarity of $\mathrm{H}_{2}$ dissociation barriers on three surfaces, we consider $\mathrm{Mo}_{2} \mathrm{C}$ (101) as an example to calculate the transport fluxes. Simple DFT calculations of $\mathrm{H}$ in crystal vanadium suggest that $\mathrm{H}$ binding energy and diffusion barrier are 0.06 and 0.12 $\mathrm{eV}$ respectively. For the hydrogen transport along a grain boundary of a $\mathrm{Mo}_{2} \mathrm{C}$ catalytic layer, it is not realistic to have a diffusion barrier because the detailed grain boundary structures are not available. In this situation, we arbitrarily account for the $\mathrm{H}$ diffusion within $65 \mathrm{~nm} \mathrm{Mo} 2 \mathrm{C}$ grain boundary processes (2) and (6) with a diffusion barrier $0.4 \mathrm{eV}$. Similar to $\mathrm{H}$ diffusion in vanadium, given diffusivity and membrane thickness, the corresponding fluxes can be calculated by Fick's law.

The recombinative desorption requires two neighbor isolated $\mathrm{H}$ overcome their own binding energies to form a $\mathrm{H}_{2}$ molecule. By taking $\mathrm{Mo}_{2} \mathrm{C}$ (101) as the example, the desorption energy is clearly $1.49 \mathrm{eV}$. For the pre-factor of the desorption rate, we just used the vibrational frequencies of two adjacent $\mathrm{H}$ and free $\mathrm{H}_{2}$ molecule to get corresponding partition functions and a pre-factor. The average adsorbate-adsorbate interaction energy for pair occupancy possibility is identified by DFT as $0.15 \mathrm{eV}$. Using a similar method as Ward's and Ling's papers by fixing the feed pressure (5 atm as experimental indicated), we choose an arbitrary flux and calculated the corresponding permeate pressure. If the calculated permeate pressure did not match the target permeate pressure, the trail flux was changed until a desired tolerance was reached. 

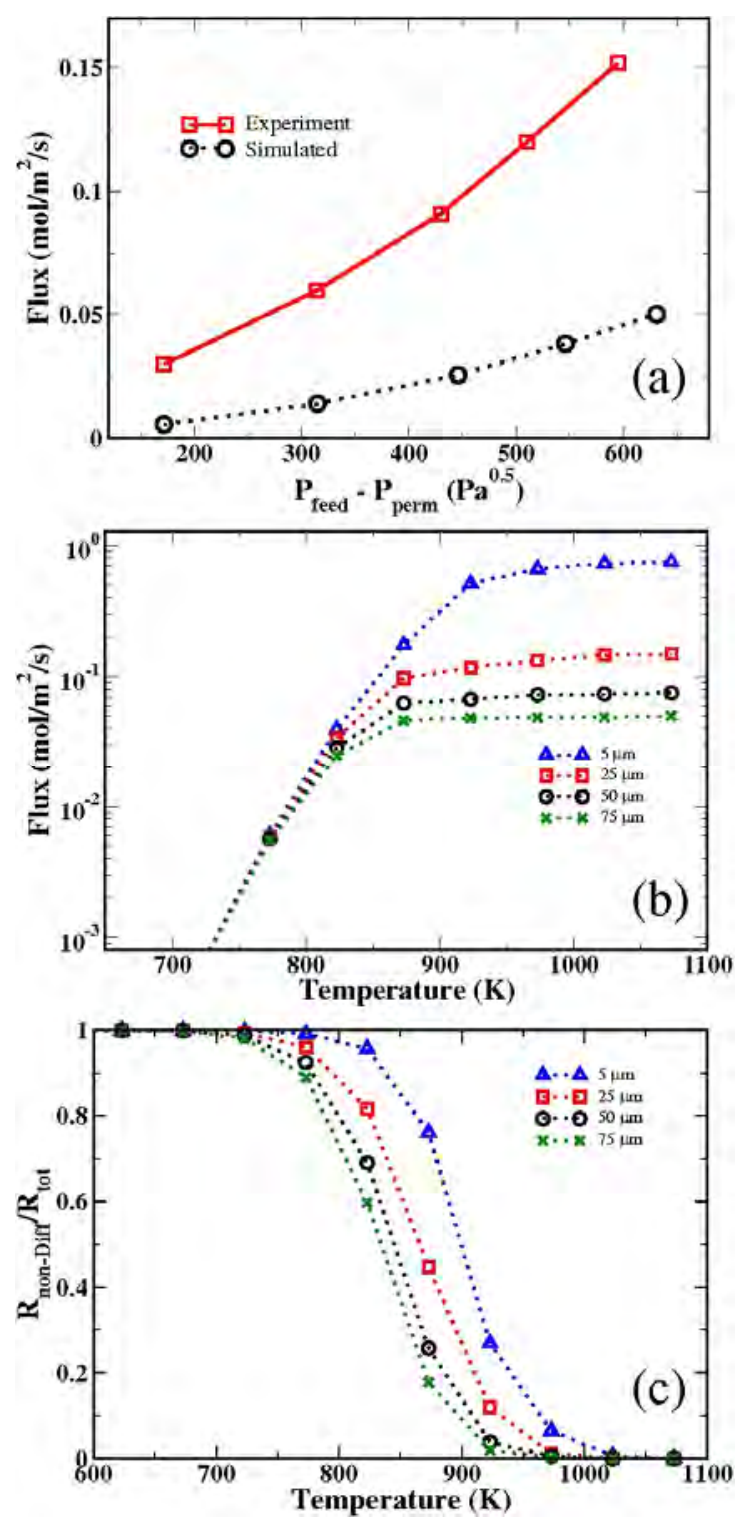

Figure 23: (a) Comparison of calculated flux as a function of pressure drop with experimental results at $600^{\circ} \mathrm{C}$. (b) Hydrogen flux as a function of temperature for $\mathrm{Mo}_{2} \mathrm{C}$ coated vanadium membranes with different thickness. The feed and permeate pressures are 5 and $10^{-5} \mathrm{~atm}$. The desorption processes of $2 \mathrm{H}$ atom forming $\mathrm{H}_{2}$ molecules are simulated on $\mathrm{Mo}_{2} \mathrm{C}(101)$ surface with a desorption energy of $1.36 \mathrm{eV}$. (c) Desorption resistance ratio as a function of temperature for $\mathrm{Mo}_{2} \mathrm{C}$ coated vanadium membranes with different thickness. The feed and permeate pressures are 5 and $10^{-5} \mathrm{~atm}$.

We first examined the flux of $\mathrm{Mo}_{2} \mathrm{C}(65 \mathrm{~nm})$ coated vanadium $(50 \mu \mathrm{m})$ at $600^{\circ} \mathrm{C}$ as a function of pressure drop and compared with experimental results as shown in Figure 23(a). Our calculated fluxes are lower than experimental results. But based on these flux values, the permeability results agree very well with theoretical results shown in Figure 23 for the literature. More importantly, the curvature of our results is consistent 
with experimental tendency, indicating slightly deviation from Sieverts' law at this condition.

Figure 23(b) shows the calculated flux through $\mathrm{Mo}_{2} \mathrm{C}$ coated vanadium membranes with several different thicknesses as a function of temperature for a feed pressure of 5 atm and a $10^{-5} \mathrm{~atm}$ condition on the permeate side. The fluxes at temperatures below $800 \mathrm{~K}$ tend to converged for samples with different thickness, indicating that the membrane diffusion flux is not the limiting step and there must be some other rate limiting steps at this temperature range. On the contrary, at temperature range higher than $950 \mathrm{~K}$, the fluxes for different samples increase reversely as the thickness of membrane decrease, implying that membrane diffusion flux is the rate limiting step at this temperature range. The fluxes for different thickness membranes at the temperature range between 800-950 K bridge the corresponding fluxes continuously, suggesting that the membrane diffusion and some other rate limiting step compete with each other and play a role simultaneously.

It is interesting to define the diffusion resistance ratio as $R_{\text {diff }} / R_{\text {tot }}$, where $R_{\text {diff }}\left(R_{t o t}\right)$ is the resistance due to bulk diffusion (the total resistance of the membrane and catalytic layer). If $J_{\text {diff }}$ is the membrane flux in the diffusion limited regime and $J_{\text {tot }}$ is the actual flux through a whole membrane and catalytic layer, then $R_{\text {diff }} / R_{\text {tot }}=J_{\text {tot }} / J_{\text {diff. }}$. Then the resistance other than bulk membrane diffusion can be denoted as $R_{\text {non-diff }} / R_{\text {tot }}=1$ $\mathrm{R}_{\text {diff }} / \mathrm{R}_{\text {tot. }}$. The resistance ratios are shown in Figure 23(c). It can be seen that for a membrane with thickness between 5 and $75 \mu \mathrm{m}$, the temperature must be larger than 950 $\mathrm{K}$ before the non-diffusion resistance is less than $10 \%$ of the total resistance. Below 950 $\mathrm{K}$, the non-diffusion resistance ratio increase gradually to 1 as the temperature decreases below $750 \mathrm{~K}$. As to compare with experimental results at $873 \mathrm{~K}$, the flux display a nonSieverts' behavior for a $50 \mu \mathrm{m}$ membrane, our results indicated that the non-diffusion resistance ratio is about 0.25 at a corresponding condition. The results explain that the non-Sieverts' behavior is coming primarily from non-diffusion resistances. Here the nondiffusion resistance includes $\mathrm{H}$ transport along the grain boundary of the catalytic layers, transition from interface to bulk and bulk to interface, and recombinative desorption. To identify which process is the dominant part among the non-diffusion resistances, we also consider only the recombination desorption contribution to the total resistance ratio and we found that other resistances are almost negligible ( $<1 \%$ of desorption resistance) even by the diffusion barrier $0.4 \mathrm{eV}$ for grain boundary diffusion. Therefore, we conclude that recombination desorption plays an important role to govern the non-Sieverts' behavior within the whole transport process. To avoid the non-Sieverts' observations at even lower temperature, a less favorable desorption energy would be expected. We therefore can generalize two basic requirements for a good catalyst selection, low dissociation barrier and less favorable atomic hydrogen adsorption energy.

Dense vanadium membranes coated with molybdenum carbides have been introduced as a new class of metallic membranes for hydrogen separation. Similar coatings may be useful in other kinds of metallic membranes. Recently, we used a microkinetic model based on density functional theory (DFT) calculations to successfully explain the above mentioned experimental observations. The group 5 metal membranes $\mathrm{V}, \mathrm{Nb}$ and Ta are known to exhibit high $\mathrm{H}_{2}$ permeabilities, but slow rates for the dissociation and re- 
association of $\mathrm{H}_{2}$. The catalytic properties of transition-metal carbides (TMCs) have a number of similarities to those of the more expensive Pt-group metals. These observations motivated us to extend our microkinetic model to other carbide-coated group 5 metal membranes.

In the current work, we systematically studied the hydrogen transport properties of $\mathrm{V}, \mathrm{Nb}$ and Ta membranes coated with different TMC catalytic layers by employing firstprinciples calculations together with statistical mechanics methods. Our purpose is to consider a range of potential surface coating materials for high permeability metal membranes of hydrogen purification. The results of our calculations indicate that TMC $(\mathrm{TM}=\mathrm{Ti}, \mathrm{Zr}, \mathrm{Hf}, \mathrm{V}, \mathrm{Nb}$ and $\mathrm{Ta}$ ) (001) surfaces are the most stable ones. The $\mathrm{H}$ adsorption energies on TMCs (001) surfaces (TM $=\mathrm{V}, \mathrm{Nb}$ and $\mathrm{Ta}$ ) are positive; however, $\mathrm{H}$ adsorbs on C-terminated $\mathrm{TiC}$ (001), ZrC (001) and HfC (001) surfaces with -0.55, 0.65 and $-0.59 \mathrm{eV}$ adsorption energies. The calculated potential energy surfaces show that $\mathrm{H}_{2}$ interacts with TMCs $\left(\mathrm{TM}=\mathrm{Ti}, \mathrm{Zr}\right.$, Hf) to form TMC- $\mathrm{H}_{2}$ complexes with $-0.63,-0.77$ and $-0.54 \mathrm{eV}$ association energies, the dissociation barriers are $-0.01,0.12$ and $0.24 \mathrm{eV}$ relative to the $\mathrm{H}_{2}$ and the TMCs surfaces; $\mathrm{H}$ absorbs in the crystalline $\mathrm{V}, \mathrm{Nb}, \mathrm{Ta}$ membrane with the most favorable $\mathrm{H}-\mathrm{M}$ bonding energies of $-0.36,-0.37$ and $-0.37 \mathrm{eV}$ and diffusion barriers of $0.11,0.17$ and $0.13 \mathrm{eV}$.

To select a range of potential surface coating materials for high permeability metal membranes of hydrogen purification, we have systematically studied hydrogen transport properties in $\mathrm{V}, \mathrm{Nb}$ and Ta membranes coated with different transition-metal carbides (TMCs) $(\mathrm{TM}=\mathrm{Ti}, \mathrm{Hf}, \mathrm{Zr}$ ) catalytic layers by employing first-principles calculations together with statistical mechanics methods. The following key results have been achieved:

(1) The TMCs (001) surface is the most stable one with the lowest surface free energy as shown in Figure 24. (Take TiC material as an example)

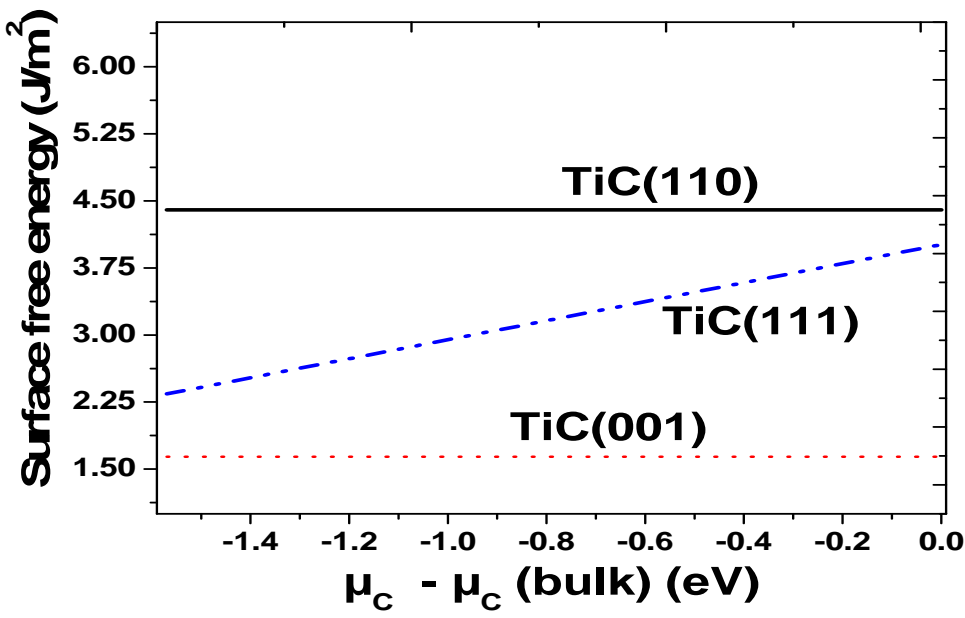

Figure 24: Surface free energy against $\mu_{C}-\mu_{C}$ (bulk). $\mu_{C}$ is the chemical potential of a $C$ atom and $\mu_{\mathrm{C}}$ (bulk) is the chemical potential in bulk phase of C. 
(2) Calculated results show that for groups 4 and 5 TMCs, the atomic hydrogen only prefers bonding to the top $\mathrm{C}$ position of group $4 \mathrm{TiC}(001), \operatorname{ZrC}(001)$ and $\mathrm{Hf}(001)$ surfaces; TiC (001) is the best one for $\mathrm{H}_{2}$ dissociation and for recombinative desorption of the dissociated $\mathrm{H}$ atoms. $\mathrm{H}_{2}$ adsorption and dissociation energy pathways on the most stable $\mathrm{TiC}(001)$, $\mathrm{HfC}(001)$ and $\mathrm{ZrC}$ (001) are shown in Figure 25.

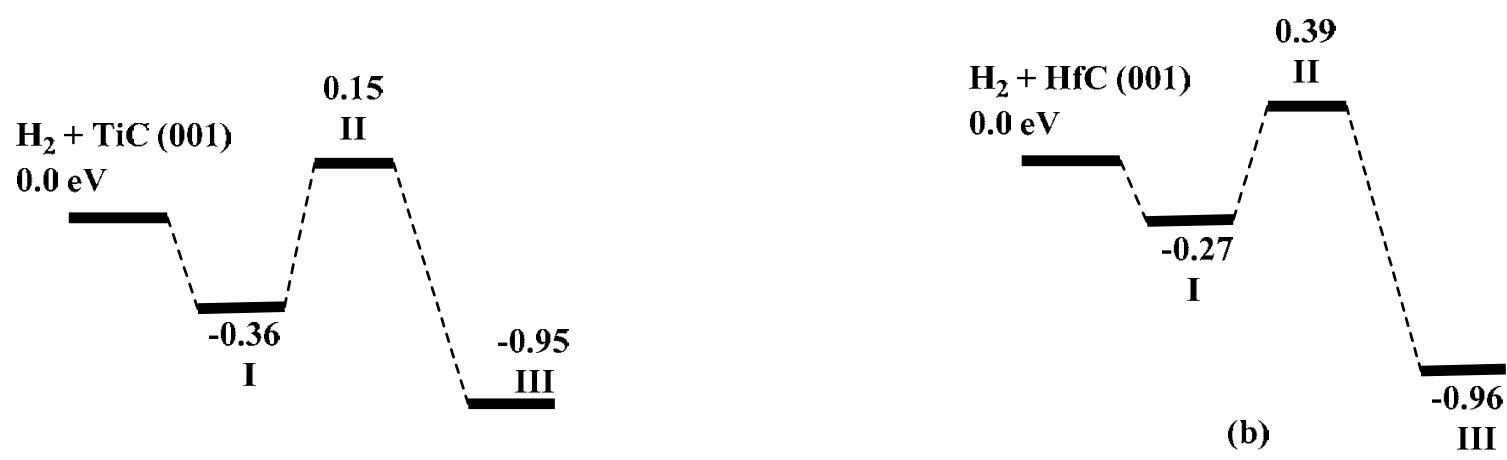

(a)

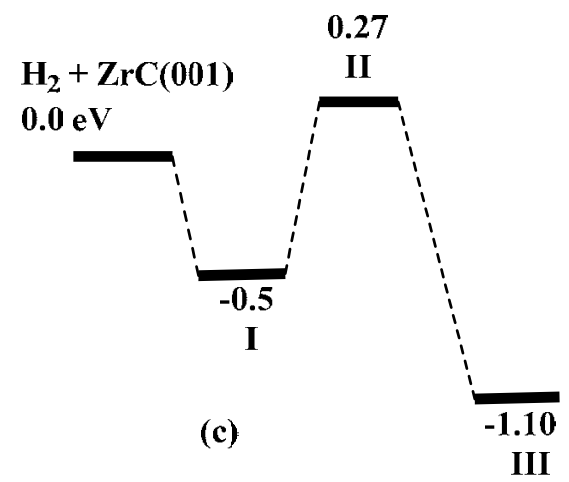

Figure 25: In the above diagrams, the energies shown in I, II and III positions correspond to $\mathrm{H}_{2}$ adsorption energies, dissociation barriers and the dissociated $\mathrm{H}$ adsorption energies on the surfaces (a) TiC(001), (b) HfC (001) and (c) $\mathrm{ZrC}$ (001). All energies in $\mathrm{eV}$ relative to the related clean surface and a gas phase $\mathrm{H}_{2}$ molecule.

The pressure dependent $\mathrm{H}$ solubility, concentration dependent diffusivity through pure $\mathrm{V}$, $\mathrm{Ta}$ and $\mathrm{Nb}$ have also been calculated. Based on these values, the hydrogen fluxes in two types of composite materials are considered:

TMC/membrane/TMC: in this case, the feed and permeate sides of membrane are coated with the same TMC $(\mathrm{TM}=\mathrm{Ti}, \mathrm{Hf}, \mathrm{Zr})$ catalytic layer, where, membrane $=\mathrm{V}, \mathrm{Ta}, \mathrm{Nb}$. Figure 26 displays the hydrogen fluxes as a function of temperature for TMC coated with $75 \mu \mathrm{m}$ thick V, Ta and Nb membranes. The predicted fluxes show that for all the three membranes, the most and least favorable coating layers are $\mathrm{TiC}$ and $\mathrm{ZrC}$, respectively. Checking the desorption energies of $\mathrm{H}_{2}$ on these surfaces $(0.95,0.96$ and $1.10 \mathrm{eV}$ on TiC, $\mathrm{HfC}$ and $\mathrm{ZrC}$ ), we find that the hydrogen flux value is inversely proportional to the $\mathrm{H}_{2}$ desorption energy on these surfaces at low and moderate temperatures. The diffusion 
resistances for the three composite materials are characterized in Figure 27. In this figure, a diffusion resistance ratio of 0 is associated with a situation where diffusion resistance through the membrane is the only resistance to hydrogen permeation. At low temperatures, the resistance ratio approaches 1 , indicating that almost all of the transport resistance is associated with processes other than diffusion through the bulk membrane. It can be seen that for all the three membranes, in order to make the no-diffusion resistance less than 0.1, the temperature must be larger than 900, 1000 and $1050 \mathrm{~K}$ for TMC/V/TMC composite; for the TMC/Ta/TMC and TMC/Nb/TMC systems, the temperature must be larger than 1050, 1110 and $1150 \mathrm{~K}$, respectively.

(a)

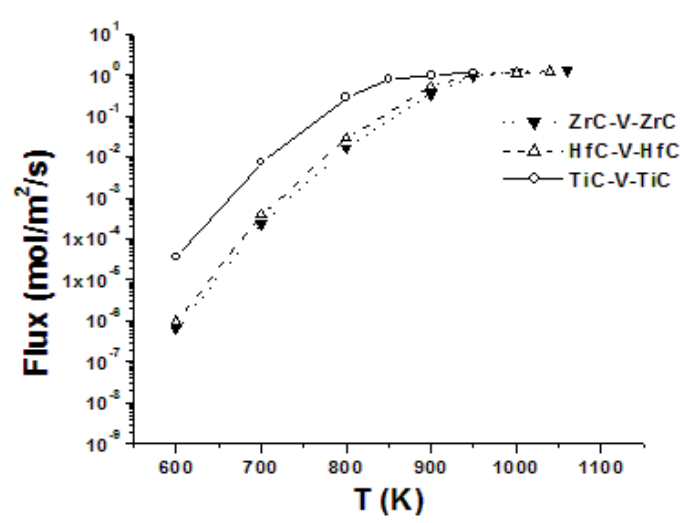

(c)

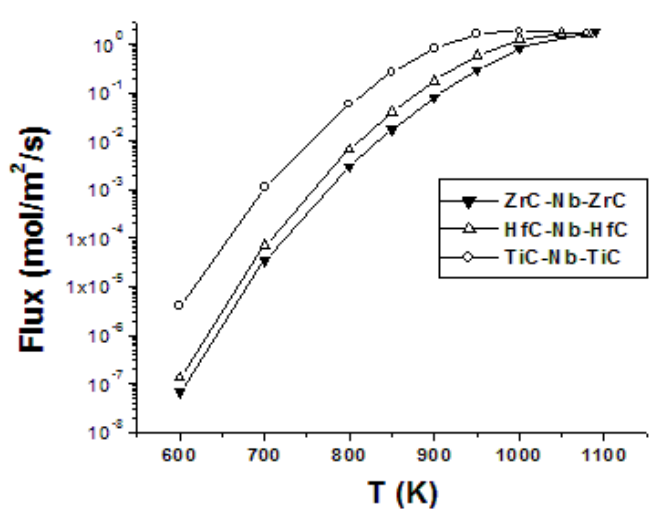

(b)

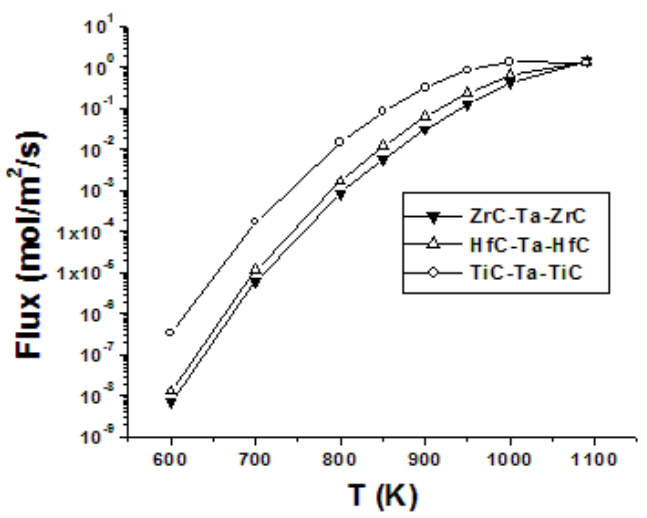

Figure 26: Hydrogen flux as a function of temperature for $\mathrm{TiC}$, $\mathrm{HfC}$ and $\mathrm{ZrC}$ coat on (a) $\mathrm{V}$, (b) $\mathrm{Ta}$ and (c) $\mathrm{Nb}$ membranes on both sides. The feed and permeate pressures are 1 and $10^{-5} \mathrm{~atm}$, and the membrane thickness is $75 \mu \mathrm{m}$. 
(a)

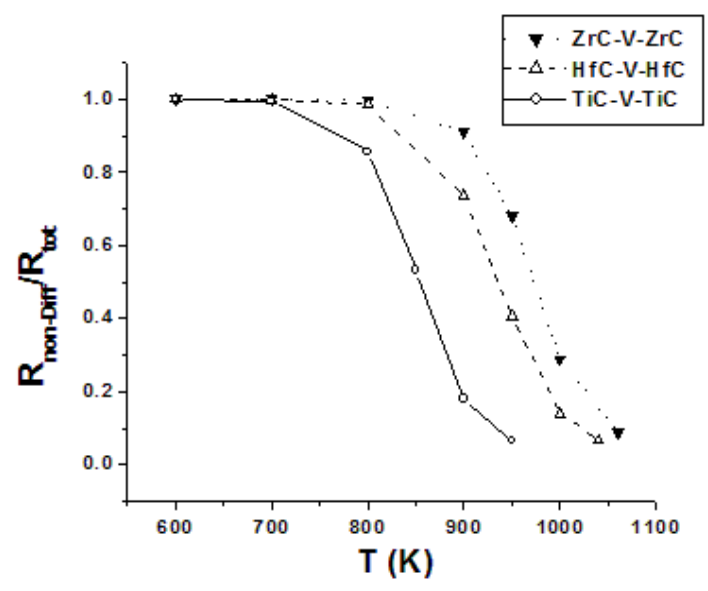

(c)

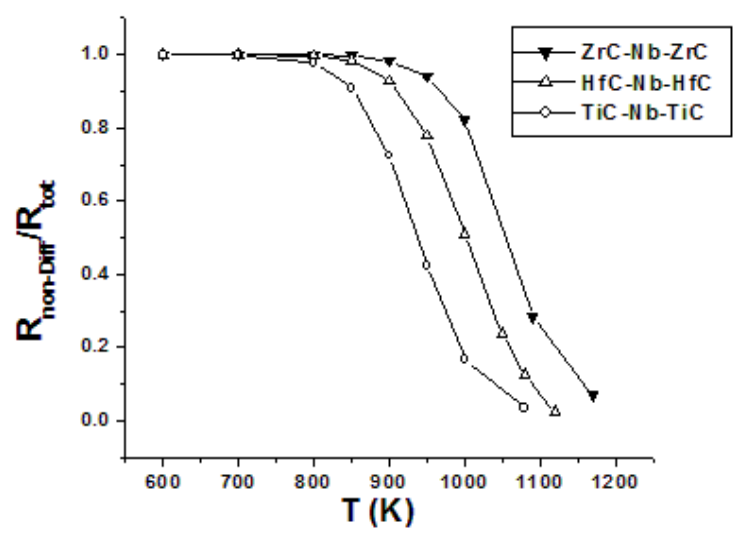

(b)

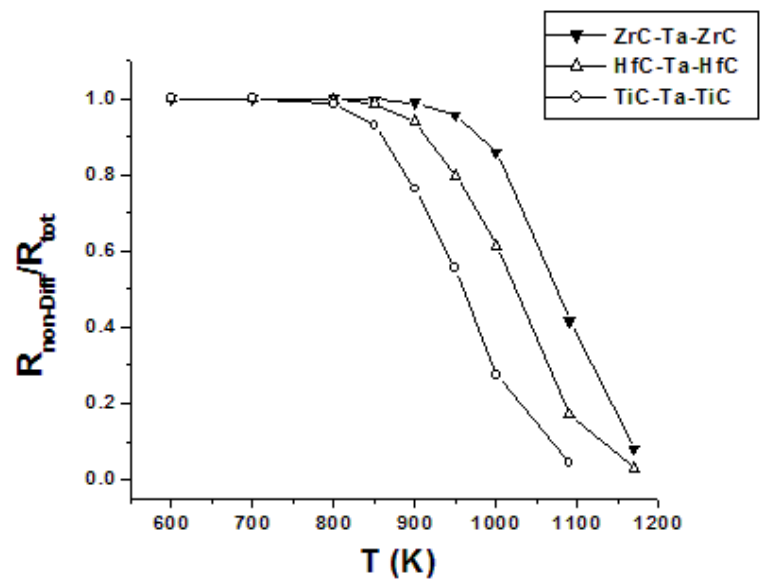

Figure 27: Diffusion resistance ratio as a function of temperature for TiC, HfC and $\mathrm{ZrC}$ coat on (a) V, (b) Ta and (c) Nb membranes on both sides. The feed and permeate pressures are 1 and $10^{-5}$ atm, and the membrane thickness is $75 \mu \mathrm{m}$.

TMC1/membrane/TMC2 composite material: For these systems we explored the possibility of using different coatings on the feed and permeate side of the membrane. For the results of $\mathrm{V}$ membrane shown in Figure 28, several feed side coatings were considered $(\mathrm{TMC} 1=\mathrm{TiC}$, HfC and $\mathrm{ZrC}$ ) while $\mathrm{TMC} 2=\mathrm{TiC}$ on the permeate side. The fluxes and related resistance ratios other than bulk membrane diffusion are shown in Figs. 28 (a) and (b), respectively. The predicted values show that the three systems have almost the same fluxes and resistance ratios, which implies that the coating material on the permeate side controls the flux at low temperature; with temperature increasing, the $\mathrm{H}$ diffusion through the membrane $\mathrm{V}$ controls the flux. 
(a)

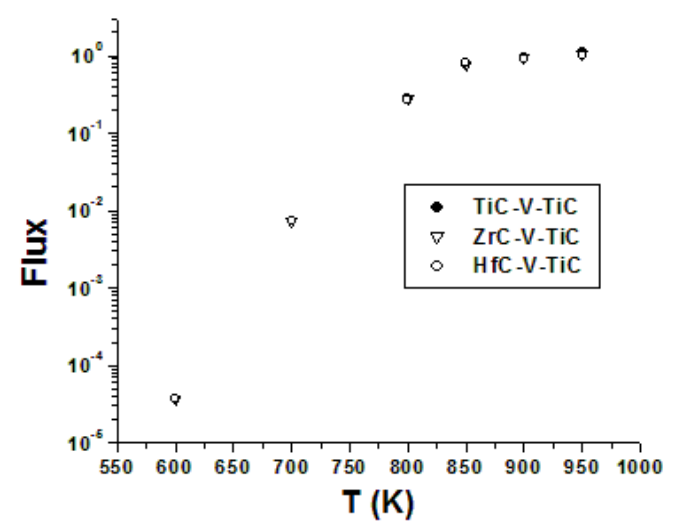

(b)

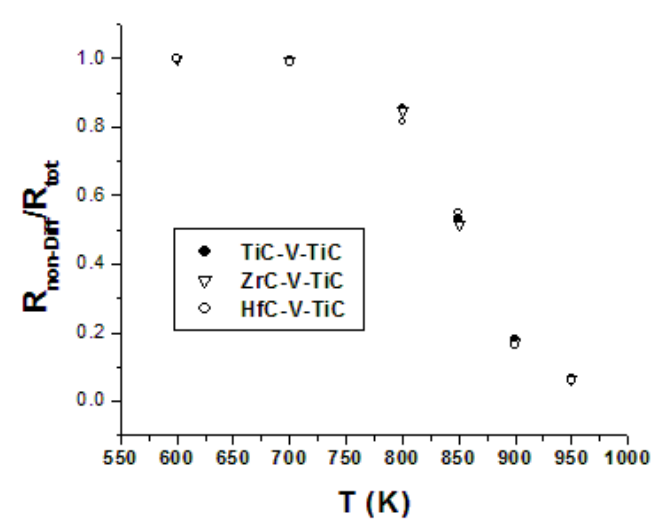

Figure 28: (a) Hydrogen flux as a function of temperature for $\mathrm{TiC} / \mathrm{V} / \mathrm{TiC}$, $\mathrm{HfC} / \mathrm{V} / \mathrm{TiC}$ and $\mathrm{ZrC} / \mathrm{V} / \mathrm{TiC}$ composites; (b) Diffusion resistance ratio as a function of temperature for $\mathrm{TiC} / \mathrm{V} / \mathrm{TiC}, \mathrm{HfC} / \mathrm{V} / \mathrm{TiC}$ and $\mathrm{ZrC} / \mathrm{V} / \mathrm{TiC}$. The feed and permeate pressures are 1 and $10^{-5}$ atm, and the membrane thickness is $75 \mu \mathrm{m}$.

Using first-principles based modeling, we have been able to identify the most promising membrane materials $\left(\mathrm{Zr}_{54} \mathrm{Cu}_{46}\right.$ and $\left.\mathrm{Zr}_{50} \mathrm{Cu}_{40} \mathrm{Ti}_{10}\right)$ and non-PGM surface catalytic (TiC) layers to theoretically approach the hydrogen gas separation performance of Pd in coalderived syngas applications. The next step is to experimentally produce these materials and characterize their physical properties.

\subsection{Membrane Deposition, Composition and Microstructure Optimization}

The first activity in experimentally producing these amorphous alloys was to perform a reference search in the following areas:

- Technical approaches for fabrication of supported amorphous alloy membranes

- PVD processing of metal membranes

- Composition of amorphous metal membranes

- Support materials for deposition of metal membranes

The information exchange contacts were established with research group of Lithuanian Energy Institute (Prof. Liudvikas Pranevičius, Vitautus Magnus University, Kaunus, Lithuania and Dr. Darius Milcius, Head of Center for Hydrogen Energy Technologies, Kaunus, Lithuania). This group has outstanding experience in magnetron and cathodic arc deposition of amorphous alloys.

The magnetron sputtering technology was identified for fabrication of supported amorphous alloy membranes. A porous stainless steel was identified as the support substrate.

The AJA chamber with two DC magnetrons having 4" diameter targets was chosen for developing the magnetron sputtering deposition process of amorphous alloy in argon as a 
processing gas. The following parameters are selected as variables for the process optimization:

- Distance between magnetrons and substrate holder table

- Substrate table vertical position

- Magnetron power

- Deposition time

- Argon pressure

RF bias of the substrates was used only during the ion cleaning stage. The RF bias setup was modified to improve RF transmission power and to make the in situ measurements of substrate table auto polarization voltage. Substrate pre-heating was applied only during substrate conditioning stage prior to coating deposition stage.

The substrates 1" x 1" glass coupons were chosen for coating development. The substrate setup includes six glass coupons which were disposed evenly around the axis of the substrate table. Two of these coupons were masked for measurement of the coating thickness using precise profilometry (VEECO Dektak 150).

The necessary composition of $\mathrm{Ni}_{\mathrm{x}} \mathrm{Zr}_{1-\mathrm{x}}$ alloy was achieved by co-deposition of $\mathrm{Ni}$ and $\mathrm{Zr}$ from two magnetron sputtering sources. The alloy composition is estimated by the following expression:

$$
\mathrm{m}(\mathrm{Zr}) / \mathrm{m}(\mathrm{Ni})=\dot{\mathrm{c}}(\mathrm{Zr}) / \dot{\mathrm{c}}(\mathrm{Ni})
$$

where $\mathrm{m}$ is mass fraction of the metal, $\dot{\mathrm{c}}$ is deposition rate of the metal. This expression and approach was proven during preliminary trials. The deposition rate was determined by one of two alternative ways: by measuring the coating thickness and by measuring the weight gain of the coated coupons.

Table 1. Characteristic parameters of magnetron sputtering process.

\begin{tabular}{|c|c|l|c|}
\hline Item \# & Process Stage & \multicolumn{1}{|c|}{ Process Parameters } & $\begin{array}{c}\text { Time of } \\
\text { Process Stage, } \\
\text { min }\end{array}$ \\
\hline 1 & Pre-heating & $\begin{array}{l}\mathrm{P}(\mathrm{Ar}) \sim 50 \mathrm{mtorr} \\
\mathrm{T}=300^{\circ} \mathrm{C} \text { (heaters ON) } \\
\mathrm{RF} \text { assistance OFF }\end{array}$ & $30 \mathrm{~min}$ \\
\hline 2 & Ion cleaning & $\begin{array}{l}\mathrm{P}(\mathrm{Ar}) \sim 50 \mathrm{mtorr} \\
\text { Heaters OFF } \\
\mathrm{RF} \text { assistance ON }\end{array}$ & $30 \mathrm{~min}$ \\
\hline 3 & Deposition & $\begin{array}{l}\mathrm{P}(\mathrm{Ar}) \text { 3mtorr } \\
\text { Heaters OFF } \\
\text { RF assistance OFF } \\
\text { Magnetron power: } 100-400 \mathrm{~W}\end{array}$ & $1-3 \mathrm{hrs}$ \\
\hline
\end{tabular}


At this stage of the project the objective was to deposit amorphous alloy thin film coatings having composition close to $\mathrm{Ni}_{74} \mathrm{Zr}$, which is a state-of-the-art composition of amorphous NiZr alloy. This coating was used during the next stage of the project as baseline material and for calibration purposes. Ni and Zr disk targets for the magnetrons were purchased for co-deposition of NiZr amorphous alloy.

For preliminary trials, both magnetrons were equipped with nickel targets to measure the deposition rate of nickel coatings vs. process parameters and equipment setup. The following parameters were kept constant during preliminary trials: rotation speed 18 RPM, distance between magnetrons and substrate table. The process formulation used for preliminary trials are shown in Table 1 . Results on nickel deposition rate are shown in Table 2.

Table 2: Preliminary results on nickel deposition rate.

\begin{tabular}{|c|c|c|c|c|c|c|c|}
\hline Item \# & Process \# & Sample\# & $\begin{array}{c}\text { Power of } \\
\text { Magnetron \#1 } \\
\text { (right side), W }\end{array}$ & $\begin{array}{c}\text { Power of } \\
\text { Magnetron \#2 } \\
\text { (left side), W }\end{array}$ & $\begin{array}{c}\text { Deposition } \\
\text { time, hr. }\end{array}$ & $\begin{array}{c}\text { Thickness } \\
\text { deposition } \\
\text { rate, } \mathbf{\mu m} / \mathbf{h r} .\end{array}$ & $\begin{array}{c}\text { Weight } \\
\text { gain change } \\
\text { deposition } \\
\text { rate, } \mathbf{~ m g / h r} .\end{array}$ \\
\hline 1 & 1 & 1 & 300 & 0 & 2 & 1.49 & 17.57 \\
\hline 2 & 1 & 1 & 200 & 0 & 2 & 0.86 & \\
\hline 3 & 1 & 2 & 200 & 0 & 2 & 0.84 & \\
\hline 4 & 2 & 1 & 400 & 0 & 1 & 2.89 & 50.88 \\
\hline 5 & 1 & 1 & & 400 & 1 & 3.52 & 20.5 \\
\hline 6 & 1 & 1 & 100 & 100 & 1 & 1.64 & \\
\hline 7 & 1 & 2 & 100 & 100 & 1 & 1.74 & \\
\hline 8 & 1 & 1 & 200 & 200 & 1 & 2.50 & \\
\hline 9 & 1 & 2 & 200 & 200 & 1 & 3.06 & \\
\hline 10 & 1 & 1 & 300 & 300 & 1 & 4.69 & \\
\hline 11 & 1 & 2 & 300 & 300 & 1 & 4.68 & \\
\hline
\end{tabular}

The typical step profile on Ni coated glass coupon prepared by masked deposition per item 5, Table 2 is shown in Figure 29. It can be seen that masked deposition allows precise measurement of the coating thickness. This method was used in future work for this project. The deposition rates measured by step profile method show almost linear dependence on magnetron power as illustrated in Figures 20 and 31 both for coatings produced by right magnetron sputtering and by co-deposition using two magnetrons with the same applied power. From the results presented in Table 2 follows that the deposition rates of right and left magnetron sources are almost equal. It can be also seen that codeposition from two magnetron almost double the deposition rate obtained by using only one magnetron source. 


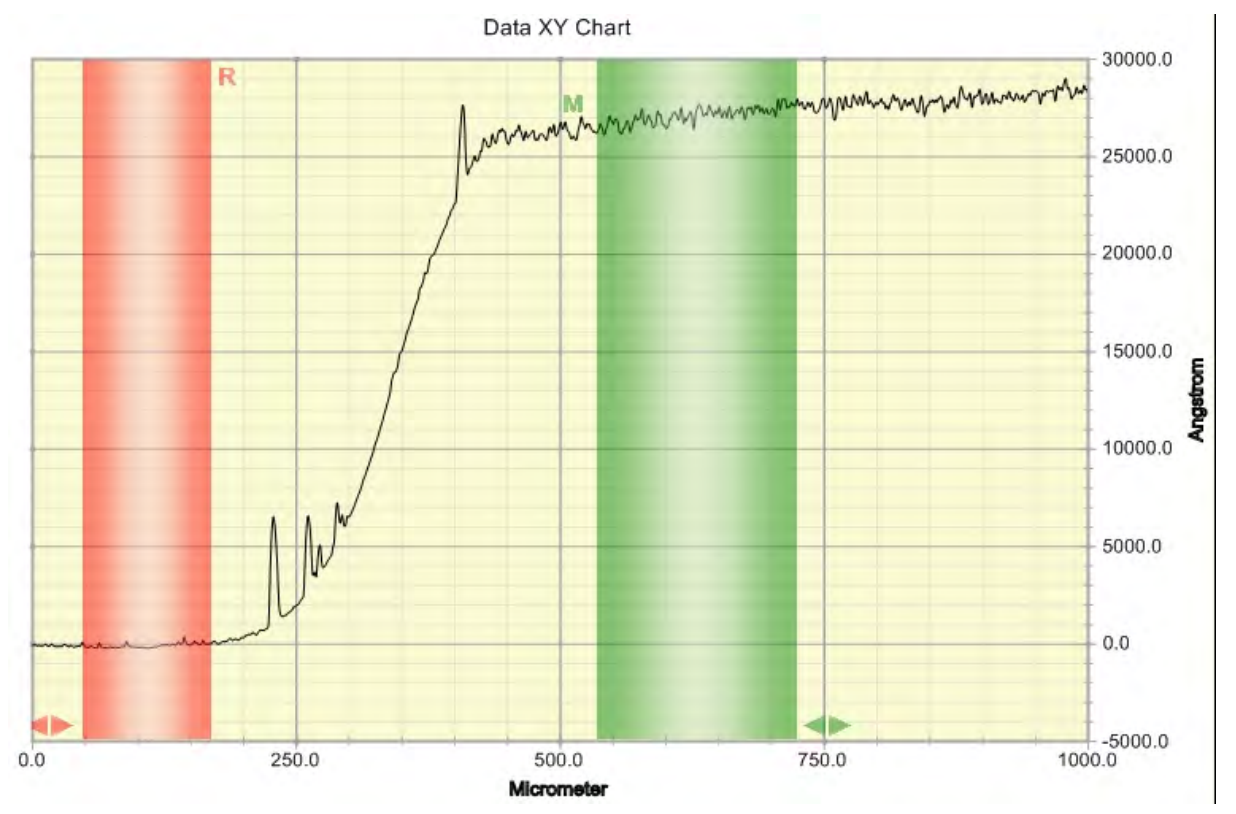

Figure 29: Step profile on masked Ni coating on glass coupon.

On the other hand, the weight gain calibration did not provide a good correlation with thickness measurement. Assuming full coverage of nickel coating over 1" x 1" glass coupon the weight of $1 \mu \mathrm{m} \mathrm{Ni}$ film can be calculated as $5.7 \mathrm{mg}$ (nickel density = $8.91 \mathrm{~g} / \mathrm{cm}^{3}$ ). This is not in agreement with the weight gain measurements shown in Table 2. Therefore the thickness measurement was selected for assessment of coating deposition rate during the latter stages of the project.

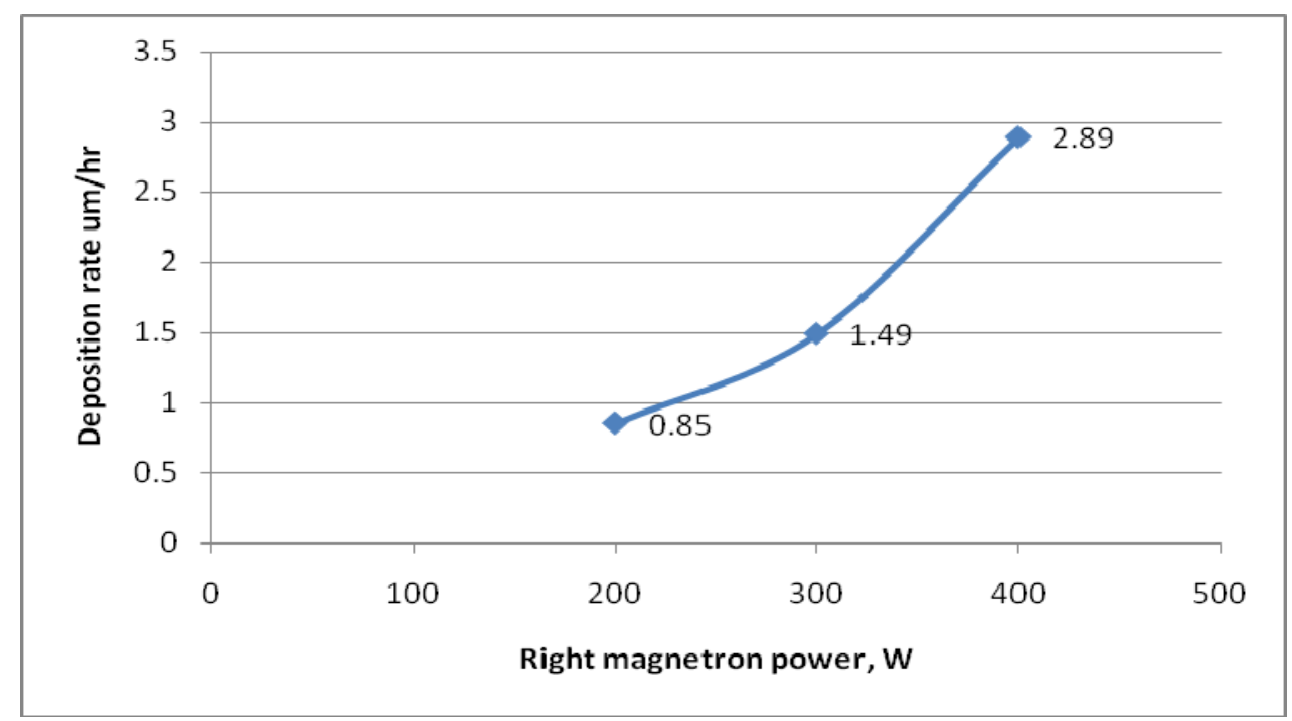

Figure 30: Deposition rate by right magnetron vs. magnetron power. 


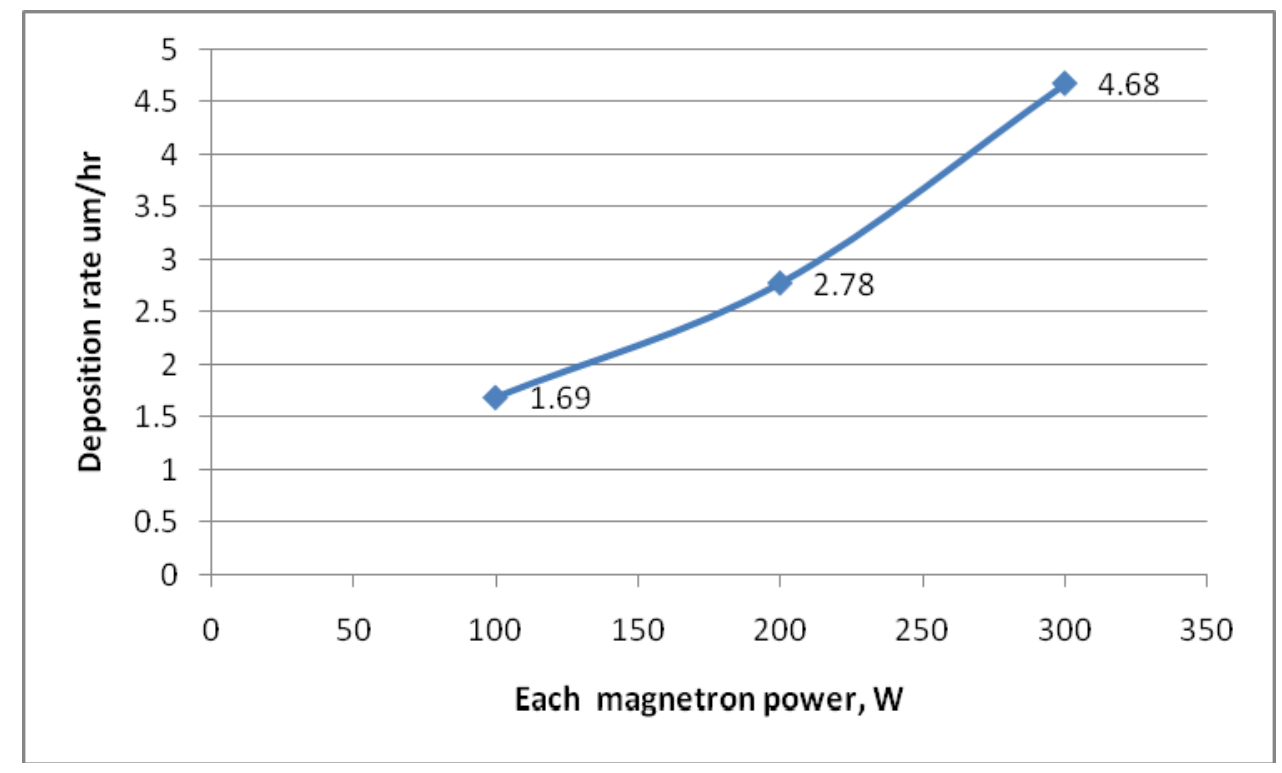

Figure 31: Deposition rate by co-deposition using two magnetron sources vs. magnetron power.

Precise deposition of metal coatings by one magnetron source and by co-deposition using two magnetron sources was demonstrated for deposition of Ni coating. This process also demonstrated good consistency and repeatability and was used during further stages of the project for fabrication of multi-elemental amorphous alloys with precise elemental composition.

The coating system setup used in this work is shown in Figure 32. Two DC magnetrons using 4" diameter targets were installed at the bottom of the vacuum processing chamber for a co-sputtering deposition process of the amorphous alloy with argon as the processing gas.

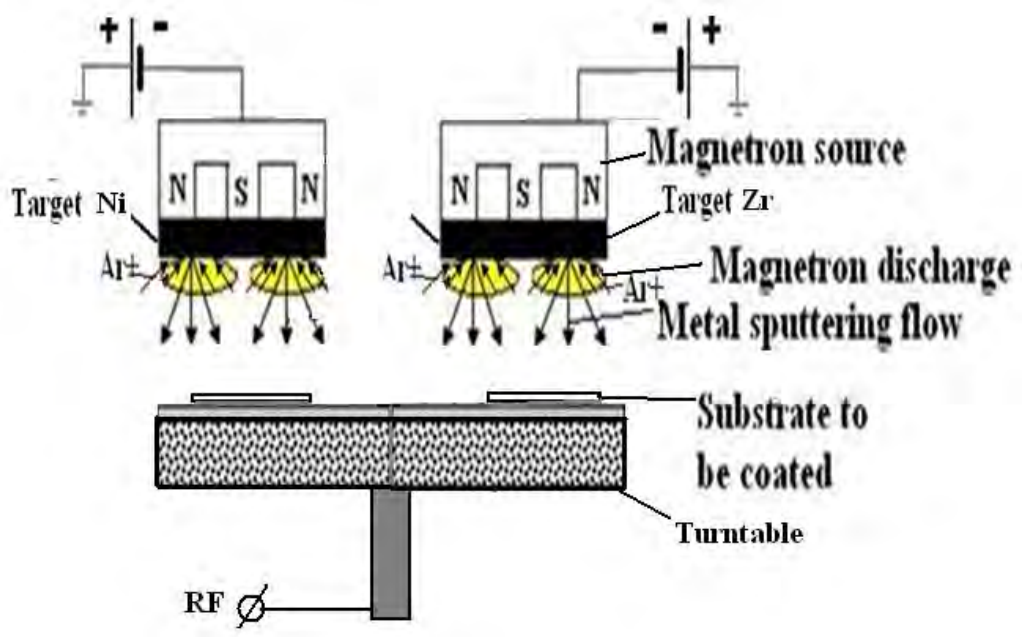

Figure 32: Magnetron co-sputtering scheme. 
The magnetrons were equipped with $\mathrm{Ni}$ and $\mathrm{Zr}$ targets for deposition of a $\mathrm{Ni}_{\mathrm{x}} \mathrm{Zr}_{1-\mathrm{x}}$ alloy coating of various compositions. The substrate-holding turntable was installed above the magnetrons at the distance of $15 \mathrm{~cm}$ from the magnetron targets and rotated at 12 RPM. Prior to the coating deposition process, substrates were pre-heated to $300^{\circ} \mathrm{C}$ by a radiant heater. At the end of the heating stage, the RF bias $(50 \mathrm{~W}, 120$ volts auto polarization potential) was applied to the substrate turntable. The RF bias of the substrates was used only during the ion cleaning stage. Substrate pre-heating was applied only during the substrate conditioning stage prior to the coating deposition stage. The argon pressure during pre-heating and RF-ion cleaning stages was 10 mtorr. When the coating deposition stage started, both substrate bias and substrate heater were turned off. Coatings were applied to stainless steel disc samples 1 " diameter, $1 / 8$ " thick and/or 1 " $\times 1$ " lime glass coupons. The substrate setup included six coupons which were placed evenly around the axis of the substrate table. Two of these coupons were masked for measurement of coating thickness. The argon pressure during coating deposition stage was 3 mTorr. The deposition duration was either 1 or 2 hrs resulting in a coating thickness ranging from $\sim 3$ to $8 \mu \mathrm{m}$. The morphology of the deposited coatings was studied by SEM and optical micro-imaging. Coating composition was studied by EDS and RBS techniques. Ion beam analysis of the coated samples was performed using a $2 \mathrm{MV}$ van de Graaff accelerator at Montana State University. It utilized $\mathrm{He}^{+}$and $\mathrm{H}^{+}$ beams up to $2 \mathrm{MeV}$. Composition profiles were determined by comparing SIMNRA computer simulations of the spectra with the original data. Crystallinity of the samples was examined by glancing angle x-ray diffractometer. A Hysitron NanoIndentor was utilized for attaining the measurements of the hardness and elastic modulus of the deposited metal films. Giving the thickness of the films, the Hysitron's load settings were adjusted in order to give an indentation of approximately 300 nanometers. The initial calibrations for the machine were performed at the desired depth and were carried out on a fused mica sample. The bulk electrical resistivity of the coatings was measured by the voltage drop between two contact electrodes made of copper foil attached to opposite ends of the deposited film when the constant current of $100 \mathrm{~mA}$ was applied. Sample annealing was conducted on stainless trays in a stainless steel tube furnace in an argon/2\% hydrogen atmosphere.

The linear extrapolations of the deposition rates of the magnetrons equipped with $\mathrm{Zr}$ and Ni targets vs. respective magnetron powers are shown in Figure 33. In addition, the figure shows the estimated combined $\mathrm{Ni}+\mathrm{Zr}$ deposition rate, calculated with assumption that $\dot{\mathrm{c}}\left(\mathrm{Ni}_{\mathrm{x}} \mathrm{Zr}_{1-\mathrm{x}}\right)=\dot{\mathrm{c}}(\mathrm{Ni})+\dot{\mathrm{c}}(\mathrm{Zr})$. 


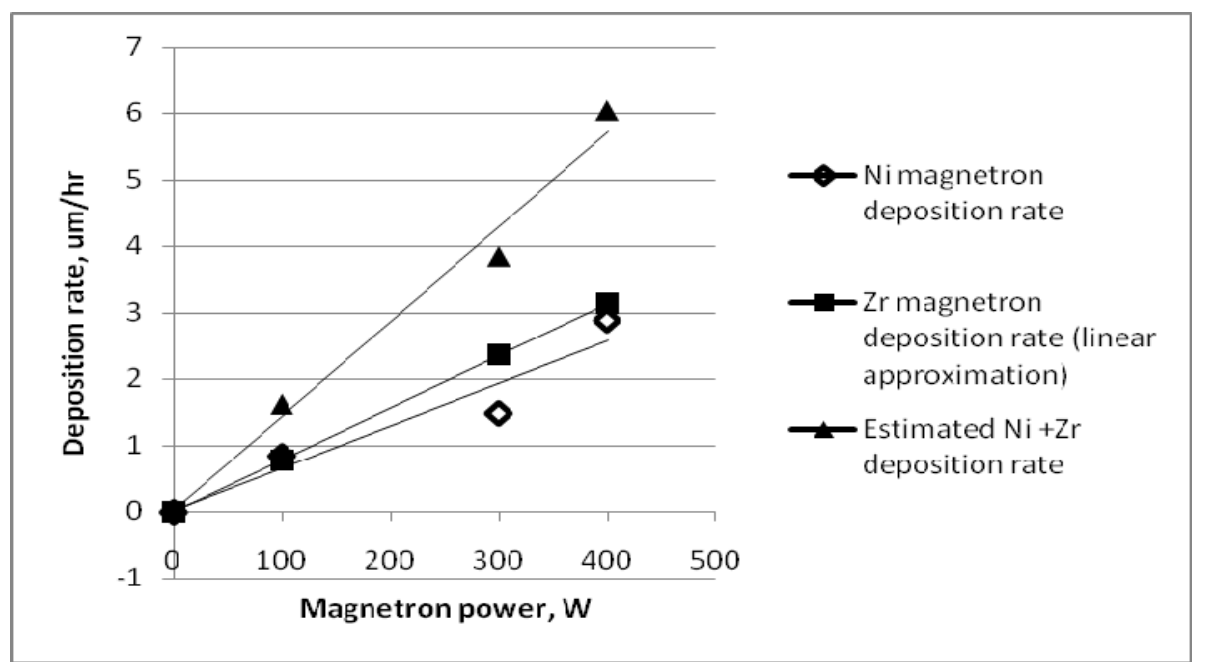

Figure 33: Deposition rates of $\mathrm{Ni}$ and $\mathrm{Zr}$ vs. magnetron power.

Table 3: Fractional Elemental Concentrations and Deposition Rates of $\mathrm{Ni}_{\mathrm{x}} \mathrm{Zr}_{1-\mathrm{x}}$ Films.

\begin{tabular}{|c|c|c|c|c|c|c|}
\hline Sample \# & Substrate & $\begin{array}{c}\mathrm{Zr} \\
\text { magnetron } \\
\text { power, } \mathrm{W}\end{array}$ & $\begin{array}{c}\mathrm{Ni} \\
\text { magnetron } \\
\text { power, W }\end{array}$ & $\begin{array}{l}\text { Deposition } \\
\text { rate, } \mu \mathrm{m} / \mathrm{hr}\end{array}$ & $\begin{array}{l}x(\text { EDS ) } \\
\text { NixZr1-x }\end{array}$ & $\begin{array}{r}\text { x (RBS) } \\
\text { NxZr1-x }\end{array}$ \\
\hline 1 & glass & 100 & 350 & 3.3 & 0.9 & 0.91 \\
\hline 2 & glass & 100 & 400 & 3.4 & 0.92 & 0.92 \\
\hline 3 & glass & 100 & 450 & 3.85 & 0.93 & 0.93 \\
\hline 4 & glass & 100 & 200 & 2.1 & 0.84 & 0.85 \\
\hline 5 & glass & 100 & 275 & 2.7 & 0.88 & 0.89 \\
\hline 6 & SS & 100 & 275 & 2.7 & 0.87 & \\
\hline 7 & SS & 150 & 275 & 2.8 & 0.81 & \\
\hline 8 & SS & 150 & 275 & 2.8 & 0.82 & \\
\hline 9 & glass & 150 & 275 & 3.0 & 0.82 & \\
\hline 10 & glass & 200 & 275 & 3.1 & 0.76 & \\
\hline 11 & glass & 250 & 275 & 3.4 & 0.71 & \\
\hline 12 & $\begin{array}{c}\text { Melt-spun } \\
\text { ribbon }\end{array}$ & N/A & N/A & N/A & 0.64 & \\
\hline 13 & $\begin{array}{c}\text { Melt-spun } \\
\text { ribbon }\end{array}$ & N/A & N/A & N/A & 0.3 & \\
\hline
\end{tabular}


$\mathrm{Ni}_{\mathrm{x}} \mathrm{Zr}_{1-\mathrm{x}}$ coatings of various compositions were deposited by co-sputtering from two magnetrons by changing the deposition rates of $\mathrm{Zr}$ and $\mathrm{Ni}$ by varying the respective magnetron powers. The compositions of the coatings deposited during different process runs using various combinations of applied magnetron powers are shown in Table 3.

Fractional concentrations of $\mathrm{Zr}$ and $\mathrm{Ni}$ in the selected coatings measured by EDS and RBS techniques have shown nearly identical results, so the less expensive EDS technique was used for the rest of the coatings studied in this work. Deposition rates and $\mathrm{Ni}$ concentrations in $\mathrm{Ni}_{\mathrm{x}} \mathrm{Zr}_{1-\mathrm{x}}$ coating vs. Ni magnetron power at $100 \mathrm{~W} \mathrm{Zr}$ magnetron power are shown in Figure 34.

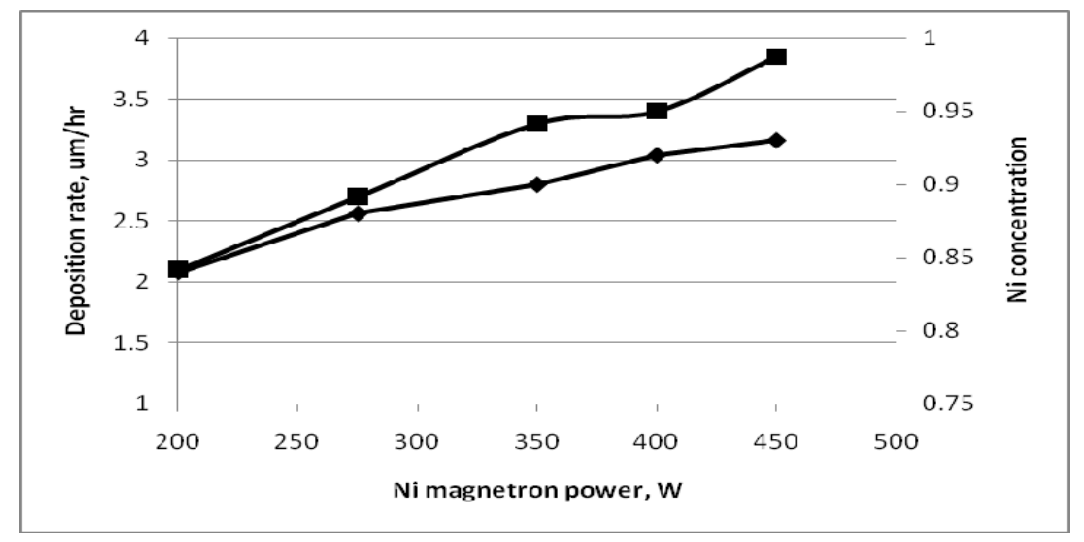

Figure 34: Deposition rate and $\mathrm{Ni}$ concentration in of $\mathrm{Ni}_{\mathrm{x}} \mathrm{Zr}_{1-\mathrm{x}}$ coating vs. Ni magnetron power at $\mathrm{Zr}$ magnetron power fixed at $100 \mathrm{~W}$.

The figure shows a nearly linear relationship between coating compositions and deposition rates vs. applied magnetron power. Comparing the deposition rate of $\mathrm{Ni}_{\mathrm{x}} \mathrm{Zr}_{1-\mathrm{x}}$ deposited at both magnetron powers near 250W (Sample \# 11, Table 3) with calculated deposition rate presented in Figure 34, shows additive behavior of co-sputtered coatings with no considerable influence of molar volume change associated with formation of $\mathrm{Ni}_{\mathrm{x}} \mathrm{Zr}_{1-\mathrm{x}}$ solid solution. This can be explained by the fact that in the co-sputtering process performed in this work, with magnetrons positioned at a substantial distance from each other, the coating is forming rather as a nanolaminated multilayer architecture than a solid solution of metal components deposited by different magnetrons. In this case, the deposition rate of co-sputtered $\mathrm{Ni}_{\mathrm{x}} \mathrm{Zr}_{1-\mathrm{x}}$ films can be estimated as a sum of the deposition rates of $\mathrm{Ni}$ and $\mathrm{Zr}$ films deposited by respective magnetron powers.

As illustrated in Figure 35, NiZr coatings deposited by co-sputtering have demonstrated a dense morphology with no pin-holes or porosity. Hardness and elastic modulus of the sputtered deposited NixZr1-x coatings have a strong correlation with their composition as shown in Figure 36. The minimal hardness and elastic modulus appears near a $\mathrm{Zr}$ content of 16 at \%. The toughness of these coatings also reaches a minimum value near 15 at $\%$ of $\mathrm{Zr}$ followed by increase with increase of the $\mathrm{Zr}$ content, reaching the maximum value in the coatings having near optimal $\mathrm{Zr}$ content of about 30 at \% associated with a fully amorphous NiZr alloy. 


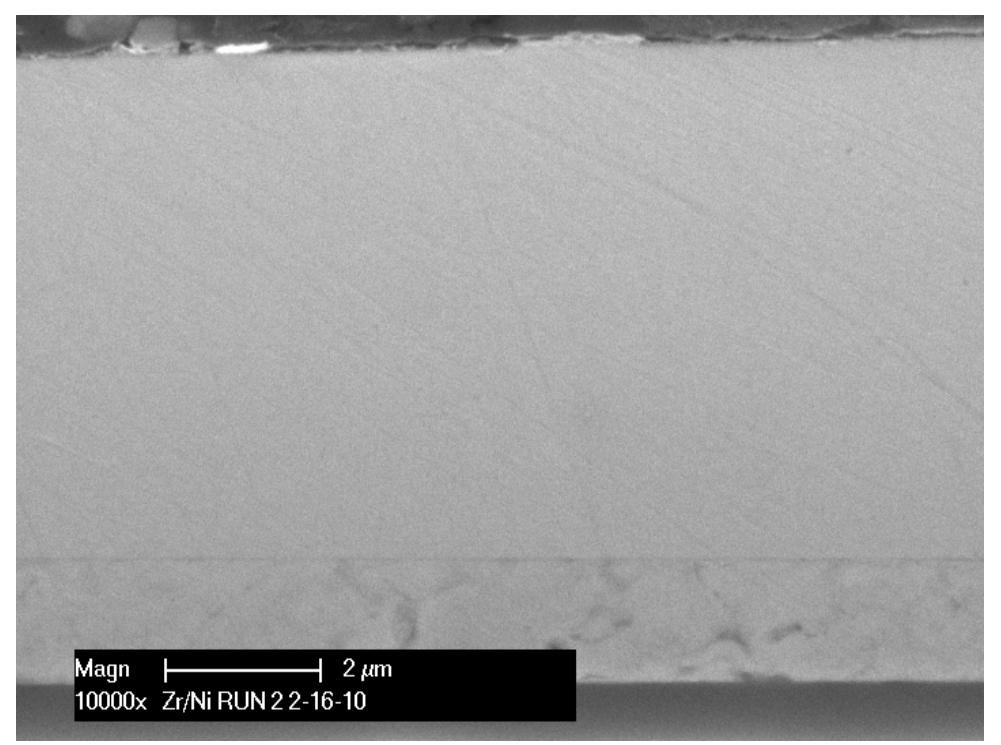

Figure 35: SEM micrograph of the cross-section of $\mathrm{Ni}_{0.93} \mathrm{Zr}_{0.07}$ coating.
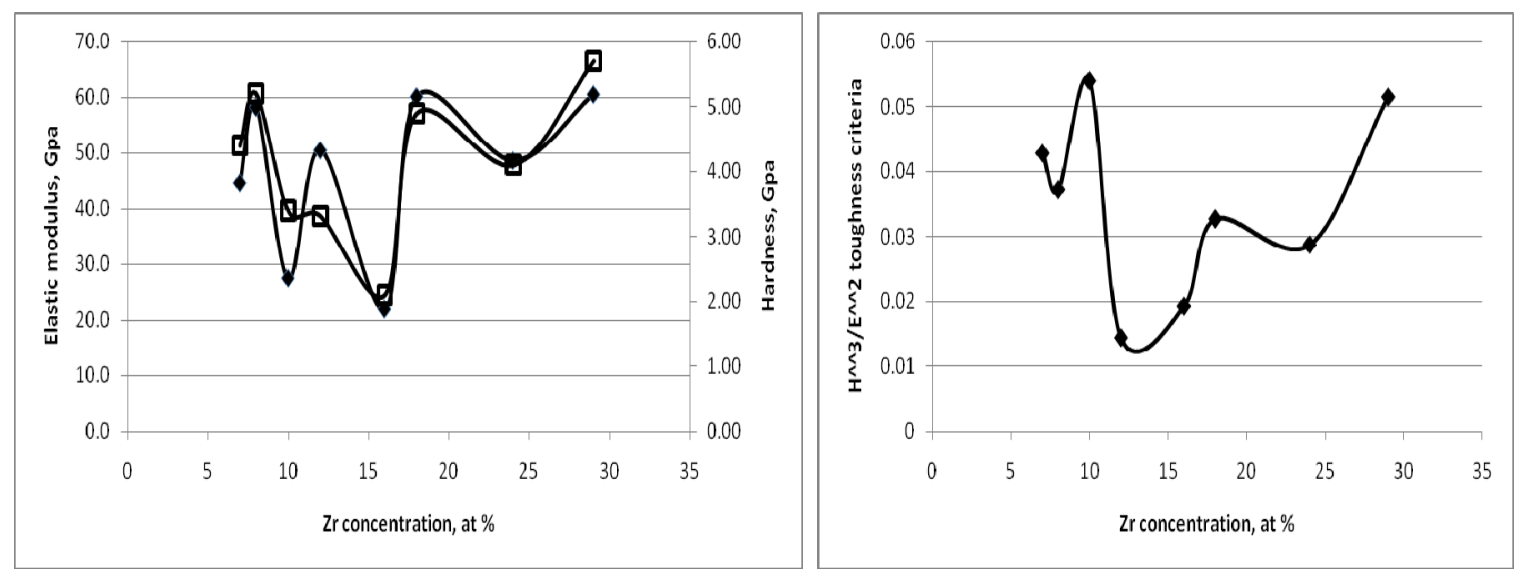

Figure 36: Mechanical properties of as deposited $\mathrm{Ni}_{\mathrm{x}} \mathrm{Zr}_{1-\mathrm{x}}$ coatings vs. coating composition: hardness and elastic modulus (left); H3/E2 toughness parameter (right).

XRD analysis of the crystallinity of NiZr coatings and ribbons has demonstrated a strong correlation between their structure and thermal stability vs. their composition. The first three samples presented in Table 3 (samples \#1-3) have relatively small Zr content, less than 10 at \%. The intense, broad peak near $44^{\circ} 2-\theta$ appears for all these three samples. The full width at half maximum intensity (FWHM) for an XRD spectra taken from these samples indicates the broadening of the $44^{\circ} 2-\theta$ peak with an increase of $\mathrm{Zr}$ in the coatings. In addition, a second, low-intensity peak at approximately $2.5^{\circ} 2-\theta$ appears in two samples (samples 2 and $3 \mathrm{~m}$ Table 3) with the smallest $\mathrm{Zr}$ content indicating the possibility of formation of other polycrystalline phases in these samples. The FWHM continues broadening with an increase of the Zr content in samples \#4-11 from Table 3 reaching the maximum value in samples \#10 and \#11 with Zr content near 30 at \% as can 
be seen in Figure 37. The XRD patterns of these samples closely resemble the XRD pattern obtained from $\mathrm{Ni}_{0.64} \mathrm{Zr}_{0.36}$ ribbon prepared by rapid quench melt-spun technique. All as-deposited samples \#1, 4-11 having $\mathrm{Zr}$ content $>9$ at \% have demonstrated the broad XRD peak with a shape typical for amorphous metal alloys.

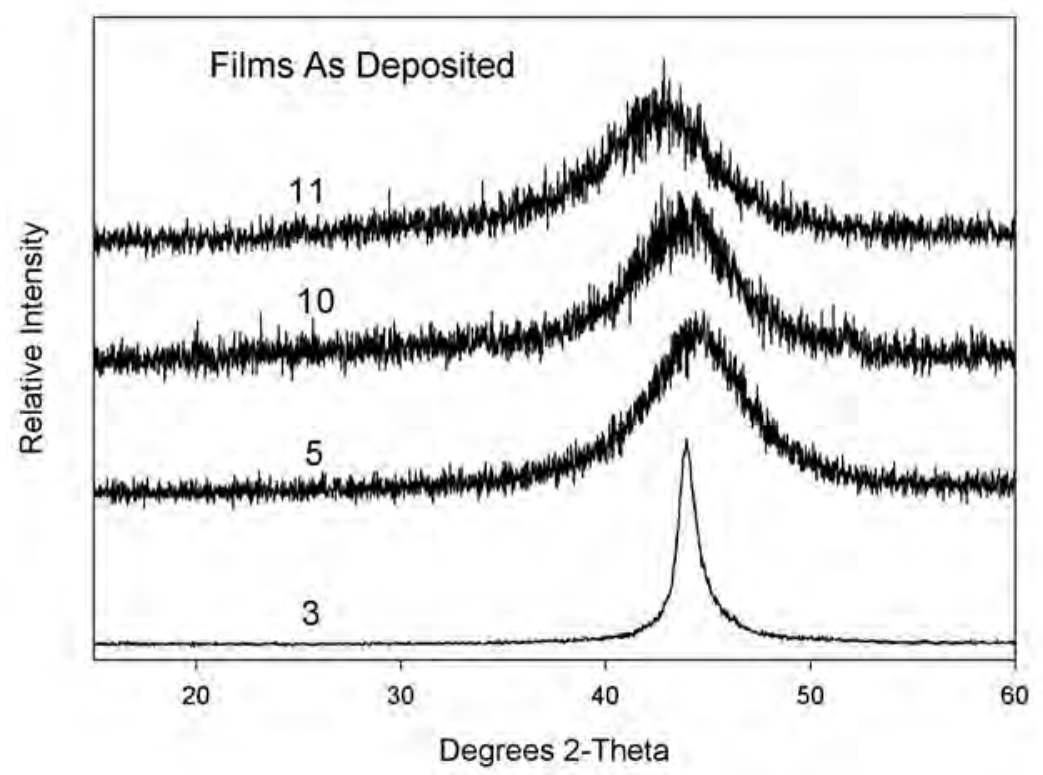

Figure 37: $\mathrm{XRD}$ patterns of as deposited $\mathrm{Ni}_{\mathrm{x}} \mathrm{Zr}_{1-\mathrm{x}}$ coatings.

Annealing of the samples and ribbons for 1 hour at $200^{\circ} \mathrm{C}$ results in no re-crystallization as illustrated in Figure 38. Broadening of the $44^{\circ} 2 \theta$ peak in sample coating \#1 can indicate further amorphization of this film by a solid amorphization reaction via fast interdiffusion between the $\mathrm{Ni}$ rich and $\mathrm{Zr}$ rich sub-layers, which may happen in this nanolaminated coating during annealing below the re-crystallization temperature via the amorphization mechanism. Coatings with higher concentrations of $\mathrm{Zr}$ have survived annealing for 1 hour at $250^{\circ} \mathrm{C}$ without re-crystallization as can be seen from Figure 39 . The re-crystallization started during $1 \mathrm{hr}$ of annealing at $300^{\circ} \mathrm{C}$ in coatings with lower $\mathrm{Zr}$ content (sample \#1), while coatings with $\mathrm{Zr}$ content $>12$ at \% do not re-crystallize, showing XRD patterns after annealing similar to the melt-spun ribbon with optimal $\mathrm{Zr}$ content associated with amorphous NiZr alloy as shown in Figure $40\left(\mathrm{Ni}_{0.64} \mathrm{Zr}_{0.36}\right.$ ribbon sample \# 12 in Table 3). On the other hand, the ribbon sample \#13 having $\mathrm{Ni}_{0.3} \mathrm{Zr}_{0.7}$ composition was fully transformed into the polycrystalline state after $1 \mathrm{hr}$ of annealing at $300^{\circ} \mathrm{C}$. The optimal composition of the NiZr amorphous alloys is a $\mathrm{Zr}$ concentration near 30 at $\%$. 


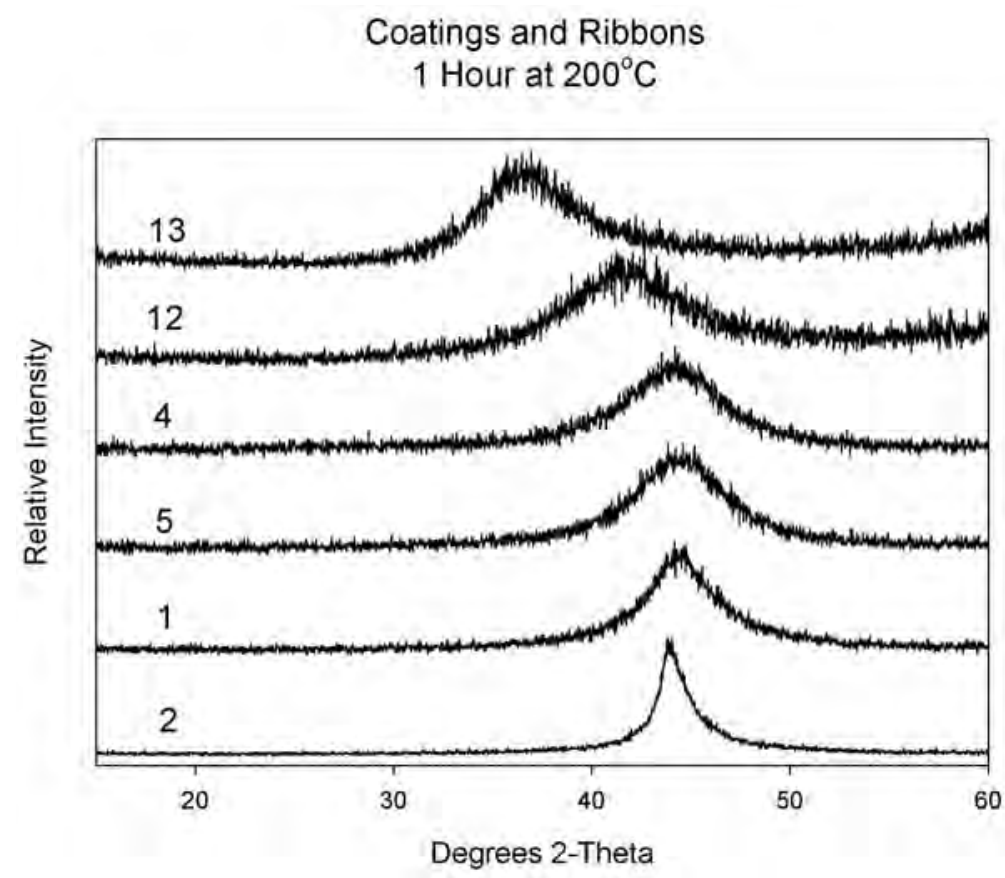

Figure 38: $\mathrm{XRD}$ patterns of $\mathrm{Ni}_{\mathrm{x}} \mathrm{Zr}_{1-\mathrm{x}}$ coatings subjected to 1 hour annealing at $200^{\circ} \mathrm{C}$.

Coatings

1 Hour at $250^{\circ} \mathrm{C}$

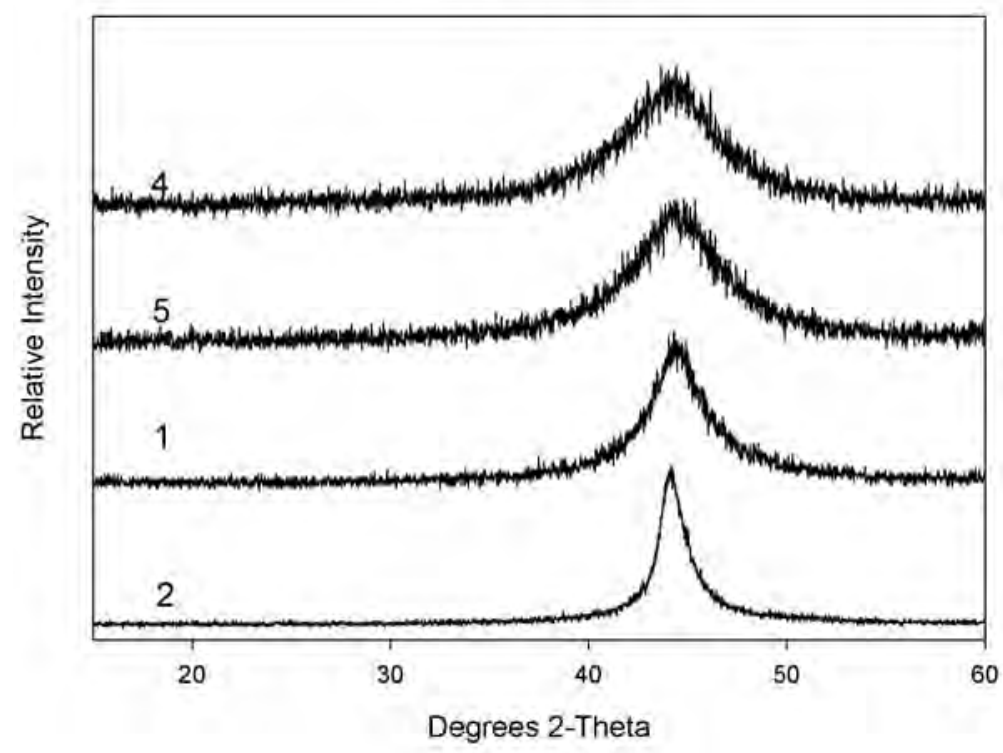

Figure 39: $\mathrm{XRD}$ patterns of $\mathrm{Ni}_{\mathrm{x}} \mathrm{Zr}_{1-\mathrm{x}}$ coatings subjected to 1 hour annealing at $250^{\circ} \mathrm{C}$. 


\section{Coatings and Ribbons}

1 Hour at $300^{\circ} \mathrm{C}$

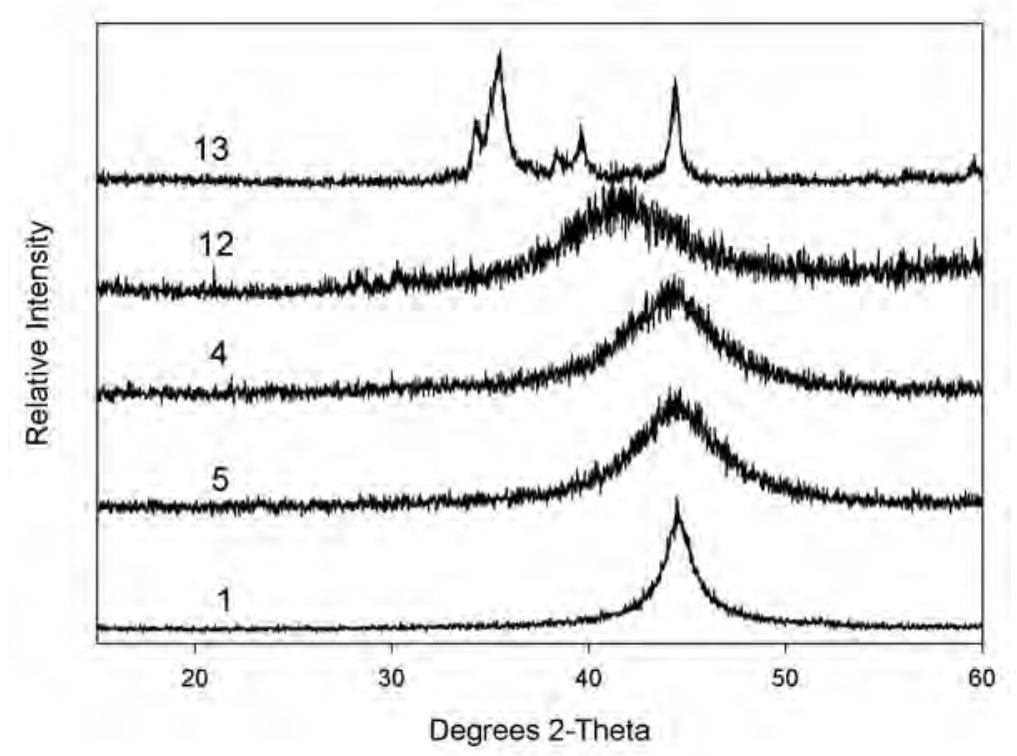

Figure 40: $\mathrm{XRD}$ patterns of $\mathrm{Ni}_{\mathrm{x}} \mathrm{Zr}_{1-\mathrm{x}}$ coatings and $\mathrm{BMG}$ ribbons subjected to 1 hour annealing at $300^{\circ} \mathrm{C}$.

Coatings and ribbons which demonstrated the best thermal stability when exposed to short-term annealing were further tested by annealing for $24 \mathrm{hrs}$ at $300^{\circ} \mathrm{C}$. The results of this test are shown in Figure 41. It can be seen that three sample coatings (samples 9, 10 and 11 from Table 3) and a melt-spun ribbon sample \#12 with near optimal Ni:Zr ratios show the mixture of polycrystalline phase with amorphous matrix after annealing for 24 hours at $300^{\circ} \mathrm{C}$. Among these samples the coating \#11 with the $\mathrm{Ni}_{0.71} \mathrm{Zr}_{0.29}$ composition and the ribbon \#12 with the $\mathrm{Ni}_{0.64} \mathrm{Zr}_{0.36}$ composition demonstrated almost identical XRD patterns after 24 hours of annealing at $300^{\circ} \mathrm{C}$. This result demonstrates that both a thin film coating deposited by co-sputtering and BMG ribbons prepared by the melt-spun technique have a similar thermal stability that is determined by their elemental composition and not by their fabrication technique. 


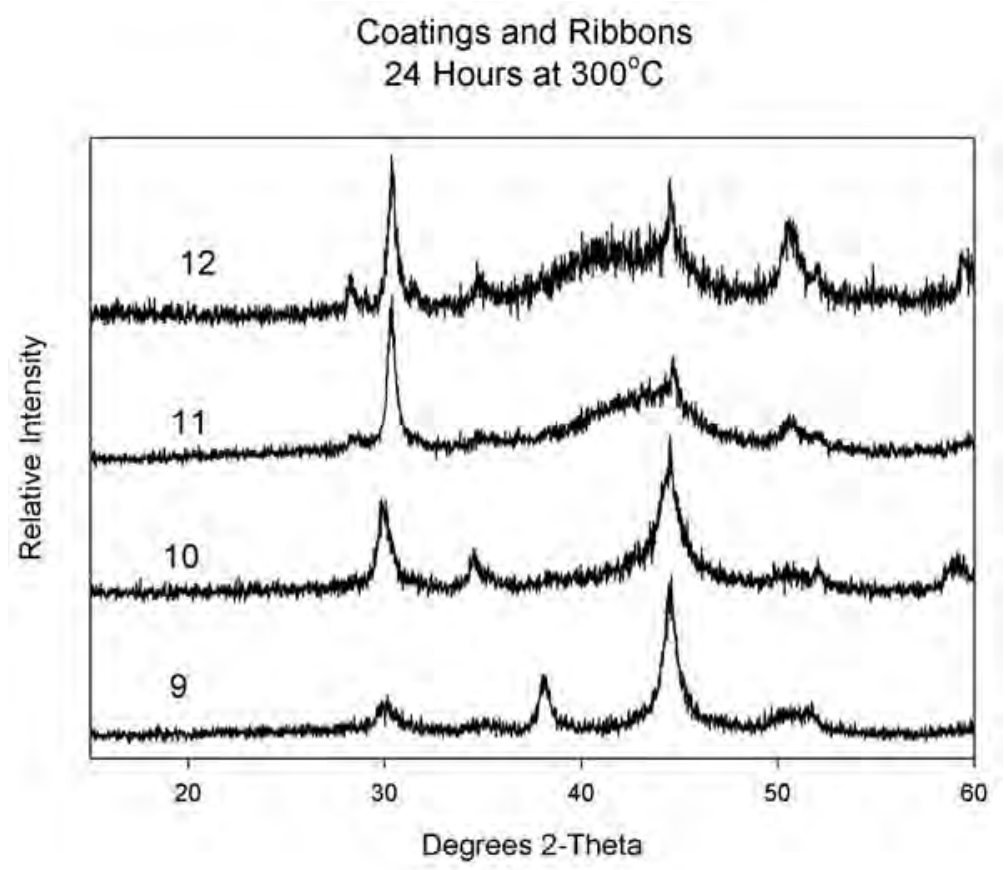

Figure 41: $\mathrm{XRD}$ patterns of $\mathrm{Ni}_{\mathrm{x}} \mathrm{Zr}_{1-\mathrm{x}}$ coatings and $\mathrm{BMG}$ ribbon subjected to 24 hours annealing at $300^{\circ} \mathrm{C}$.

The electrical resistivity in thin films is very sensitive to their structure. Electrical resistivities of polycrystalline $\mathrm{Ni}$ and $\mathrm{Zr}$ metals are $6.99 \times 10^{-6} \mathrm{Ohm} . \mathrm{cm}$ and $42.4 \times 10^{-6}$ Ohm.cm, respectively. Using this data, the electrical resistivity $\rho$ of the polycrystalline $\mathrm{Ni}_{\mathrm{x}} \mathrm{Zr}_{1-\mathrm{x}}$ films can be estimated based on a simplistic mechanical mixture model which can be expressed by the following equation:

$$
\rho\left(\mathrm{Ni}_{\mathrm{x}} \mathrm{Zr}_{1-\mathrm{x}}\right)=\mathrm{x} \rho_{\mathrm{Ni}}+(1-\mathrm{x}) \rho_{\mathrm{Zr}},
$$

Both electrical conductivities of as-deposited $\mathrm{Ni}_{\mathrm{x}} \mathrm{Zr}_{1-\mathrm{x}}$ films and the values of their electrical resistivities calculated from Eqn. 2 are presented in Figure 42. It can be seen that the electrical resistivity of as-deposited $\mathrm{Ni}_{\mathrm{x}} \mathrm{Zr}_{1-\mathrm{x}}$ films increased with $\mathrm{Zr}$ content and achieved up to two times greater than that of pure $\mathrm{Zr}$ at a $\mathrm{Zr}$ content of 29 at. \% when the coating was fully amorphous. In addition, the electrical resistivity of the as-deposited coatings is approximately 4 to 5 times greater than that calculated as a mixture of respective polycrystalline metals (Eqn. 2). The electrical resistivity of amorphous metal alloys is generally greater than that in a polycrystalline state due to the increase in electron scattering on grain boundaries of nano-sized grains within the amorphous metals. 


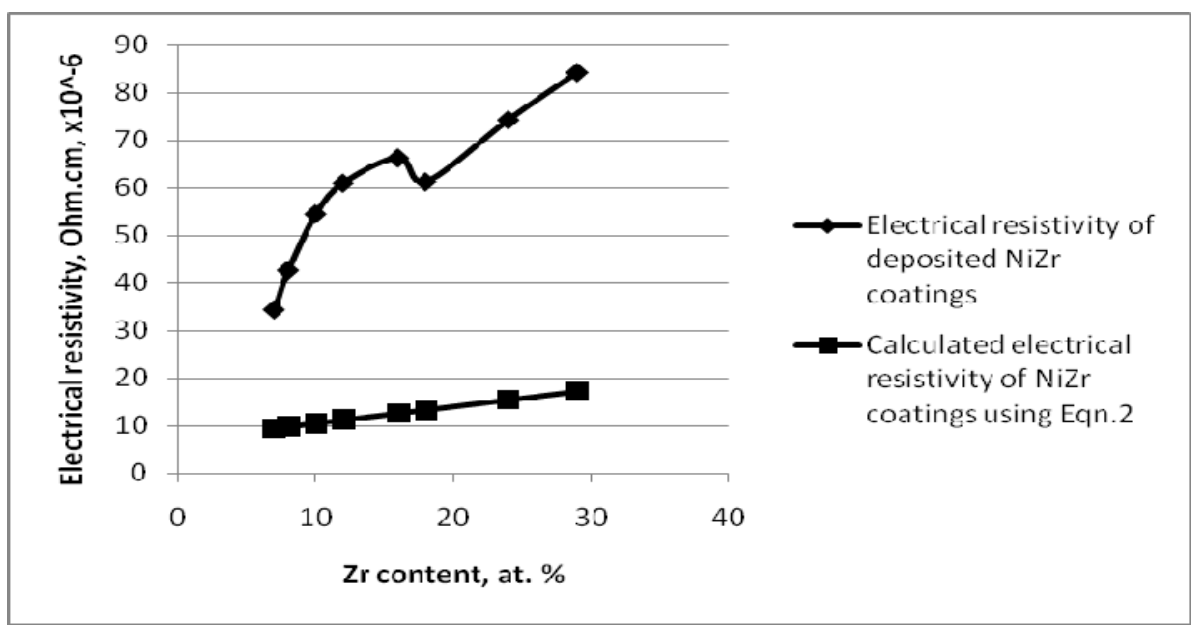

Figure 42: Electrical conductivity of as deposited $\mathrm{Ni}_{\mathrm{x}} \mathrm{Zr}_{1-\mathrm{x}}$ coatings.

The AJA chamber with three DC magnetrons, two of them using 4" diameter targets and one using 2" diameter target was used for development of the magnetron co-sputtering process for deposition of ternary NiZrNb amorphous alloy films with argon as a processing gas. The substrate holder was equipped with a heater and with modified RF bias setup featuring improved transmission power and capability of in situ measurements of substrate table auto polarization voltage. The substrate setup includes both $1 \times 1$ " square glass coupons and 1" diameter disk stainless steel (SS) coupons which were attached evenly around the axis of the rotating substrate holding turntable. At least one of the glass coupons was masked for the measurement of the coating thickness.

Initially, substrate pre-heating and RF bias were applied only during the substrate conditioning stage prior to the coating deposition stage. However, the preliminary trials revealed that ternary NiZrNb coatings having thickness greater than $1 \mu \mathrm{m}$ started developing cracks and delaminating. This behavior of the ternary NiZrNb coatings is typical for highly brittle metal glasses. The cracks in NiZrNb coatings were found both on glass and SS substrates, but on glass substrates the density of cracks was much greater than that on SS coupons resulting in nearly complete delamination of the coatings deposited on the glass substrates. Based on this observation SS coupons were chosen for the next deposition trials of ternary NiZrNb coatings.

Table 4: NiZrNb coating deposition composition vs. process parameters.

\begin{tabular}{|c|c|c|c|c|c|c|c|c|c|c|}
\hline Item \# & $\begin{array}{c}\text { Run } \\
\text { date }\end{array}$ & Run \# & $\mathbf{N i ~ W}$ & $\begin{array}{c}\mathbf{Z r} \\
\mathbf{W}\end{array}$ & $\begin{array}{c}\mathbf{N b} \\
\mathbf{W}\end{array}$ & $\begin{array}{c}\text { Dep. } \\
\mathbf{t i m e} \\
\mathbf{h r}\end{array}$ & $\begin{array}{c}\text { Dep. } \\
\mathbf{r a t e} \\
\mathbf{u m} / \mathbf{h r}\end{array}$ & $\begin{array}{c}\mathbf{N i} \\
\mathbf{a t \%}\end{array}$ & $\begin{array}{c}\mathbf{Z r} \\
\mathbf{a t \%}\end{array}$ & $\begin{array}{c}\mathbf{N b} \\
\mathbf{a t \%}\end{array}$ \\
\hline 1 & $7 / 8$ & 1 & 275 & 200 & 100 & 1 & 3.6 & 65.9 & 28.4 & 5.7 \\
\hline 2 & $7 / 8$ & 2 & 275 & 200 & 150 & 1 & 3.7 & 64.3 & 27.6 & 8.1 \\
\hline 3 & $7 / 7$ & 1 & 275 & 200 & 200 & 1 & 3.8 & 63.1 & 26.8 & 10.1 \\
\hline 4 & $7 / 6$ & 3 & 275 & 200 & 200 & 0.45 & 3.9 & 63.3 & 26.8 & 9.9 \\
\hline
\end{tabular}


During the next trial, substrate heating and RF bias were applied for optimization of coating mechanical stability. It was found that both substrate heating at $\sim 300^{\circ} \mathrm{C}$ and applying $\sim 50 \mathrm{~W}$ RF bias at $13.56 \mathrm{MHz}$ during coating deposition process is beneficial for coating stability and to obtain coatings on SS substrates without delamination. These process settings were used for all subsequent coatings of ternary NiZrNb.

EDS composition of ternary NiZrNb coatings deposited by magnetron co-sputtering vs. power of magnetrons equipped with different targets is shown in Table 4. In these coatings the Ni:Zr ratio was kept near the previously developed NiZr coatings with $\mathrm{Zr}$ concentration of about $\sim 28 \mathrm{at} \%$. The concentration of $\mathrm{Nb}$ in these coatings ranged from 5 to 10 at \%. Thickness of these NiZrNb coatings was in a range from 3 to 4 microns because thicker coatings have shown poor mechanical stability (peeling).

A team from Colorado School of Mines provided several vycor tubes and a molybdenum carbide (MoC) sputter target to apply thin coatings. SwRI coated 500nm of Pd to each side of the supplied foils. A total of 18 hours were spent applying the catalyst coatings. The DOE funded team from the University of Nevada at Reno (UNR) provided several melt spun NiZrNb membranes that required a Pd catalyst coating. SwRI coated 500nm of Pd to each side of the supplied foils. A total of 18 hours were spent applying the catalyst coatings UNR.

The AJA chamber with three DC magnetrons, two of them using 4" diameter targets and one using 2" diameter target was then used for development of the magnetron cosputtering process for deposition of ternary CuZr and CuZrTi amorphous alloy films with argon as a processing gas. The substrate holder was equipped with a heater and with modified RF bias setup. The substrate setup included both $1 \times 1$ " square glass coupons and 1" diameter disk stainless steel (SS) coupons which were attached evenly around the axis of the rotating substrate holding turntable. At least one of the glass coupons was masked for the measurement of the coating thickness. In Figure 43, the deposition rate for a given magnetron power is plotted for copper, zirconium and titanium. Copper and Zirconium were deposited from 4"guns and the titanium from a 2" gun. Using a linear regression a calculated deposition rate could be determined and an alloy composition derived. Using this plot, CuZr alloys with compositions of 80/20, 60/40, 40/60 and 20/80 atomic percent were targeted. 


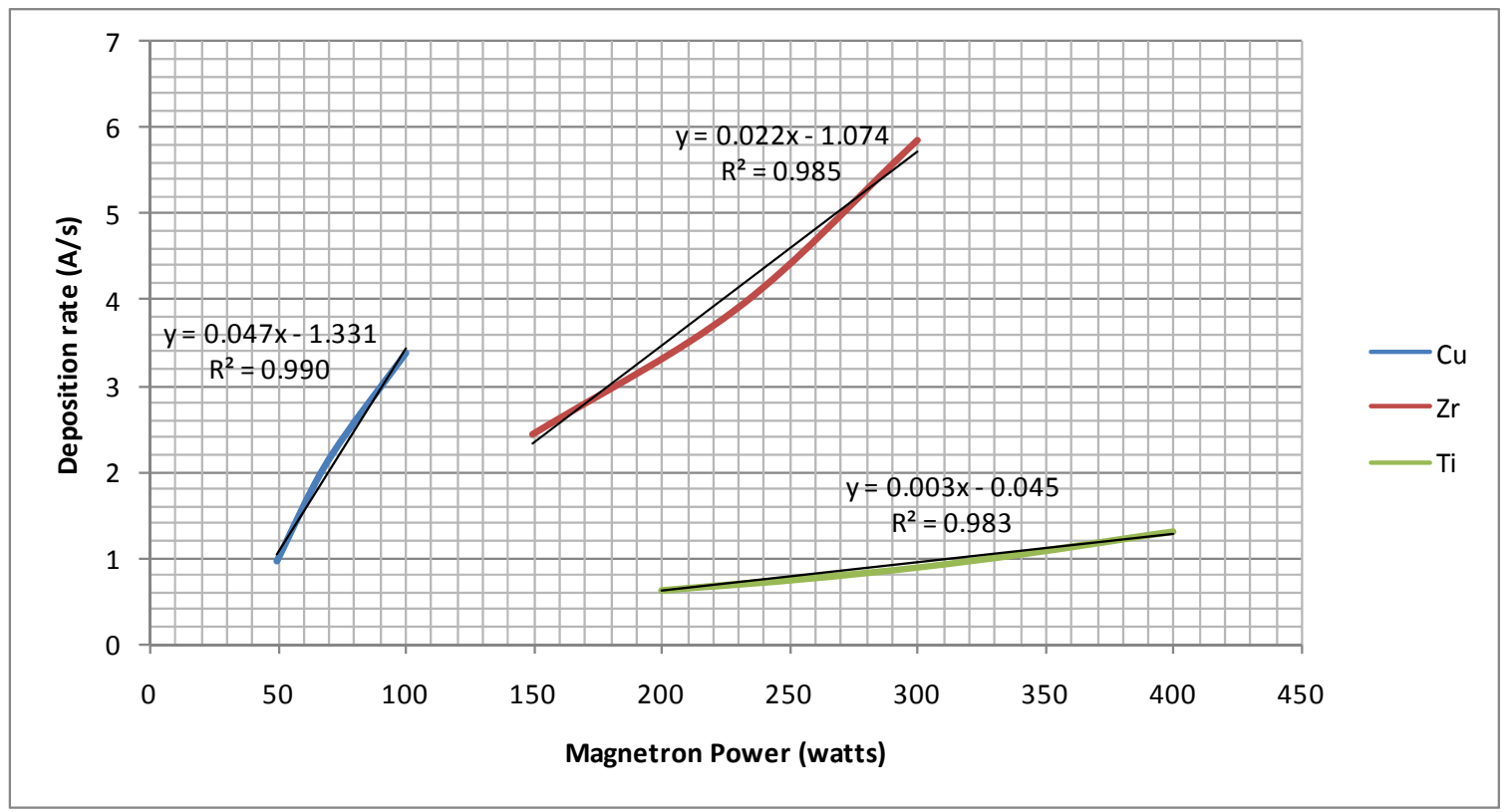

Figure 43: Deposition rate for a given magnetron power to establish coating alloy compositions.

For the targeted compositions four 1"X1" coupons of porous stainless steel supplied by Mott were loaded with a stainless coupon. Initially, substrate RF bias was applied and the coatings applied without any substrate pre-treatment. Three separate coating trials were attempted but the coating flaked off in all cases. A pre-cleaning step was established with a hot filament plasma clean operating at 120 volts DC with approximately $1.0 \mathrm{amp}$ of bias current measured at the sample for 1 hour. There were no subsequent adhesion issues and all future samples were run using this cleaning step. The following table outlines the measured composition and the magnetron power settings. All coatings were run for 1 hour which resulted in thickness ranging from 2 to 3 microns.

Table 5: CuZr coating deposition composition vs. process parameters.

\begin{tabular}{|c|c|c|c|c|}
\hline \multirow{2}{*}{ Run \# } & \multirow{2}{*}{$\begin{array}{c}\text { Cu } \\
\text { At\% }\end{array}$} & \multirow{2}{*}{$\begin{array}{c}\text { Zr } \\
\text { At\% }\end{array}$} & \multicolumn{2}{|c|}{$\begin{array}{c}\text { Magnetron } \\
\text { power } \\
\text { (watts) }\end{array}$} \\
\cline { 4 - 5 } & & & Cu & Zr \\
\hline 1 & 76.5 & 23.5 & 95 & 95 \\
\hline 2 & 52.5 & 47.5 & 65 & 155 \\
\hline 3 & 40 & 60 & 50 & 181 \\
\hline 4 & 22.1 & 77.9 & 41 & 258 \\
\hline
\end{tabular}

All of these samples were sent to WRI for thermal stability and permeation testing. In addition, following the Ti tooling runs shown in Figure 43, one run was coated at a target atomic composition of $\mathrm{Cu}(60) \mathrm{Zr}(30) \operatorname{Ti}(10)$. This sample was also sent to WRI. 
The AJA chamber with three DC magnetrons, two of them using 4" diameter targets and one using 2" diameter target was used for development of the magnetron co-sputtering process for deposition of ternary CuZrTi and CuZrTa amorphous alloy films with argon as a processing gas. The substrate holder was equipped with a heater and with modified RF bias setup. The substrate coated included both $1 \mathrm{x} 1$ ” square glass coupons, 1 ” diameter porous stainless steel (SS) disks, stainless steel coupons and a porous stainless steel disks welded into stainless steel gaskets. The substrates were distributed evenly around the axis of a rotating substrate holding turntable. At least one of the glass slides was masked for the measuring the coating thickness. In Figure 44, the deposition rate for a given magnetron power is plotted for copper, zirconium, titanium and tantalum. Copper and zirconium were deposited from 4"guns and the titanium and tantalum from a 2" gun. Using a linear regression, the calculated deposition rate could be determined and an alloy composition derived.

A pre-cleaning step was established with the hot filament plasma clean operating at 120 volts DC with approximately $1.0 \mathrm{amp}$ of bias current measured at the sample for 1 hour. There were no adhesion issues and all samples were run using this cleaning step. The following table outlines the measured composition and the magnetron power settings. Coatings were run for 3 hours which resulted in a thickness of approximately 7 microns.

Table 6: CuZrTi and CuZrTa coating deposition composition vs. process parameters.

\begin{tabular}{|c|c|c|c|c|c|c|c|c|}
\hline \multirow{2}{*}{ Date } & \multicolumn{5}{|c|}{ Magnetron power (watts) } & \multicolumn{4}{c|}{ actual } \\
\cline { 2 - 8 } & $\mathrm{Cu}$ & $\mathrm{Zr}$ & $\mathrm{Ti}$ & $\mathrm{Ta}$ & $\mathrm{Cu}$ At\% & Zr At\% & Ti At\% & Ta At\% \\
\hline $1 / 18 / 2001$ & 85 & 135 & 185 & 0 & 61.23 & 35.74 & 3.03 & 0 \\
\hline $1 / 19 / 2011$ & 56 & 170 & 242 & 0 & 42.87 & 52.71 & 4.42 & 0 \\
\hline $1 / 20 / 2011$ & 56 & 170 & 270 & 0 & 43.13 & 52.04 & 4.83 & 0 \\
\hline $1 / 21 / 2011$ & 56 & 170 & 300 & 0 & 42.67 & 51.91 & 5.42 & 0 \\
\hline $1 / 24 / 2011$ & 56 & 170 & 540 & 0 & 40.75 & 49.72 & 9.53 & 0 \\
\hline $1 / 25 / 2011$ & 56 & 170 & 540 & 0 & 40.84 & 49.77 & 9.39 & 0 \\
\hline $1 / 26 / 2011$ & 67 & 139 & 600 & 0 & 49.62 & 40.62 & 9.76 & 0 \\
\hline $1 / 27 / 2011$ & 67 & 139 & 600 & 0 & 50.38 & 40.13 & 9.49 & 0 \\
\hline $1 / 28 / 2011$ & 67 & 139 & 600 & 0 & 52.63 & 39.04 & 8.33 & 0 \\
\hline $1 / 31 / 2011$ & 78 & 110 & 660 & 0 & 63.3 & 28.44 & 8.26 & 0 \\
\hline $2 / 3 / 2011$ & 57 & 200 & 0 & 151 & 40.06 & 50.27 & 0 & 9.68 \\
\hline $2 / 7 / 2011$ & 64 & 167 & 0 & 180 & 49.28 & 40.01 & 0 & 10.72 \\
\hline $2 / 8 / 2011$ & 73 & 140 & 0 & 180 & 57.3 & 33.05 & 0 & 9.65 \\
\hline $2 / 9 / 2011$ & 76 & 130 & 0 & 180 & 59.43 & 30.95 & 0 & 9.62 \\
\hline $2 / 25 / 2011$ & 76 & 130 & 0 & 180 & 55.52 & 34.38 & 0 & 10.1 \\
\hline $3 / 1 / 2011$ & 85 & 135 & 540 & 0 & 61.84 & 31.96 & 6.2 & 0 \\
\hline $3 / 2 / 2011$ & 63 & 183 & 0 & 0 & 49.01 & 50.99 & 0 & 0 \\
\hline
\end{tabular}

The measured atomic composition was plotted versus magnetron power for each constituent in the CuZrTi samples. In Figure 44, the plots show that the concentration of the particular elements correlated well with the magnetron power which allows very tight compositional control to be maintained. 


\section{$\mathrm{Cu}(\mathrm{Ti})$}
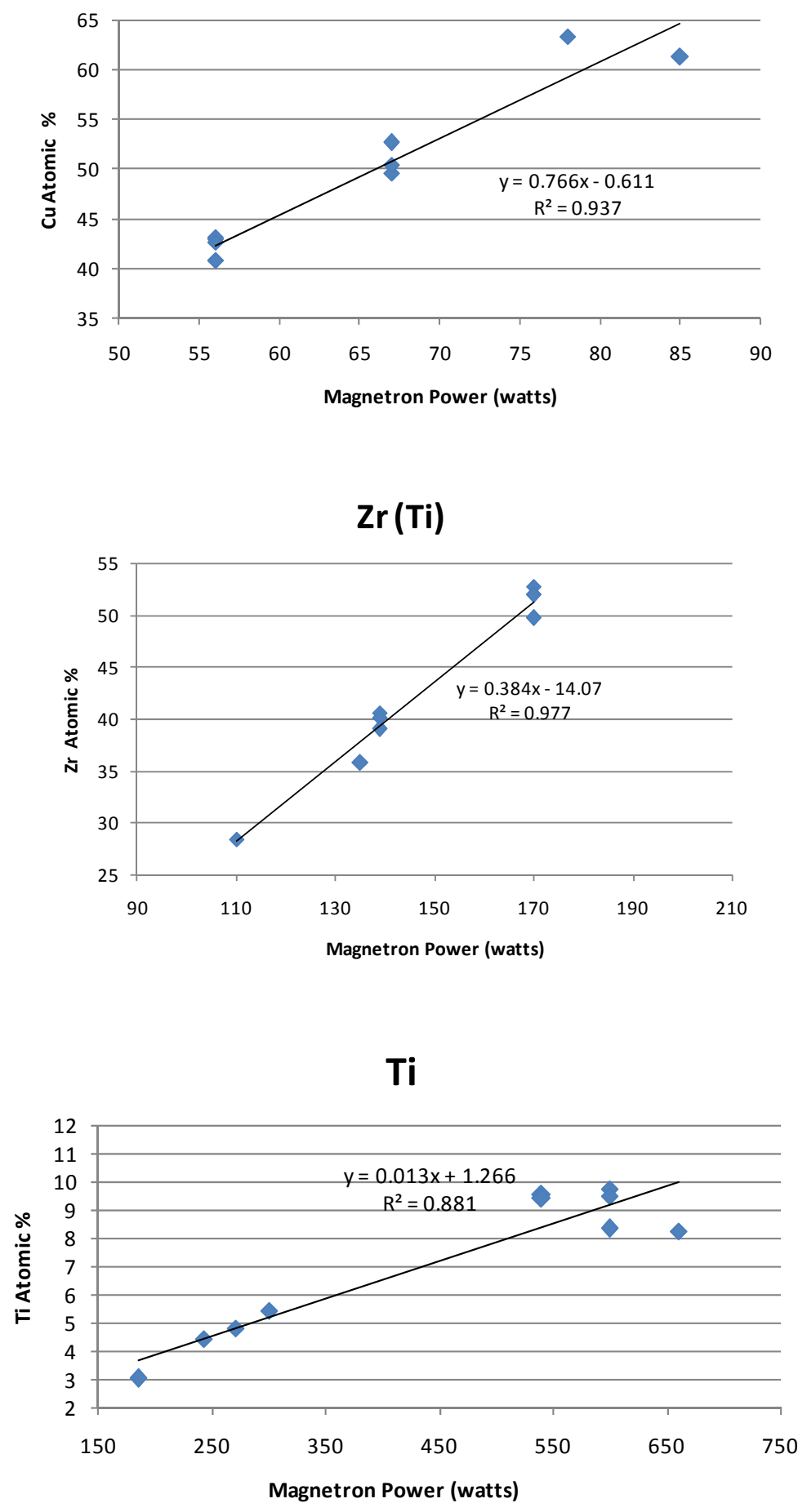

Figure 44: Measured (EDS) atomic concentration of $\mathrm{Cu}, \mathrm{Zr}$ and $\mathrm{Ti}$ for CuZrTi alloys deposited using magnetron sputtering. 
Similarly, plots of magnetron power versus measured elemental composition were made for the CuZrTa alloys. For this alloy the $\mathrm{Cu}$ and $\mathrm{Zr}$ show a strong linear correlation but the $\mathrm{Ti}$ is not as predictable.
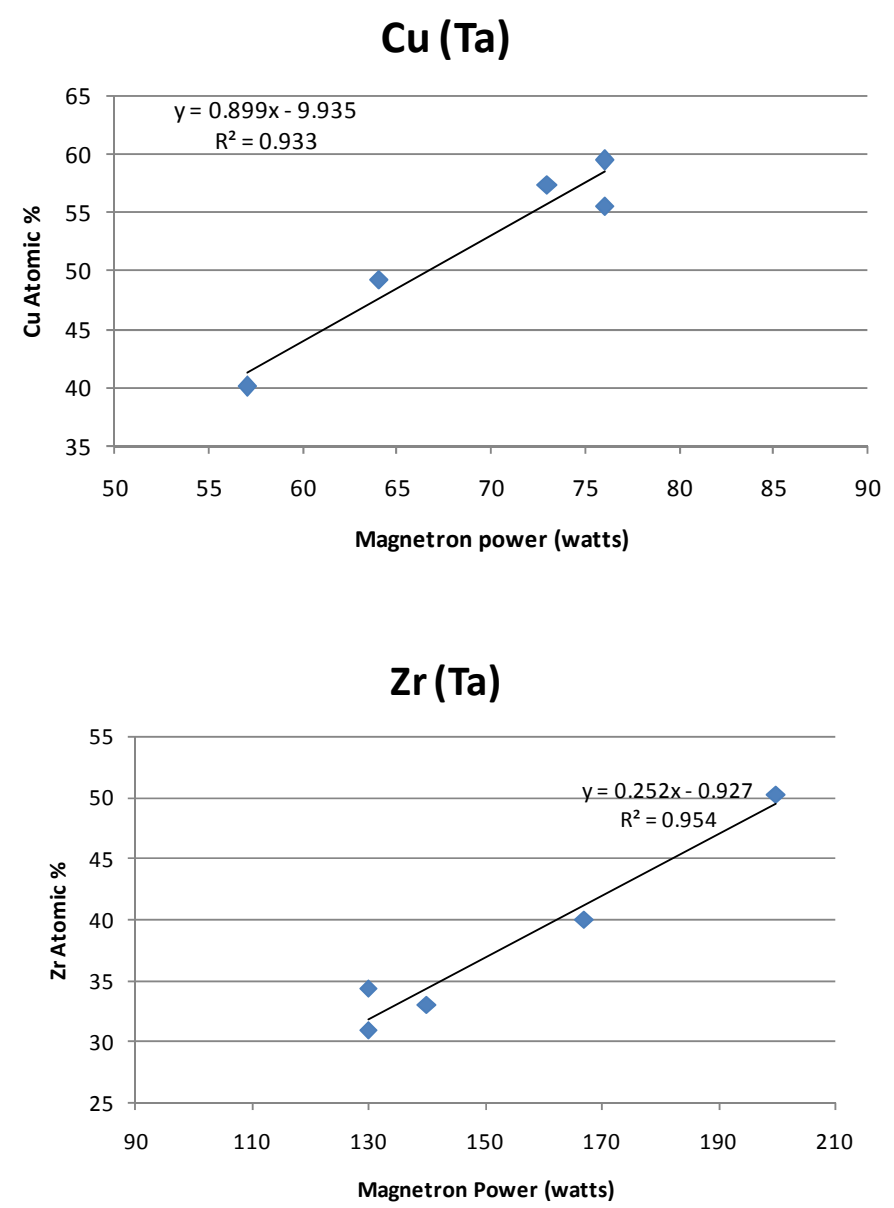

$\mathrm{Ta}$

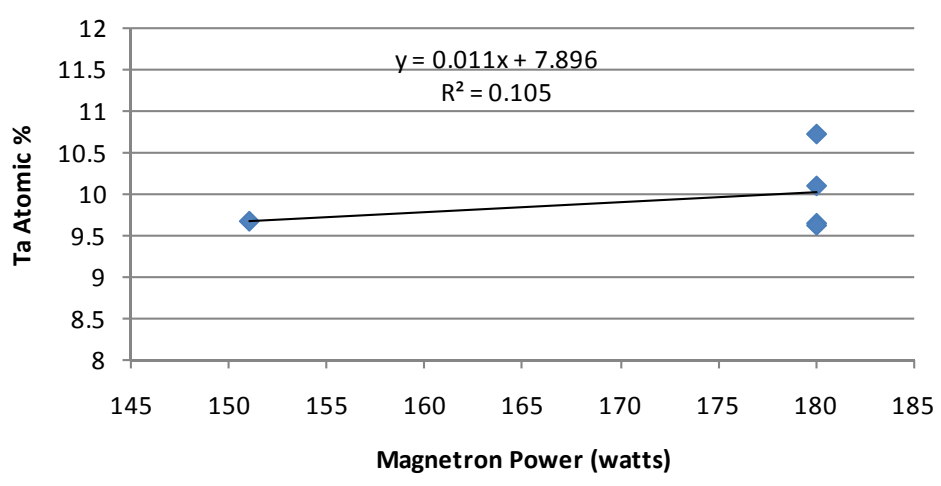

Figure 45: Measured (EDS) atomic concentration of $\mathrm{Cu}, \mathrm{Zr}$ and Ta for CuZrTa alloys deposited using magnetron sputtering. 
Additional CuZr, CuZrTa and CuZrTi amorphous alloy films were coated onto porous stainless steel substrates. The following table outlines the magnetron power settings, coating duration and measured coating thickness following the run.

Table 7: CuZrTi and CuZrTa coating process parameters, duration and measured thickness.

\begin{tabular}{|c|c|c|c|c|c|c|}
\hline \multirow[b]{2}{*}{ Date } & \multicolumn{4}{|c|}{ Magnetron power (watts) } & Duration & Thickness \\
\hline & $\mathrm{Cu}$ & $\mathrm{Zr}$ & $\mathrm{Ti}$ & $\mathrm{Ta}$ & (hr) & (microns) \\
\hline $4 / 11 / 2011$ & 76 & 130 & 0 & 180 & 16 & 29.2 \\
\hline $4 / 21 / 2011$ & 63 & 183 & 0 & 0 & 16 & 27.6 \\
\hline $4 / 29 / 2011$ & 85 & 135 & 540 & 0 & 16 & 30.4 \\
\hline $6 / 14 / 2011$ & 85 & 135 & 540 & 0 & 16 & 30.6 \\
\hline $6 / 23 / 2011$ & 85 & 135 & 540 & 0 & 16 & 31.4 \\
\hline
\end{tabular}

All samples were sent to WRI for characterization and the porous stainless steel mounted into a stainless gasket were loaded into the permeation test apparatus at WRI. All the samples coated in April (4/11, 4/21 \& 4/29) leaked when they were tested and were returned to SwRI for characterization. The following are optical microscopy images of the surface.
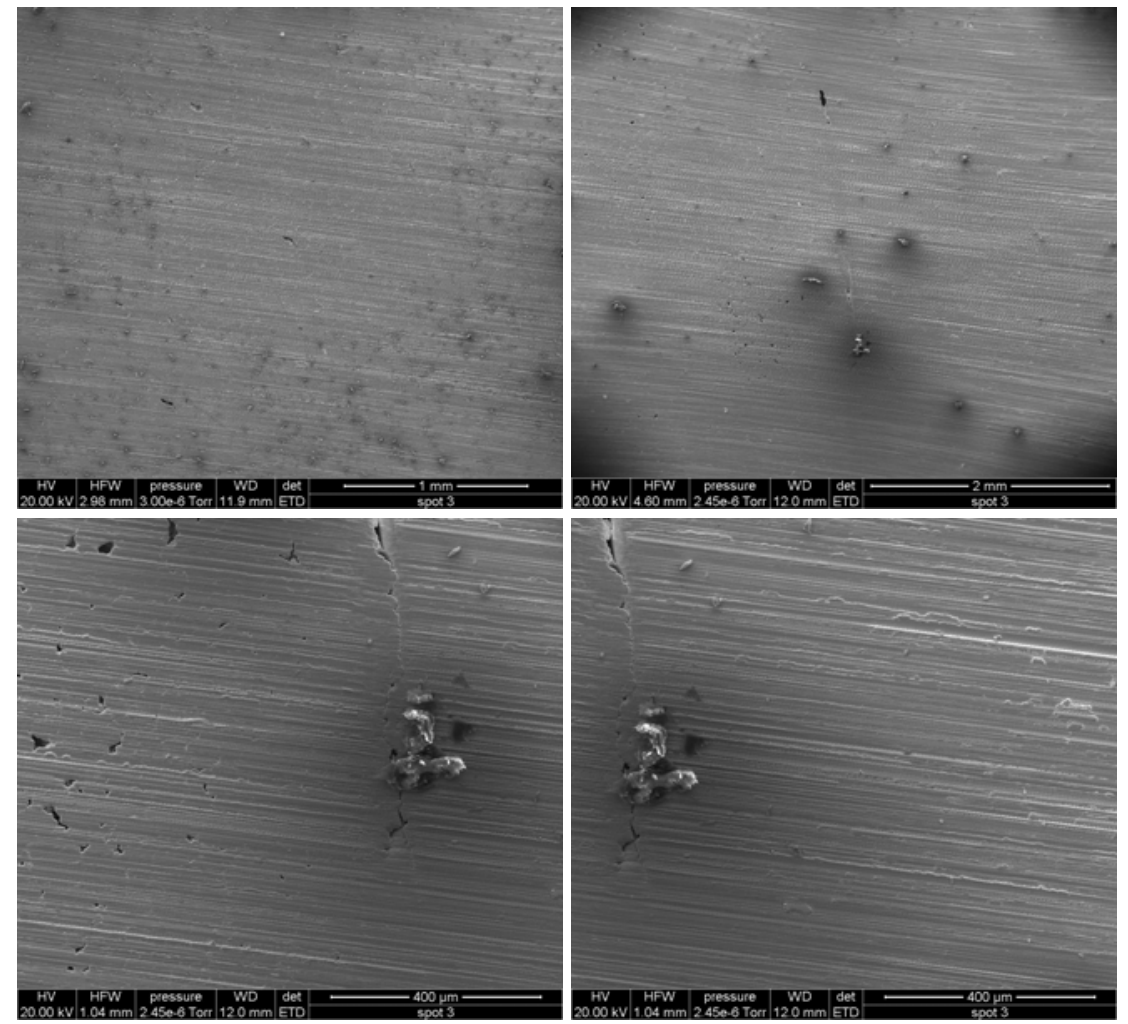

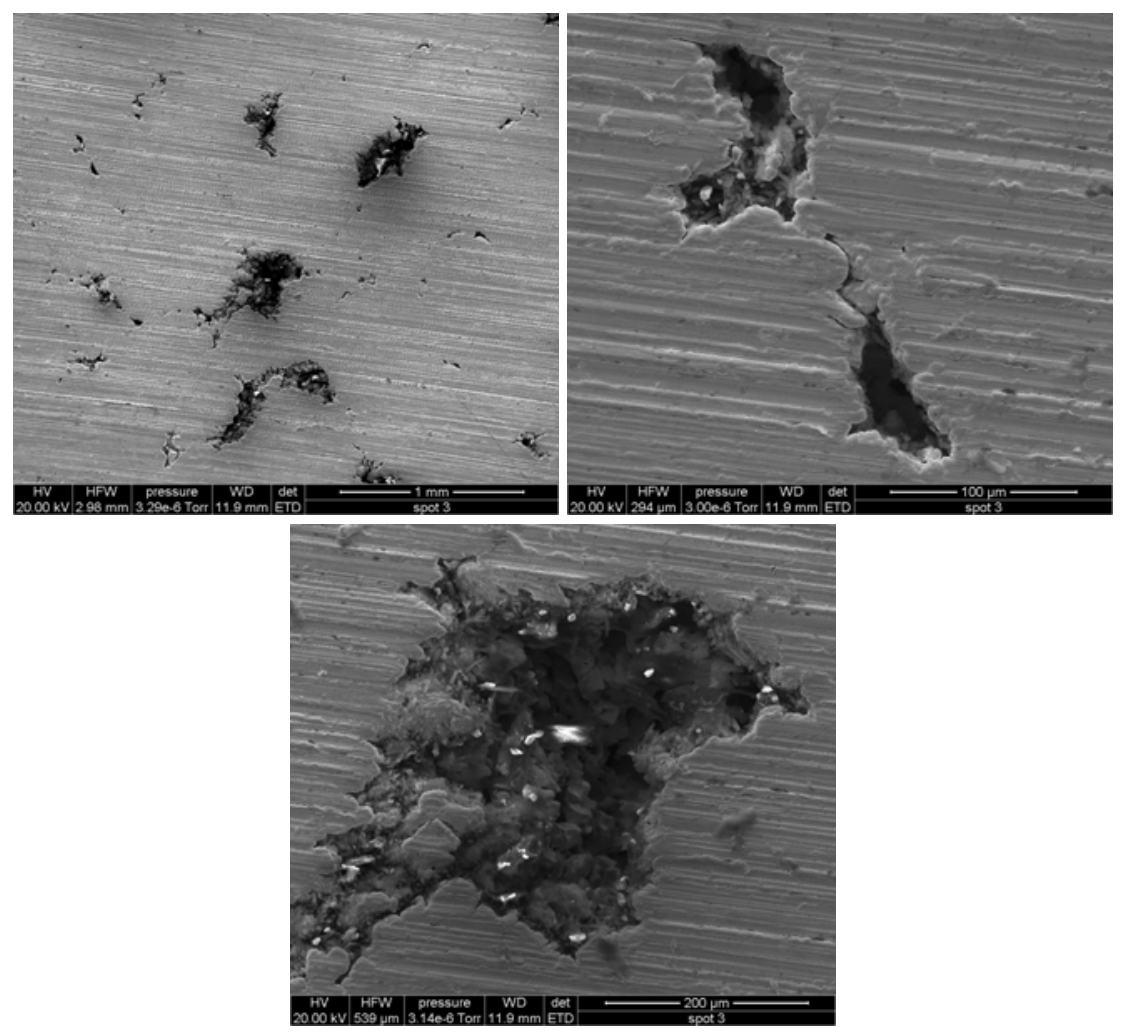

Figure 46. Optical microscopy images of the surface of a coated porous substrate. In the latter images unfilled pores are magnified.

Based on the optical microscopy images it appears the 30 micron thick coatings were not thick enough to completely fill the pores in the substrate. There was some concern that there was porosity in the coating so cross section images of the coating using SEM were completed and are shown below.
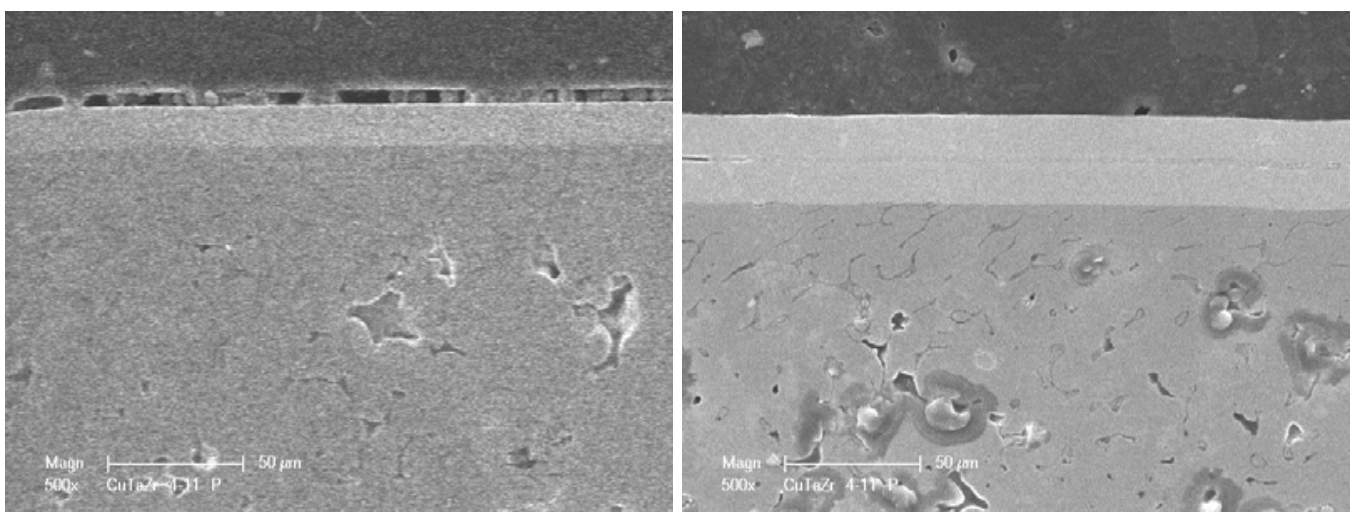

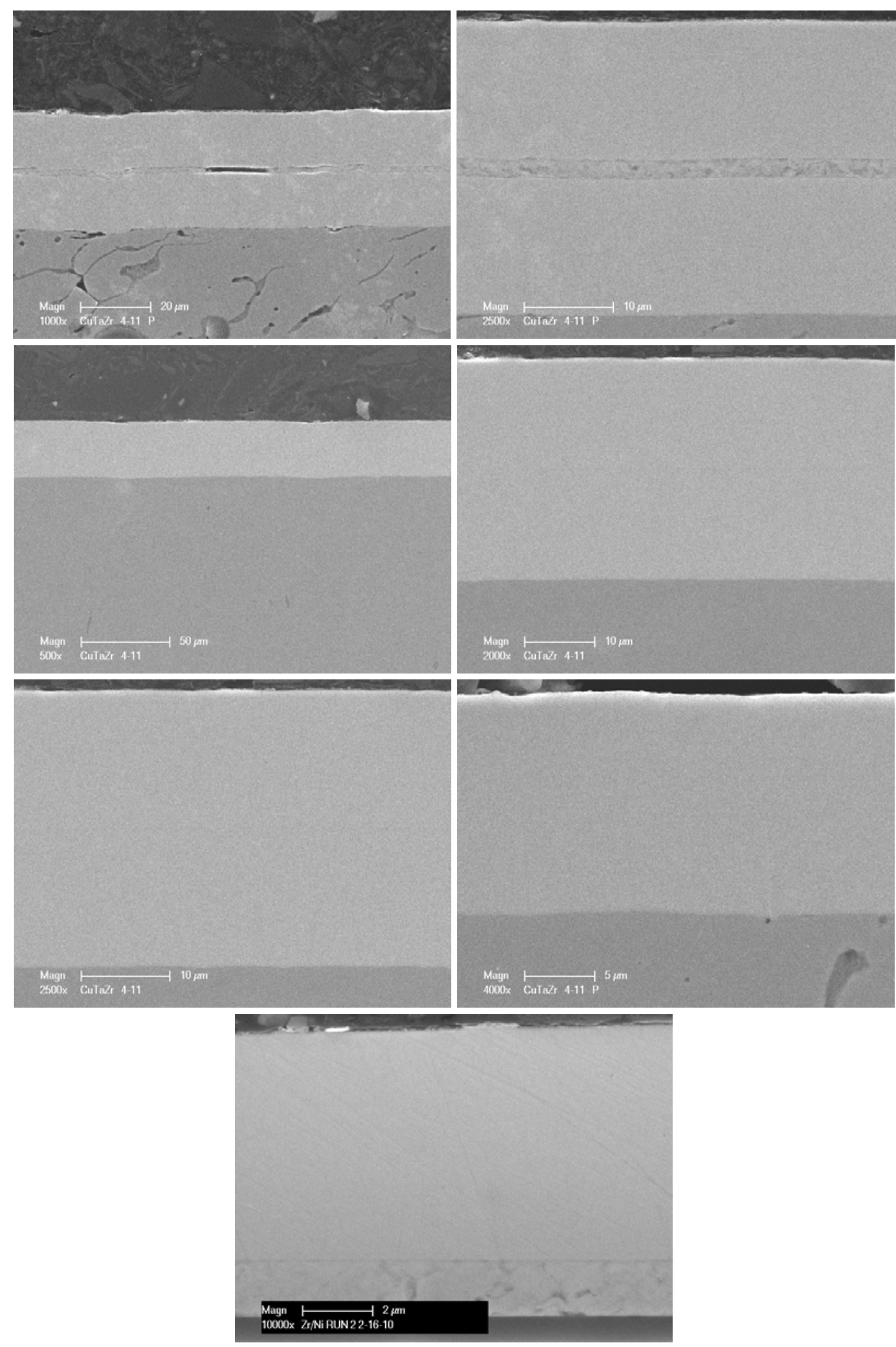

Figure 47: SEM cross section images of the coated porous substrate. 
The cross section images confirm that the coating is uniform, amorphous, and there are no through film defects contributing to the leaks. This further confirms the solution to the leak problem is thicker coatings.

On a separate project, $\mathrm{Ru}$ and $\mathrm{Ru} / \mathrm{V}$ membranes were prepared and characterized using a newly purchased MicroCT. Below are images of a porous stainless steel disk from Mott Corporation that has had 50 microns of Cr applied.
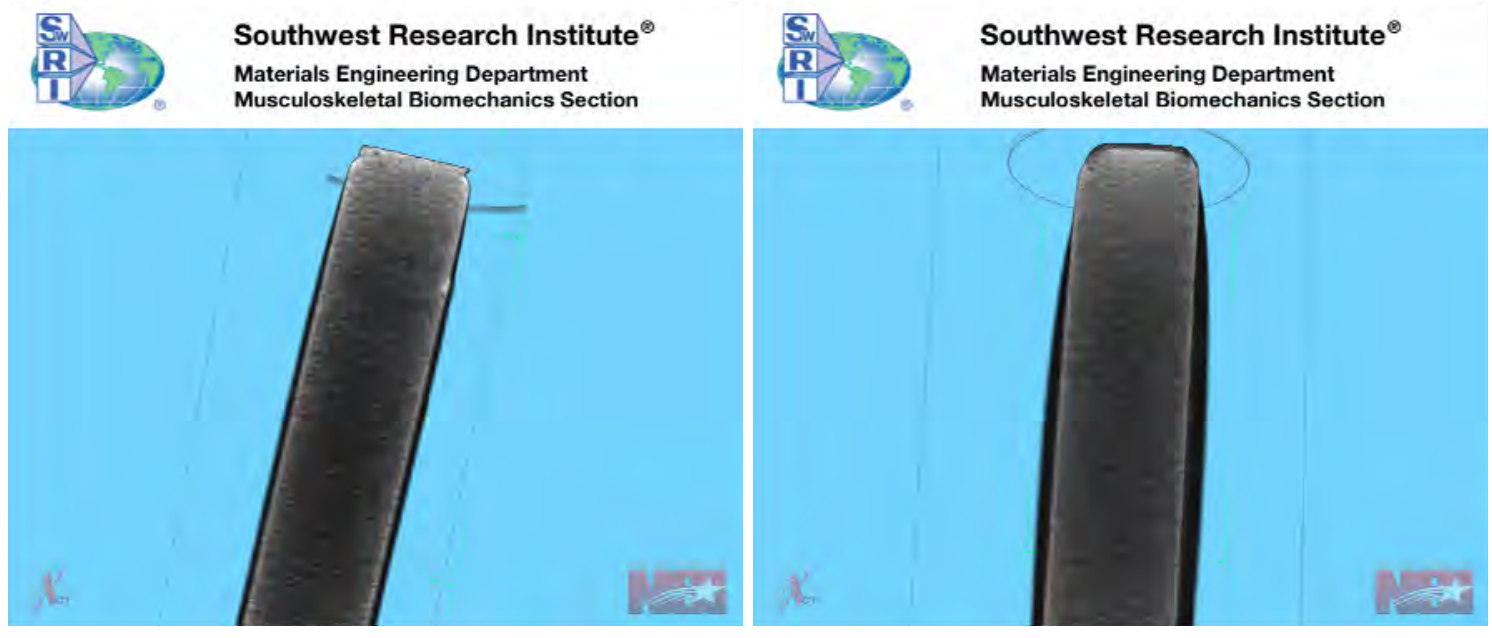

Figure 48: MicroCT images of $\mathrm{Cr}$ coated porous membranes.

While not clearly evident in these images, on the instrument you could see the $\mathrm{Cr}$ infiltration into the pores to a depth of approximately 5 microns. Subsequent images were made of a 10 micron thick $\mathrm{Ru} / \mathrm{V}$ coating on the same substrate.

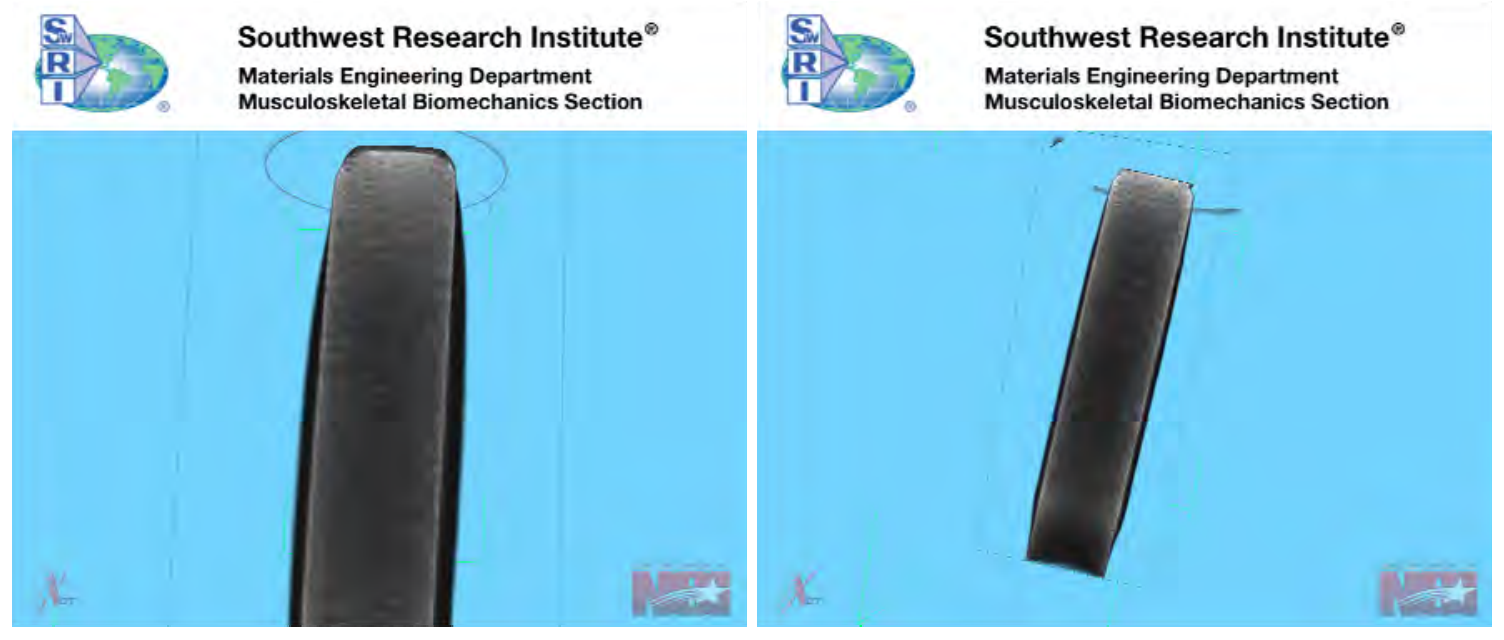

Figure 49: MicroCT images of Ru/V coated porous membranes. 
While the prediction was that the $\mathrm{Ru} / \mathrm{V}$ would fill the pores what was actually observed was the coating filled only $50 \%$ of the pores leaving the substrate open to other gases passing through. The MicroCT was useful in defining substrate/coating interactions and coating penetration.

The AJA chamber was used for the magnetron sputtering process for deposition of $\mathrm{Cr}$ films with argon as a processing gas. These coating were prepared to determine if the magnetron sputtering process regardless of material could make a pin-hole free coating. The following table outlines the magnetron power settings, coating duration and measured coating thickness following the run.

Table 8: Cr coating process parameters, duration and measured thickness.

\begin{tabular}{|c|c|c|c|}
\hline \multirow{2}{*}{ Date } & $\begin{array}{c}\text { Magnetron } \\
\text { power (watts) }\end{array}$ & Duration & Thickness \\
\cline { 2 - 4 } & Cr & (hr) & (microns) \\
\hline $7 / 28 / 2011$ & 200 & 1 & 1.8 \\
\hline $8 / 18 / 2011$ & 200 & 27 & 50 \\
\hline
\end{tabular}

The disk sample that was coated with a 50 micron thick chromium coating leaked indicating that the disk approach to testing the materials is not viable.

Multiple sources were contacted at universities, commercial companies and porous substrate suppliers to identify an approach to solve the disk sealing issue. The most common approach was to use a porous tube as the supporting substrate. The joining of the porous tubes to a solid tube is established and an additional sealing coating can be applied after the hydrogen selective membrane is applied to seal the areas outside of the separation zone. Two suppliers were contacted and substrates ordered.

The change in geometry from a disk to tube design required a modification to the coating apparatus for applying the amorphous alloys. SwRI constructed a fixture to hold and rotate tubes that can be coated. This was the approach to address the previously identified sealing issues with the disk approach. An image of the apparatus is shown below. 

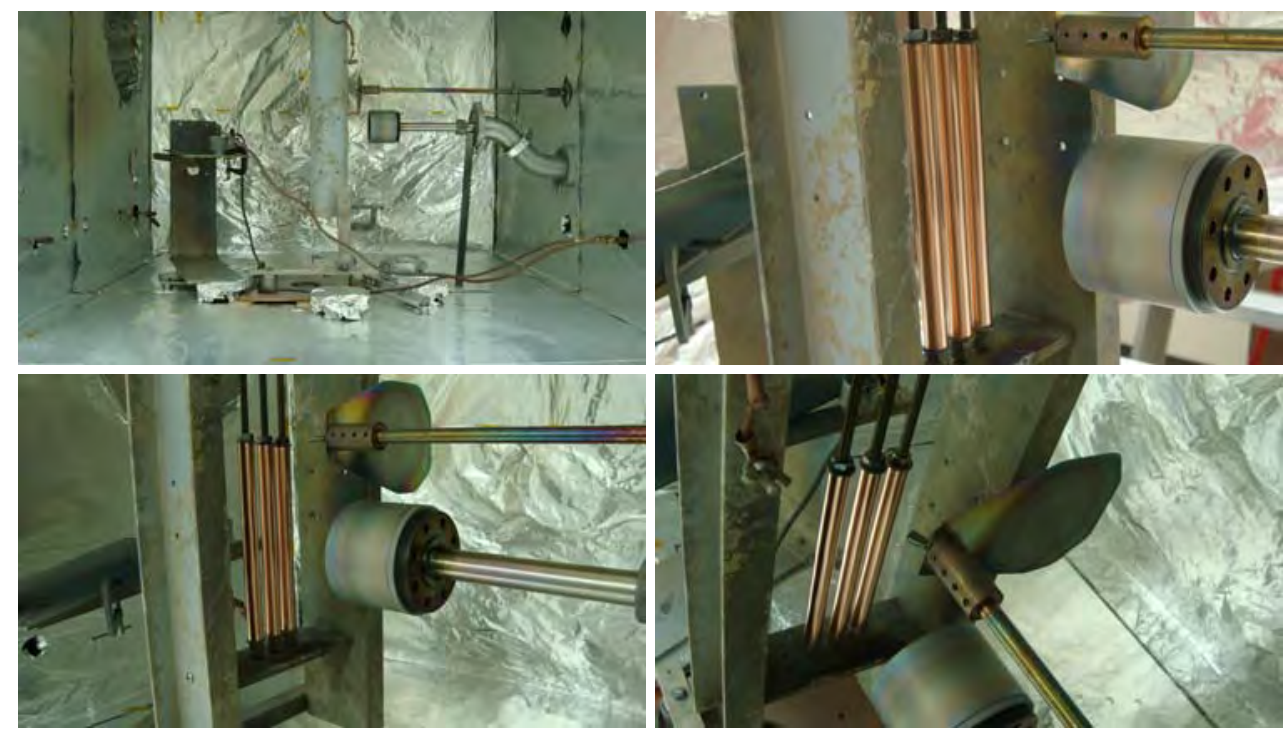

Figure 50: Magnetron sputtering set-up for porous tubes.
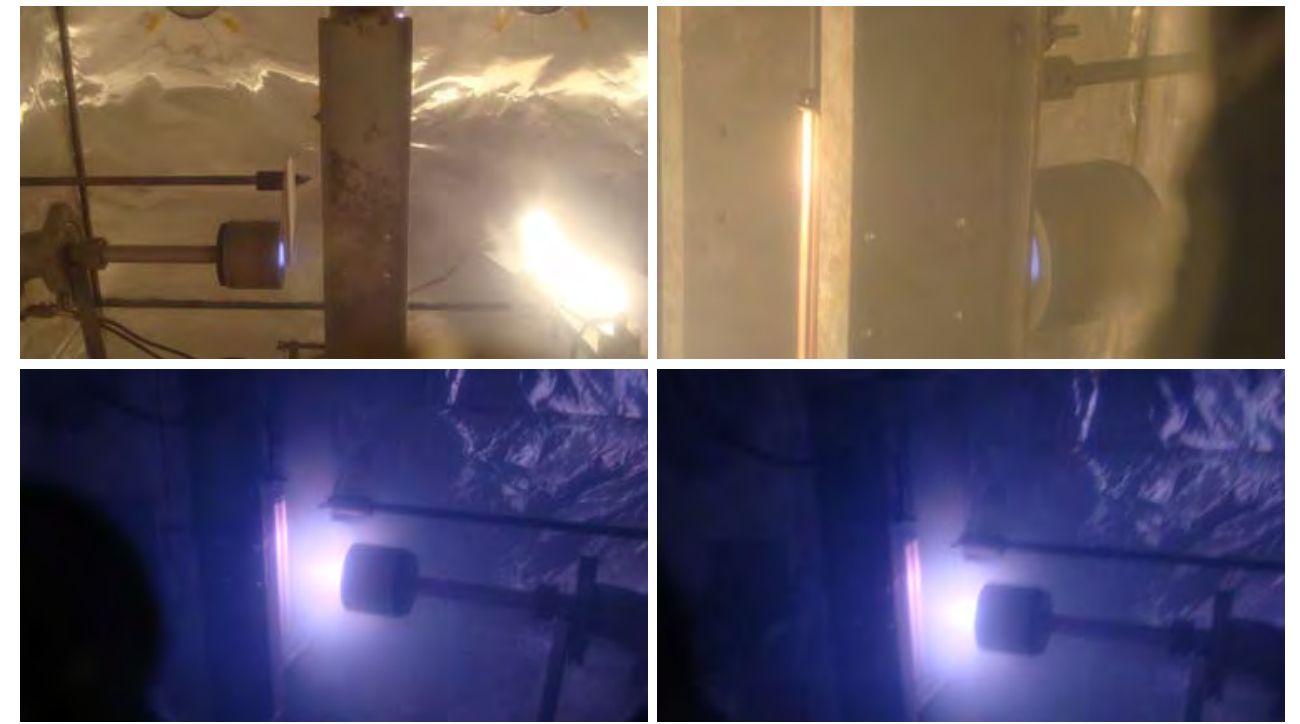

Figure 51: Magnetron sputtering of the tubes in operation.

Using the constructed fixture to hold and rotate tubes $\mathrm{Cr}$ was applied and a sealing compound applied which resulted in a sealed tubular membrane. Using the tube approach copper $(\mathrm{Cu})$ was applied and the sealing compound applied which resulted in a sealed tubular membrane. In the following image the tube can be seen rotating at the center of the deposition zone as the $\mathrm{Cu}$ is sputtered. 


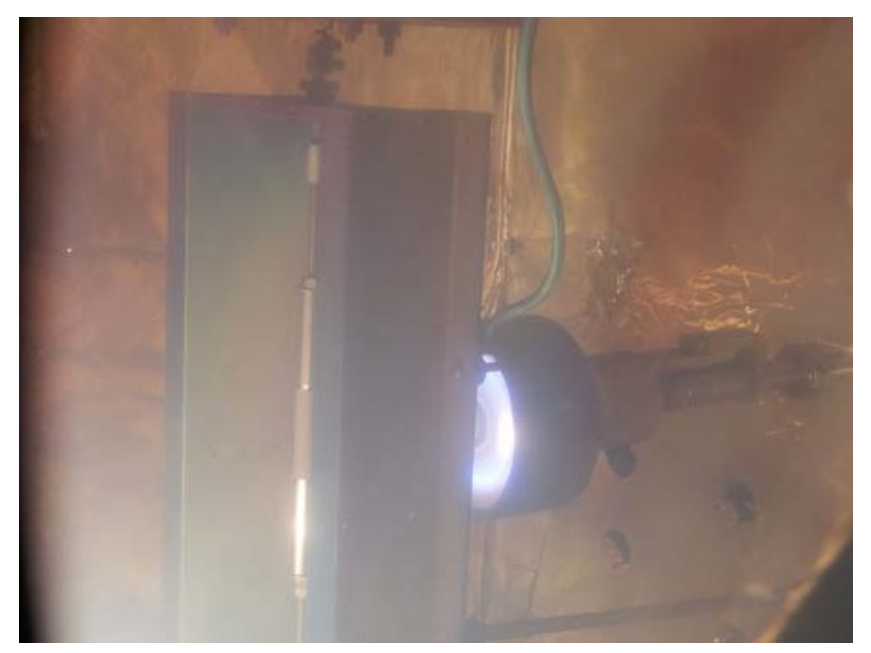

Figure 52: A porous stainless steel tube in sputtering fixture.

On the right hand side of Figure 52 is a 4" magnetron. For the alloy compositions multiple magnetrons were positioned around the tube as opposed to the previous design where the magnetrons faced the disc. The process steps for coating the tubes were that the tubes were loaded and the vacuum chamber evacuated to approximately $5 \times 10^{-6}$ torr. The chamber was then back filled with argon (Ar) to 3.0 millitorr and the parts biased to $120 \mathrm{~V}$ while a hot filament is used to create $\mathrm{Ar}^{+}$ions that are attracted to the surface to sputter off any contaminates or native oxide. In Figure 53, the sputter cleaning process is shown.

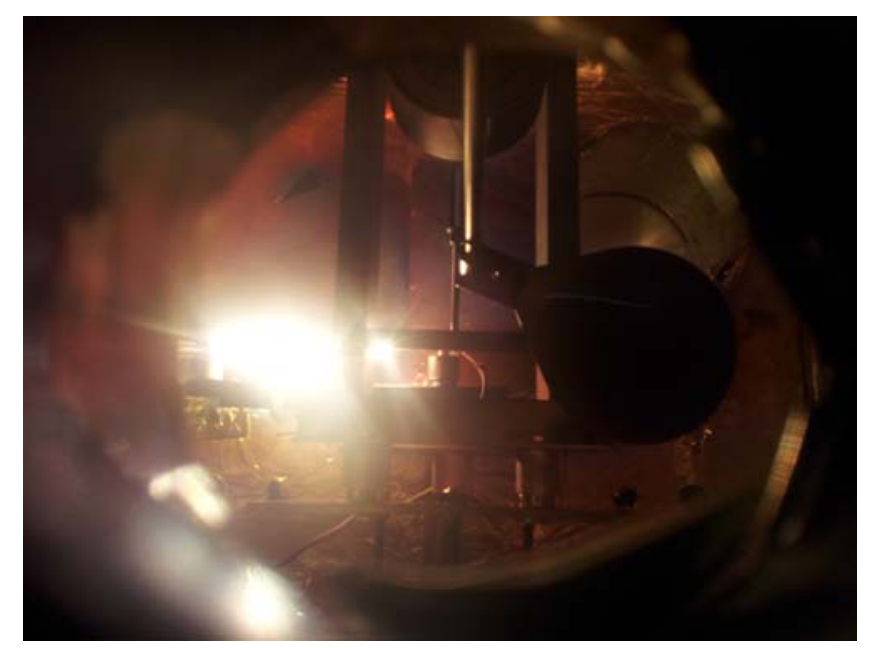

Figure 53: A porous stainless steel tube during the sputter cleaning process.

The sputter cleaning lasted 30 minutes and then the magnetron is turned on and coating proceeded. For the $\mathrm{Cu}$ coating the deposition rate was $\sim 5.0$ microns/hour with a total thickness of 11.0 microns. Images of the coating in-progress are shown in Figure 54. 

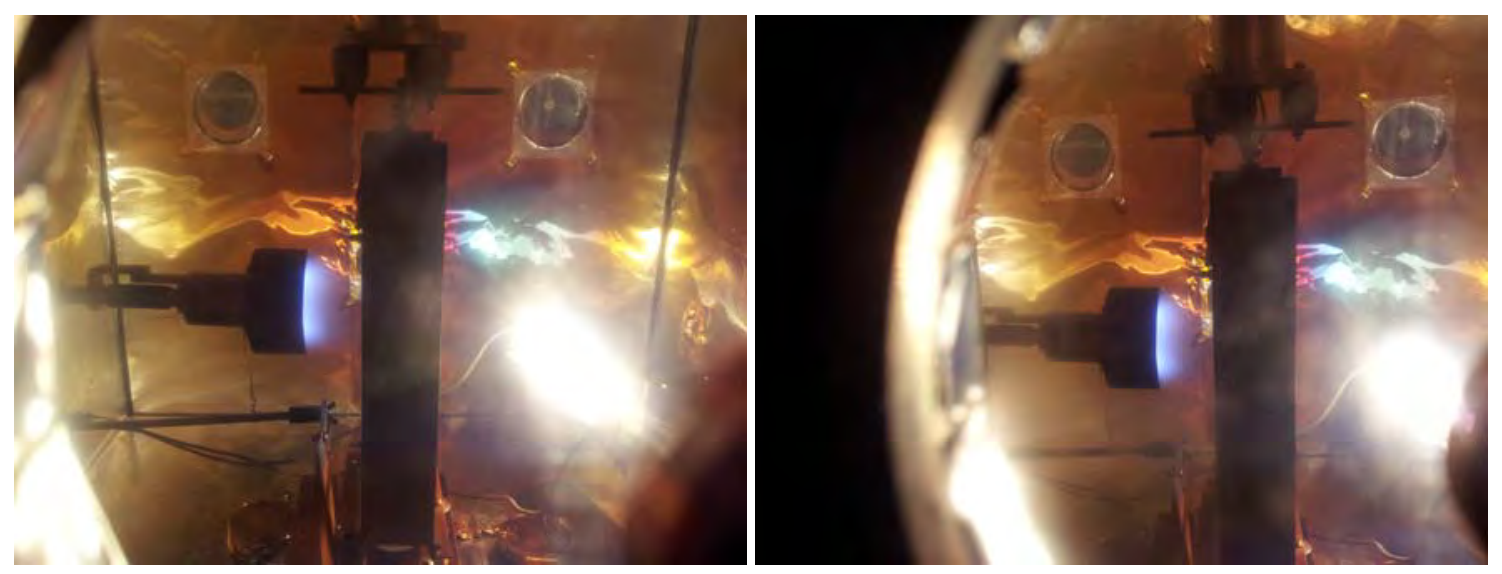

Figure 54: Magnetron sputtering of $\mathrm{Cu}$ onto a porous stainless steel tube.

Subsequently alloys of RuV and RuNb with 5, 20 and $30 \% \mathrm{Ru}$ were applied at a thickness of 10.0 microns on top of the zirconia. These samples were provided to Jennifer Wilcox at Stanford University for evaluation.

A new process was developed to apply a zirconia $\left(\mathrm{ZrO}_{2}\right)$ intermediate layer to the stainless steel porous support. Using a recipe suggested by Doug Way, zirconium (Zr) was sputter deposited directly onto a Mott support and the support was then annealed in air to $400^{\circ} \mathrm{C}$. The targeted $\mathrm{Zr}$ thickness was 10.0 microns and given the lattice expansion expected by the oxidation ( 1.5) the total thickness of the zirconia is on the order of 15 microns. Following the oxidation step the support had a translucent white powder appearance which supported the presence of $\mathrm{ZrO}_{2}$. Below are SEM Images of Mott porous tubular support coated with 10 microns of $\mathrm{ZrO}_{2}$.
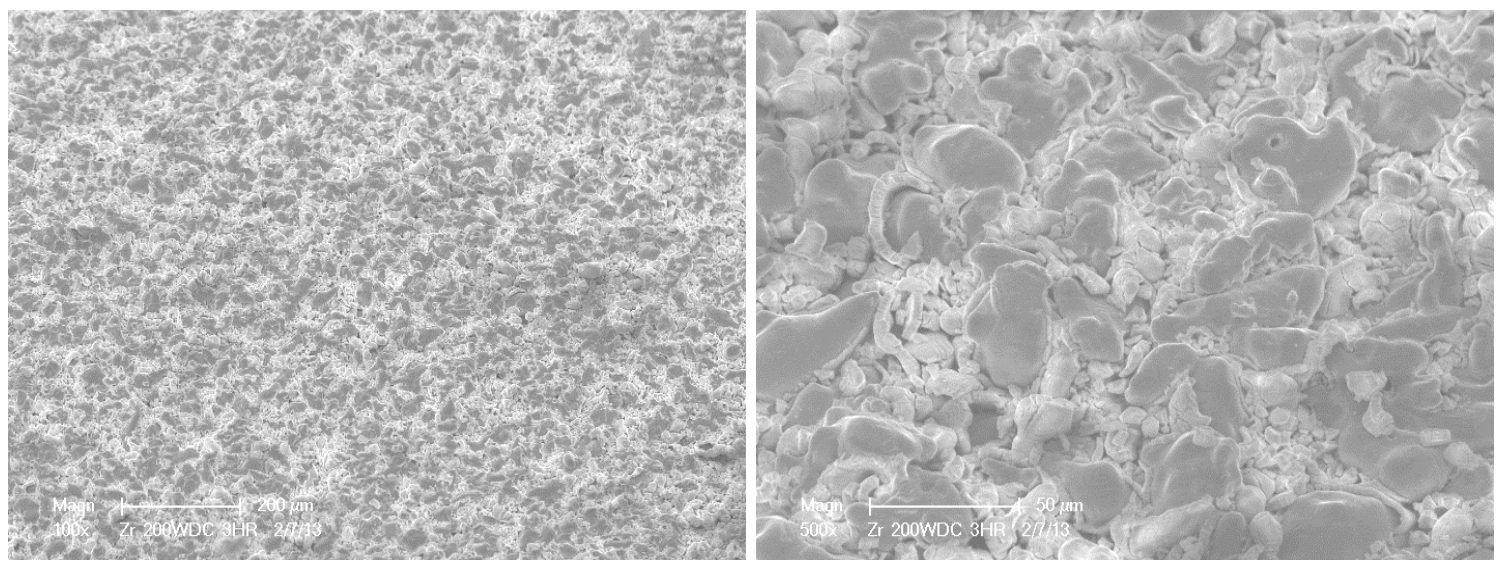

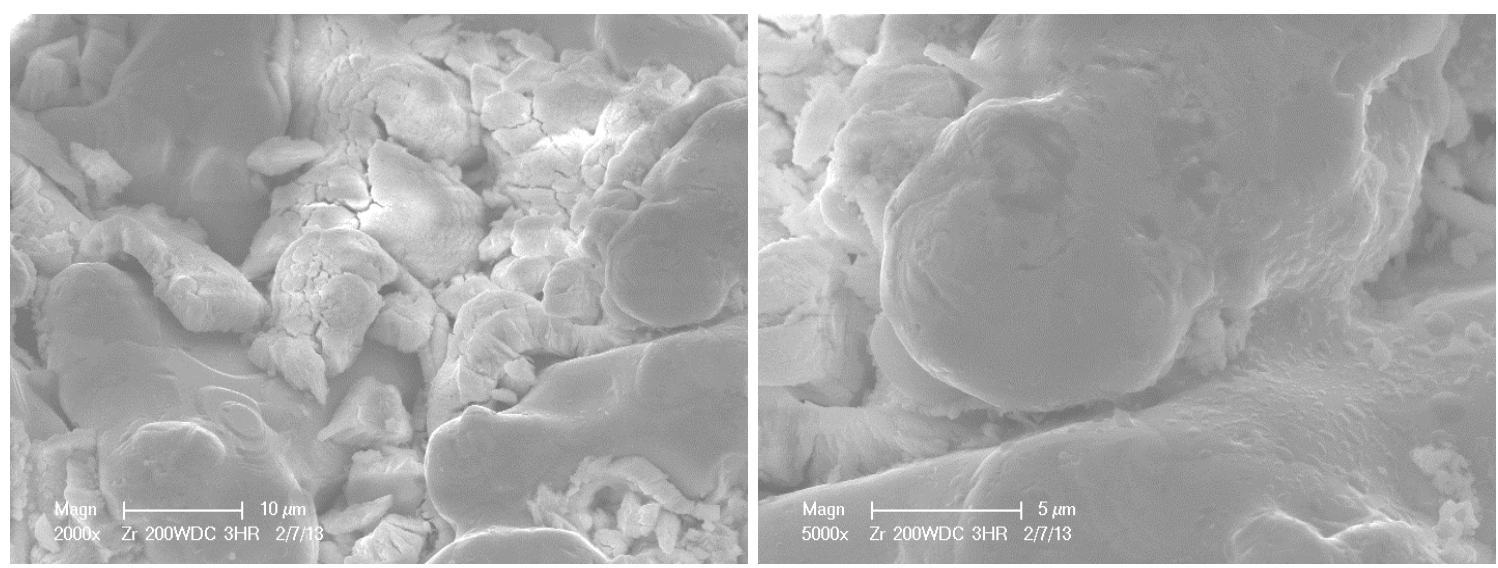

Figure 55: SEM Images of zirconia coated Mott porous membranes.

Subsequently alloys of $\mathrm{ZrCu}$ were applied at a thickness of 10.0 microns on top of the zirconia. Using previous magnetron power vs. thin film alloy concentration curves the targeted powers were 60 watts for $\mathrm{Cu}$ and 200 watts for $\mathrm{Zr}$. Below is the calibration run to establish the $\mathrm{ZrCu}$ ratio.

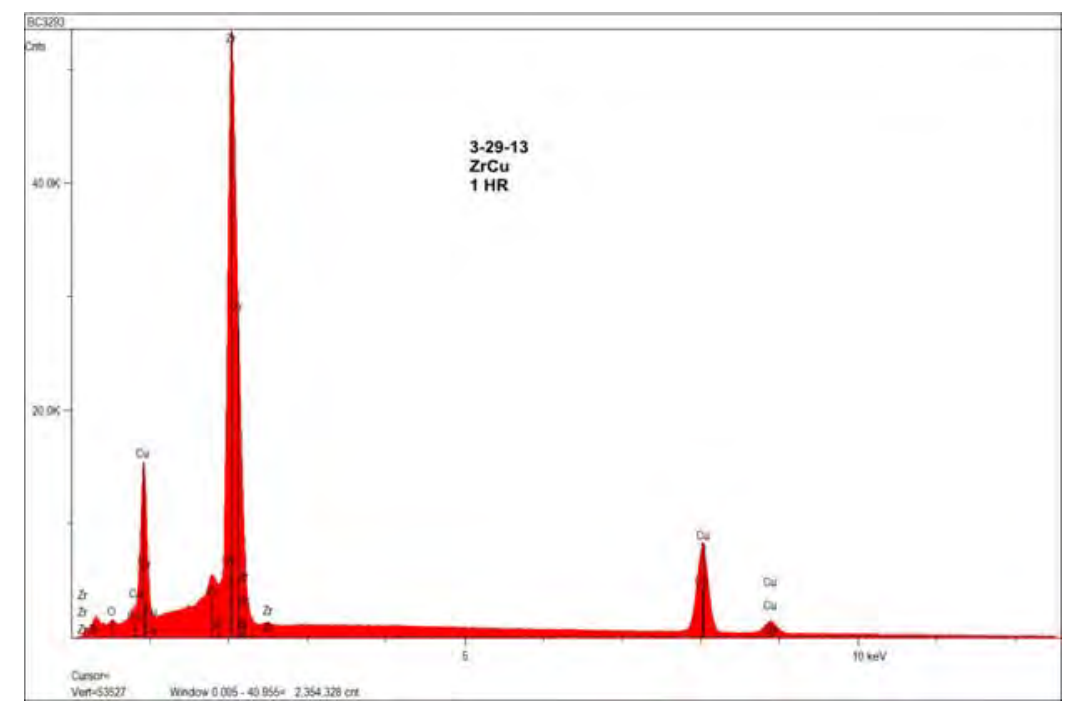

Figure 56: EDS spectra of ZrCu coating.

The measured alloy ratio for the calibration run was $\mathrm{Zr}_{72} \mathrm{Cu}_{28}$. The target was $\mathrm{Zr}_{54} \mathrm{Cu}_{46}$. For the next two runs the following magnetron powers were used.

Table 9: $\mathrm{ZrCu}$ coating process parameters.

\begin{tabular}{|c|c|c|}
\hline Run \# & Zr Power (watts) & Cu Power (watts) \\
\hline 1 & 200 & 100 \\
\hline 2 & 200 & 150 \\
\hline
\end{tabular}


A previously coated $\mathrm{ZrCu}$ was over coated with an additional 20 microns of $\mathrm{ZrCu}$. The coating was subsequently annealed at 200C in air to try and seal the pinhole leaks that had been seen before. The coated sample was sent to WRI for testing but the tests were not successful.

\subsection{Testing \& Characterization}

Thermal tests were conducted by WRI on a number of alloys to determine the stability of the amorphous character of the alloys with time and temperature. Coupons were prepared at 1" square of glass and of stainless steel. Films of the amorphous alloys were deposited on the coupons at 10 microns thick. X-ray diffraction was conducted on the coupons to confirm the amorphous character of the alloys. The coupons were put into a furnace between 700 and $800^{\circ} \mathrm{C}$ under argon and maintained at temperature for up to 100 hours. After thermal treatment, the coupons were re-examined by XRD for amorphous character. X-ray photoelectron spectroscopy was used on a small number of coupons to investigate any surface segregation of doping elements following thermal tests. The choice of glass and stainless steel coupons was used to determine if substrate crystallinity influenced the stability of the alloys.

WRI identified a local vendor (University of Wyoming Geology Department) who conducted all x-ray crystallography tests that determined the extent of amorphous character of membrane materials deposited on stainless steel and glass substrates. A small stainless steel pressure vessel that was designed and used for testing a variety of materials under syngas conditions at a range of temperatures and pressures

The XRD patterns obtained from as-deposited ternary NiZrNb coating have shown their amorphous structure as illustrated in Figure 57. To assess their thermal stability against recrystallization, $\mathrm{NiZrNb}$ coatings were annealed in air and in an $\mathrm{Ar} / 2 \% \mathrm{H}_{2}$ atmosphere. The annealing time was either $1 \mathrm{hr}$ or $24 \mathrm{hrs}$ followed by XRD analysis. Similar to the previously developed binary NiZr coatings with high $\mathrm{Zr}$ concentration, all NiZrNb coatings demonstrated good thermal stability after $1 \mathrm{hr}$ annealing at $300^{\circ} \mathrm{C}$ in an $\mathrm{Ar} / 2 \% \mathrm{H}_{2}$ atmosphere. 
7-7-10 Zr/Ni/Nb Run 1 Sample 4

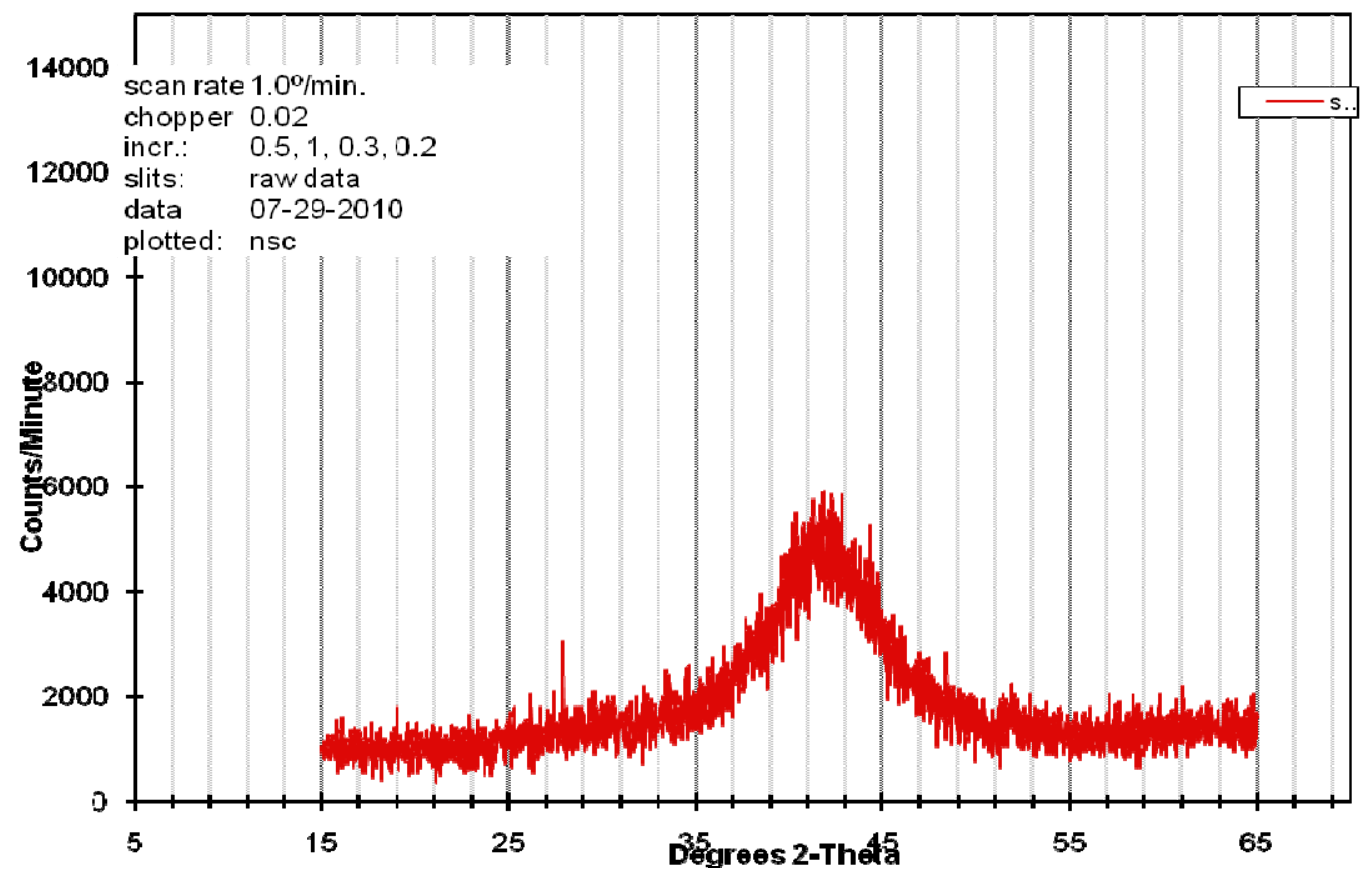

Figure 57: As deposited NiZrNb coatings demonstrated XRD-amorphous patterns.

It was found that ternary NiZrNb coatings have considerably better thermal stability than NiZr coatings having similar $\mathrm{Zr}$ concentration when exposed to $\mathrm{Ar} / 2 \% \mathrm{H}_{2}$ atmosphere at 300 deg $\mathrm{C}$ during 24 hrs. The XRD pattern of NiZr coatings and melt-spun ribbons with high $\mathrm{Zr}$ concentration after annealing in $\mathrm{Ar} / \mathrm{H}_{2}$ atmosphere during $24 \mathrm{hrs}$ have demonstrated substantial re-crystallization as shown in Figure 58. 


$$
\begin{aligned}
& >9-\mathrm{N}_{0.82} \mathrm{Zr}_{0.18} \\
& >10-\mathrm{N}_{0.76} \mathrm{Zr}_{0.24} \\
& >11-\mathrm{N}_{0.71} \mathrm{Zr}_{0.29} \\
& >12 \text { (melt-spun } \\
& \text { ribbon)- } \mathrm{N}_{0.64} \mathrm{Zr}_{0.36}
\end{aligned}
$$

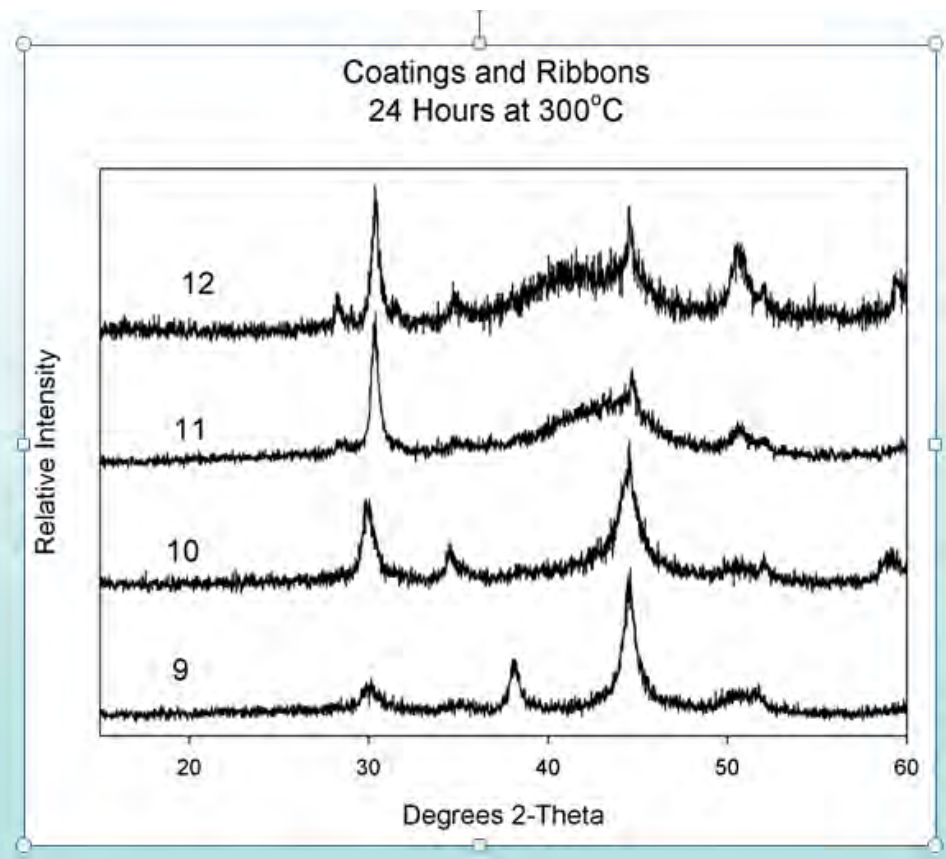

Figure 58: XRD patterns of NixZr1-x coatings and melt-spun ribbons after $24 \mathrm{Hr}$ annealing in $\mathrm{Ar} / 2 \% \mathrm{H} 2$ at 300 deg $\mathrm{C}$ vs. $\mathrm{Zr}$ content.

This behavior is in a sharp contrast with NiZrNb coatings having similar Zr concentration and approximately 10at \% of $\mathrm{Nb}$ as can be seen in Figure 59.

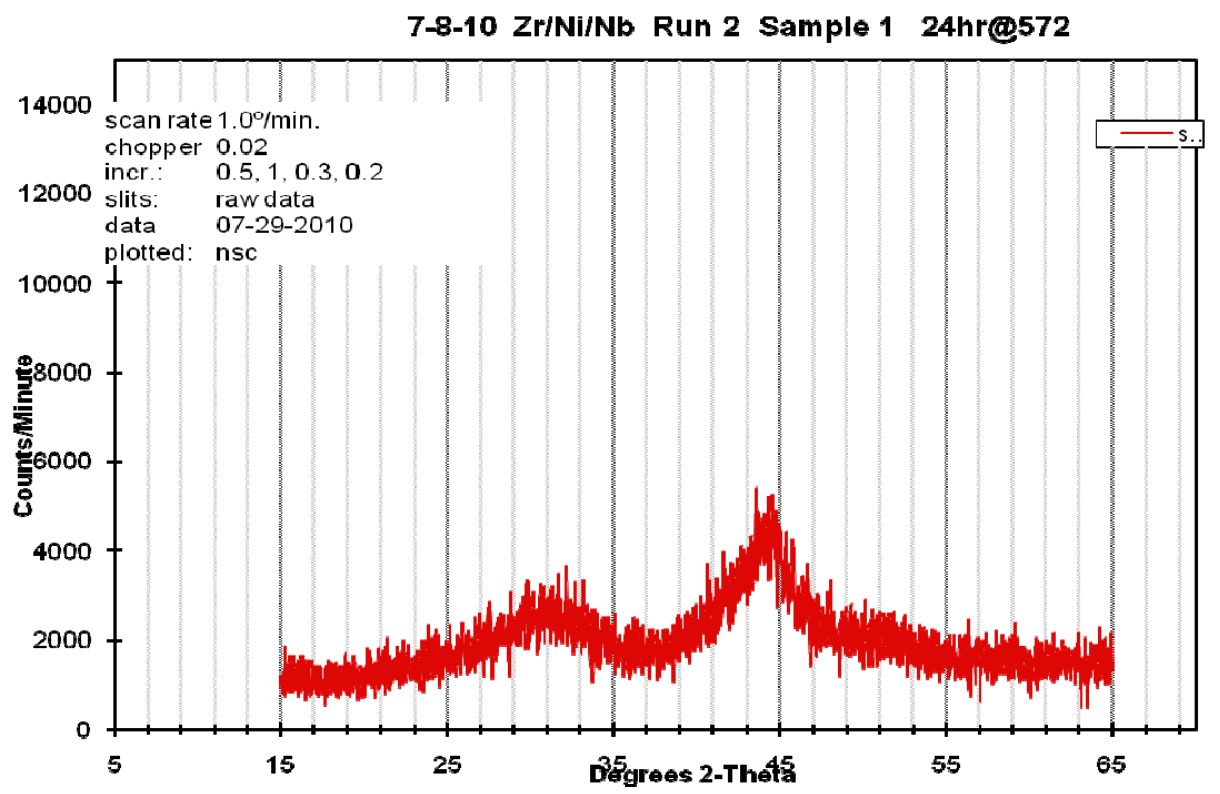

Figure 59: $\mathrm{XRD}$ patterns of Ni64Zr28Nb8 coating after $24 \mathrm{Hr}$ annealing in $\mathrm{Ar} / 2 \% \mathrm{H}_{2}$ at $300^{\circ} \mathrm{C}$. This coating which has about the same $\mathrm{Zr}$ concentration as coating \#11 in Figure 58 has typical amorphous pattern which remains unchanged after 24 annealing. 
Further investigation of thermal-chemical stability of ternary NiZrNb coatings has revealed that the coating is losing its thermal stability after annealing in $\mathrm{Ar} / 2 \% \mathrm{H}_{2}$ atmosphere at $400^{\circ} \mathrm{C}$ even during one hour of annealing time. Both NiZr and NiZrNb coatings have demonstrated poor thermal stability during annealing in air which can be attributed to partial oxidation of these coatings in air annealing conditions. This is illustrated in Figure 60 which shows the bluish oxide scale on a top of NiZr metal alloy thin film coating.

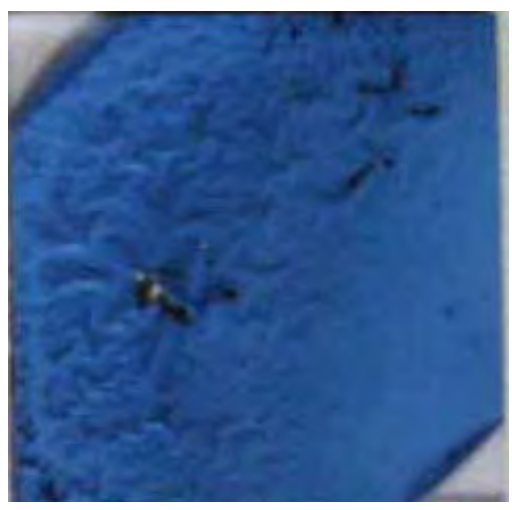

Figure 60: Optical photograph of oxidized NiZr coating after 24 hrs of air annealing at $300^{\circ} \mathrm{C}$.

Four samples were placed in the furnace for 24 hours at $350^{\circ} \mathrm{C}$. During warm up, soak, and cool down, a slow flow of gas $\left(2 \% \mathrm{H}_{2}\right.$, balance $\left.\mathrm{Ar}\right)$ passed through the sample chamber of the furnace. Samples that were subjected to the 24 hour heat test were sent to UW for XRD analyses. Duplicates of the four samples that were not subjected to the 24 hour heat test were sent to UW for XRD and EDS analyses.

Table 10: EDS Data.

\begin{tabular}{|c|c|c|c|c|c|}
\hline Date & Run & Cu & Zr & Ratio & EDS \\
\hline $1 / 10 / 11$ & 2 & 76.5 & 23.5 & 3.3 & 3.92 \\
\hline $1 / 11 / 11$ & 1 & 52.5 & 47.5 & 1.1 & 1.33 \\
\hline $1 / 11 / 11$ & 2 & 40.0 & 60.0 & 0.66 & 0.83 \\
\hline $1 / 12 / 11$ & 1 & 22.1 & 77.9 & 0.28 & 0.43 \\
\hline
\end{tabular}

EDS analyses of the as received foils were consistently higher in copper than the suggested ratios provided by SwRI. We don't know if this is an artifact of the analysis or a true deviation from the production ratios. Each of the as received $\mathrm{CuZr}$ foils showed as an amorphous hump with sharp peaks at 43.5 and $51^{\circ} 2 \theta$ corresponding to the stainless steel substrate. The center of the amorphous hump varied between 37 and $42^{\circ}$ without any specific relationship with the $\mathrm{Cu} / \mathrm{Zr}$ ratio. 
Each of the XRD patterns for the foils run at $350^{\circ} \mathrm{C}$ for 24 hours showed the growth of crystalline peaks. There are at least two species that form depending on the $\mathrm{Cu} / \mathrm{Zr}$ ratio. In the high copper foils, the peaks form for one species at $28.5,30.5$ and $31.5^{\circ} 2 \theta$. A different species forms with the high zirconium alloy at 32.5 and $36^{\circ} 2 \theta$.

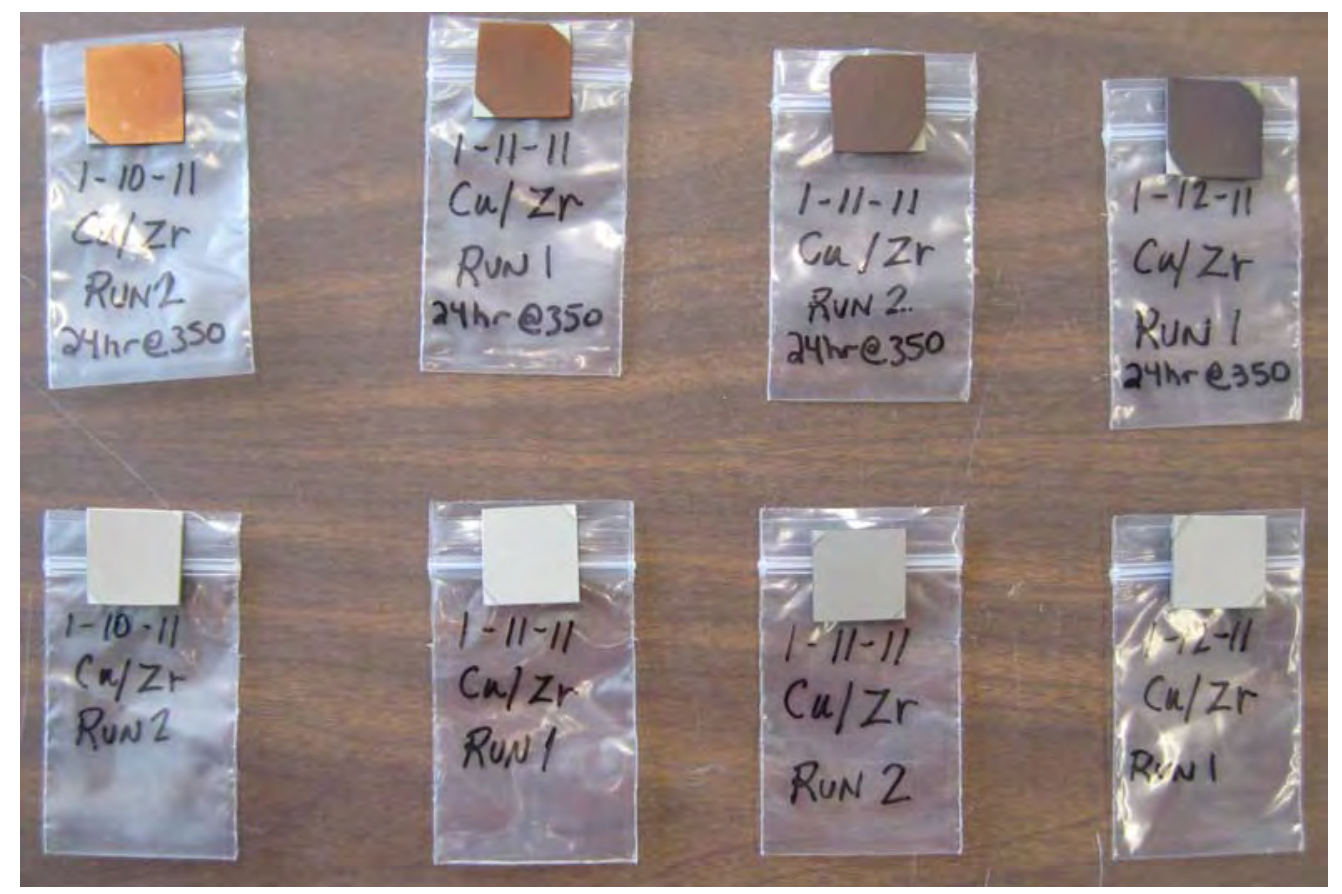

Figure 61: Color change of samples following exposure to $350^{\circ} \mathrm{C}$.

The colors after heat treatment were consistent with the presence of excess copper.

None of the CuZr foils are stable at $350^{\circ} \mathrm{C}$. The decomposition species vary with copper content. Three samples were placed in the furnace for 24 hours at $350^{\circ} \mathrm{C}$. During warm up, soak, and cool down, a slow flow of gas $\left(2 \% \mathrm{H}_{2}\right.$, balance Ar) passed through the sample chamber of the furnace. Samples that were subjected to the 24 hour heat test were sent to UW for XRD analyses. Duplicates of the three samples that were not subjected to the 24 hour heat test were sent to UW for XRD and EDS analyses.

Table 11: EDS Data as Atomic Percent.

\begin{tabular}{|c|c|c|c|}
\hline Date & Cu & Zr & Ti \\
\hline $1 / 18 / 11$ & 66.5 & 30 & 3.5 \\
\hline $1 / 19 / 11$ & 49 & 46 & 5 \\
\hline $1 / 20 / 11$ & 48 & 46 & 6 \\
\hline
\end{tabular}

Each of the as received CuZrTi foils showed as an amorphous hump with sharp peaks at 43.5 and $51^{\circ} 2 \theta$ corresponding to the stainless steel substrate. The center of the 
amorphous hump varied between 39 and $41^{\circ}$ without any specific relationship with the $\mathrm{Cu} / \mathrm{Zr}$ ratio. Each of the XRD patterns for the foils run at $350^{\circ} \mathrm{C}$ for 24 hours showed the growth of crystalline peaks. A comparison with standard spectra of $\mathrm{Cu}$ metal, $\mathrm{Zr}$ metal, $\mathrm{CuZr}_{2}$, CuZr, and $\mathrm{Cu}_{5} \mathrm{Zr}$ was surprisingly unproductive. These are the most likely species to be found from crystallization of the amorphous alloy, but except for what might be $\mathrm{Zr}$ metal in the alloys with the most $\mathrm{Zr}$, there is no obvious presence of any of the other species in the XRD spectra. The XRD of the alloy with the most copper in this batch of CuZrTi was similar to the XRD of the CuZr alloy with the most copper with peaks at 28.5, 30.5 and $31.5^{\circ} 2 \theta$. The spectra for the alloys with more $\mathrm{Zr}$ and $\mathrm{Ti}$ are more complex but remain undefined.

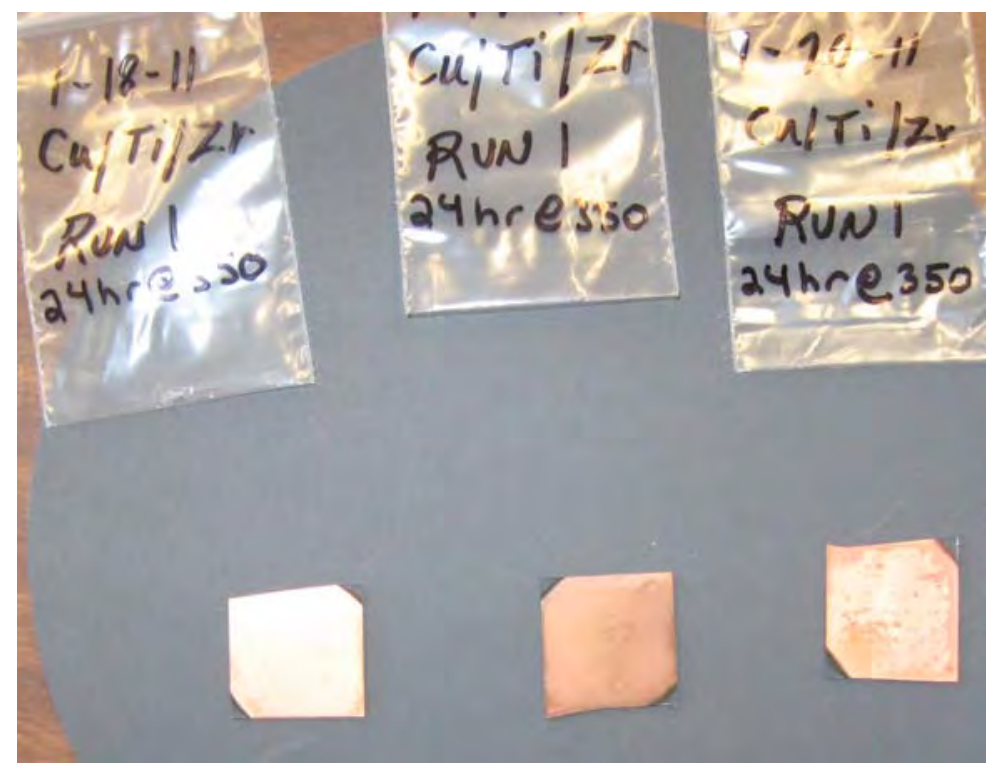

Figure 62: Color change following heat treatment to $350^{\circ} \mathrm{C}$.

The colors after heat treatment were consistent with the presence of excess copper. Three samples were placed in the furnace for 24 hours at $250^{\circ} \mathrm{C}$. During warm up, soak, and cool down, a slow flow of gas $\left(2 \% \mathrm{H}_{2}\right.$, balance $\left.\mathrm{Ar}\right)$ passed through the sample chamber of the furnace. Samples that were subjected to the 24 hour heat test were sent to UW for XRD and EDS analyses. There was an incident with the first batch of samples intended for a $250^{\circ} \mathrm{C}$ test were taken to $350^{\circ} \mathrm{C}$ for 45 minutes by accident. That test was stopped and the samples replaced in the furnace and restarted. 
Table 12: EDS Data as Atomic Percent.

\begin{tabular}{|l|l|l|l|l|l|l|}
\hline \multirow{2}{*}{ Date } & \multicolumn{3}{|c|}{ Nominal } & \multicolumn{3}{c|}{ UW Test Data } \\
\cline { 2 - 7 } & $\mathbf{C u}$ & $\mathbf{Z r}$ & $\mathbf{T i}$ & $\mathbf{C u}$ & $\mathbf{Z r}$ & \multicolumn{1}{|c|}{$\mathbf{i}$} \\
\hline $1 / 21 / 11$ & 43 & 52 & 5.4 & 58 & 36 & 5.6 \\
\hline $1 / 24 / 11$ & 41 & 50 & 9.5 & 45 & 44 & 10.8 \\
\hline $1 / 25 / 11$ & 41 & 50 & 9.4 & 47 & 43 & 10.3 \\
\hline $1 / 26 / 11$ & 50 & 41 & 9.8 & 55 & 34 & 10.4 \\
\hline $1 / 27 / 11$ & 50 & 40 & 9.5 & 55 & 34 & 10.1 \\
\hline $1 / 28 / 11$ & 53 & 39 & 8.3 & 60 & 30 & 9.8 \\
\hline $1 / 31 / 11$ & 63 & 28 & 8.3 & 73 & 18 & 9.0 \\
\hline
\end{tabular}

Because there were not sufficient unheated samples for EDS analysis, the heat treated samples were used for EDS. The copper sheen of most of the heat treated materials and the excessive amount of copper found on the surface of the tested alloys relative to the nominal composition may indicate that there is some differentiation of copper on the surface caused by the thermal test.

In general, the XRD data from the $250^{\circ} \mathrm{C}$ thermal treatment showed that the alloys were much more stable than they had been at $350^{\circ} \mathrm{C}$. The spectra were mostly amorphous humps with small indications of peaks developing. The exception was the samples from the alloy produced on 1/21/11 which had somewhat larger XRD peaks. The small counts attributed to the stainless steel substrates were smaller than for some previous samples which indicate that these alloy coatings may have been thicker. The individual patterns are attached.

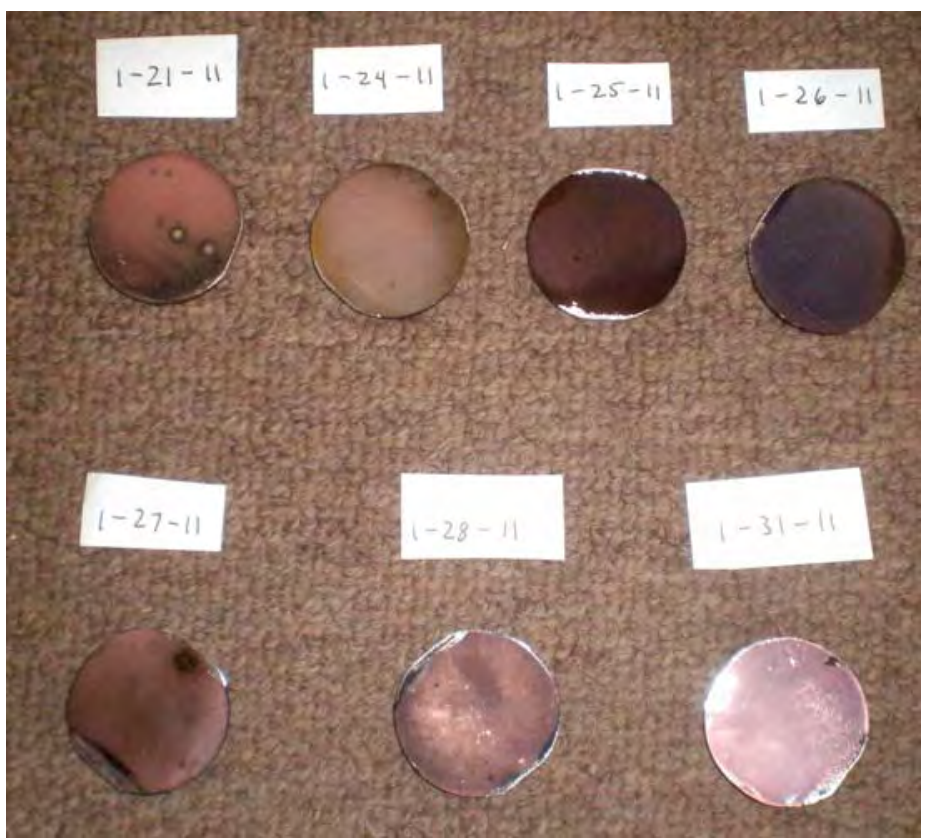

Figure 63: Sample discoloration after heating to $250^{\circ} \mathrm{C}$. 
The colors after heat treatment were consistent with the presence of excess copper at the surface. The darker colors for samples from $1 / 25$ and 1/26 were consistent with the most amorphous character noted from XRD.

Three samples were placed in the furnace for 24 hours at $200^{\circ} \mathrm{C}$. During warm up, soak, and cool down, a slow flow of gas $\left(2 \% \mathrm{H}_{2}\right.$, balance Ar) passed through the sample chamber of the furnace. Samples that were subjected to the 24 hour heat test were sent to UW for XRD and EDS analyses.

Table 13: EDS data as atomic percent.

\begin{tabular}{|c|c|c|c|c|c|c|}
\hline \multirow{2}{*}{ Date } & \multicolumn{3}{|c|}{ Nominal } & \multicolumn{3}{c|}{ UW Test Data } \\
\cline { 2 - 7 } & $\mathbf{C u}$ & $\mathbf{Z r}$ & Ta & $\mathbf{C u}$ & $\mathbf{Z r}$ & Ta \\
\hline $2 / 3 / 11$ & 40 & 50 & 10 & 45 & 46 & 9 \\
\hline $2 / 7 / 11$ & 49 & 40 & 11 & 54 & 36 & 10 \\
\hline $2 / 8 / 11$ & 57 & 33 & 10 & 62 & 29 & 10 \\
\hline $2 / 9 / 11$ & 59 & 31 & 10 & 64 & 27 & 9 \\
\hline
\end{tabular}

The XRD data from the $200^{\circ} \mathrm{C}$ thermal treatment showed that the CuZrTa alloys were stable. The spectra were amorphous humps. The small counts attributed to the stainless steel substrates were smaller than for some previous samples which indicate that these alloy coatings may have been thicker. The individual patterns are attached.

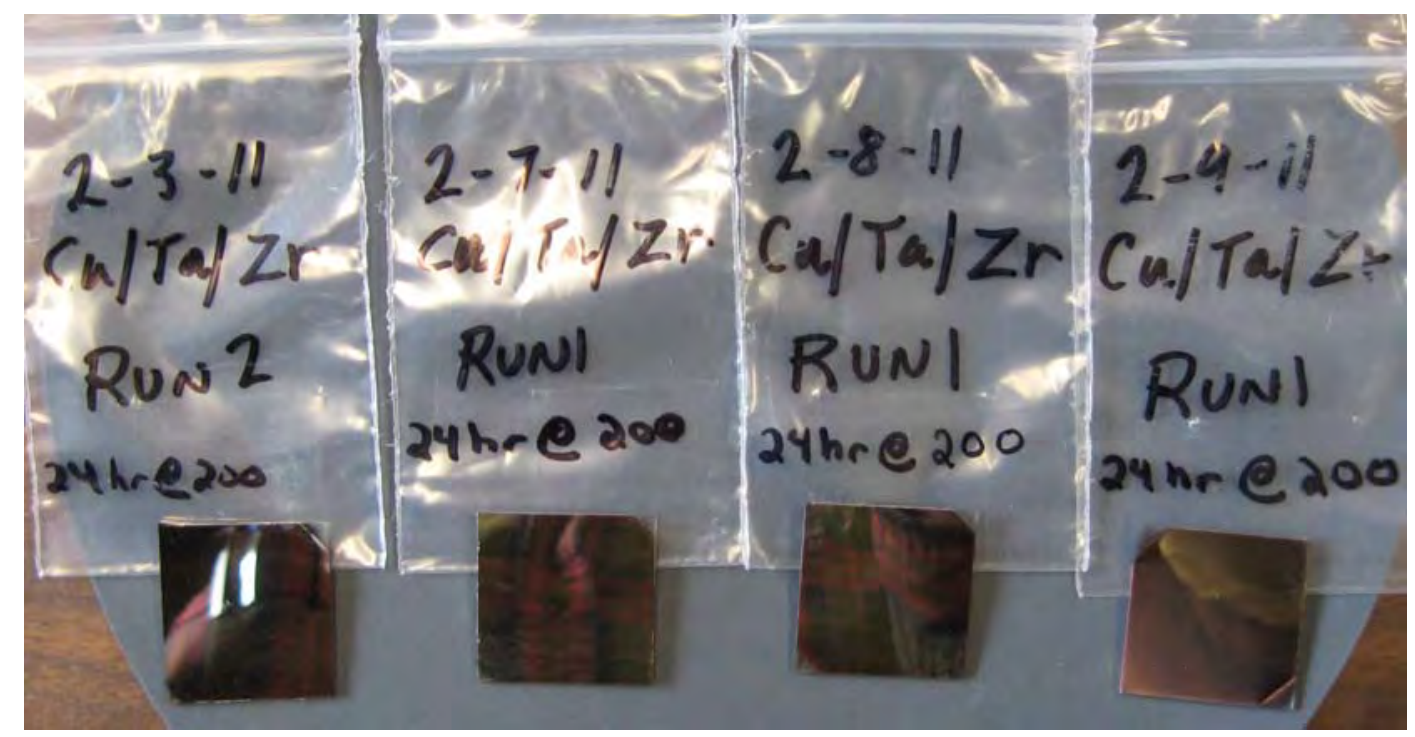

Figure 64: Discoloration after heating to $200^{\circ} \mathrm{C}$. 
Discoloration after 24 hours at $200^{\circ} \mathrm{C}$ was minimal. Three samples were placed in the furnace for 24 hours at $200^{\circ} \mathrm{C}$. During warm up, soak, and cool down, a slow flow of gas ( $2 \% \mathrm{H}_{2}$, balance $\mathrm{Ar}$ ) passed through the sample chamber of the furnace. Samples that were subjected to the 24 hour heat test were sent to UW for XRD and EDS analyses.

Table 14: EDS Data as Atomic Percent

\begin{tabular}{|l|l|l|l|l|l|l|}
\hline \multirow{2}{*}{ Date } & \multicolumn{3}{|c|}{ Nominal } & \multicolumn{3}{c|}{ UW Test Data } \\
\cline { 2 - 7 } & $\mathbf{C u}$ & $\mathbf{Z r}$ & \multicolumn{1}{|c|}{ Ta } & $\mathbf{C u}$ & $\mathbf{Z r}$ & \multicolumn{1}{|c|}{ Ta } \\
\hline $2 / 3 / 11$ & 40 & 50 & 10 & 45 & 46 & 9 \\
\hline $2 / 7 / 11$ & 49 & 40 & 11 & 54 & 36 & 10 \\
\hline $2 / 8 / 11$ & 57 & 33 & 10 & 62 & 29 & 10 \\
\hline $2 / 9 / 11$ & 59 & 31 & 10 & 64 & 27 & 9 \\
\hline
\end{tabular}

The XRD data from the $200^{\circ} \mathrm{C}$ thermal treatment showed that the CuZrTa alloys were stable. The spectra were amorphous humps. The small counts attributed to the stainless steel substrates were smaller than for some previous samples which indicate that these alloy coatings may have been thicker.

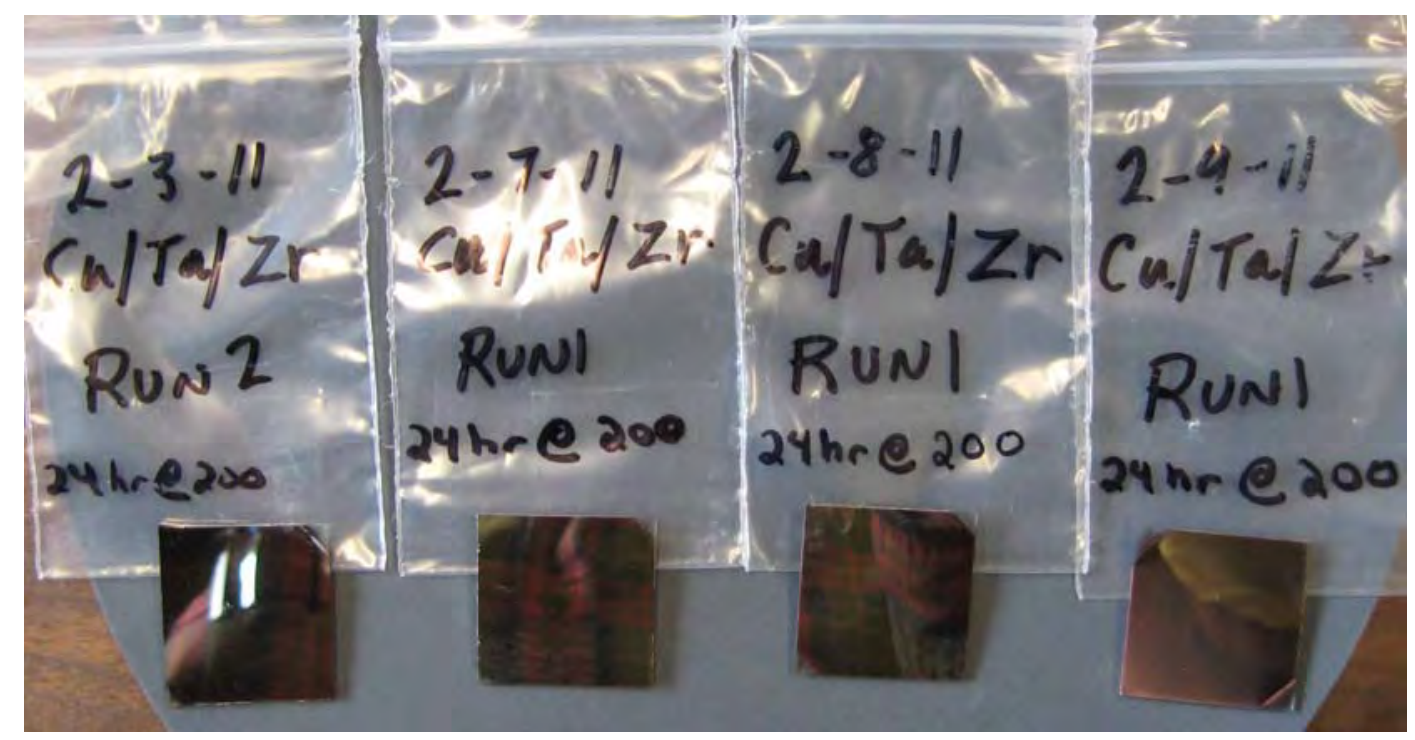

Figure 65: Discoloration after 24 hours at $200^{\circ} \mathrm{C}$ was minimal.

NETL has established a protocol for testing of hydrogen separating membranes which includes criteria for gas composition, sweep gas, feed pressure and temperature. Supported amorphous alloy membranes were prepared of a number of alloy compositions with a nominal size of 1 " diameter cylinder with an active length of 6". The hydrogen flux of these membranes were measured in equipment previously used for testing 
vanadium disc membranes. Helium leak tests at 200 psig were conducted first to determine the presence of any membrane defects. Baseline tests were conducted using pure hydrogen at 100 psig and argon sweep near atmospheric pressure. A gas chromatograph was used to measure hydrogen product concentrations. Each membrane was then tested in the protocol test mixture \#1 and flux values recorded over 8 hours. The alloys showing best performance were then tested under protocol test mixtures 2a, $2 \mathrm{~b}$, and 2c. The best performing alloy were tested under a chosen test mixture for 100 hours. Alterations of the slip stream of syngas from WRI's coal gasifier were planned to increase the testing pressure of the system. In a parallel project funded from the State of Wyoming and a DOE Cooperative agreement, WRI designed a hydrogen test facility which contained the equipment for future membrane testing.

Table 15: NETL test conditions.

\begin{tabular}{|c|c|c|c|c|}
\hline & Test 1 & Test 2a & Test 2b & Test 2c \\
\hline Gas Comp. & & & & \\
\hline $\mathrm{H}_{2} \%$ & 50 & 50 & 33 & 5 \\
\hline $\mathrm{CO} \%$ & 1 & 1 & 1.3 & 2 \\
\hline $\mathrm{CO}_{2} \%$ & 30 & 30 & 40 & 57 \\
\hline $\mathrm{H}_{2} \mathrm{O} \%$ & 19 & 19 & 25 & 36 \\
\hline $\mathrm{H}_{2} \mathrm{~S}$ ppm & 0 & 20 & 30 & 40 \\
\hline Pressure & $200 \mathrm{psig}$ & $200 \mathrm{psig}$ & $200 \mathrm{psig}$ & $200 \mathrm{psig}$ \\
\hline Temperature & $500-650^{\circ} \mathrm{C}$ & $500-650^{\circ} \mathrm{C}$ & $500-650^{\circ} \mathrm{C}$ & $500-650^{\circ} \mathrm{C}$ \\
\hline
\end{tabular}

The Cr coating on the porous substrate held 100 psid but leaked continuously at ambient temperature.

2 samples were sent to the Southern Research Institute, National Carbon Capture Center for exposure to syngas during gasifier run R06. These samples were designated 1-11-11 (2 notches) and 1-20-11 (3 notches). These samples were installed in the WPI guard vessel and were exposed to the following approximate conditions:

Exposure time $=550$ hours

Gas Temperature $=250 \mathrm{~F}$

Gas Pressure $=175$ psig

Typical Gas Composition:

\begin{tabular}{|c|c|}
\hline $\mathrm{H} 2$ & 33.09 \\
\hline $\mathrm{N} 2$ & 52.01 \\
\hline $\mathrm{CH} 4$ & 0.84 \\
\hline $\mathrm{CO}$ & 6.65 \\
\hline $\mathrm{CO} 2$ & 6.60 \\
\hline $\mathrm{H} 2 \mathrm{~S}$ & 0.00 \\
\hline
\end{tabular}


Unfortunately, the $\mathrm{H}_{2} \mathrm{~S}$ sorbent vessel upstream of the samples exceeded expectations and essentially no $\mathrm{H}_{2} \mathrm{~S}$ was present at our location.

A copper coated tube was supplied to WRI to develop a fixture for holding the new design and to see if the application of an intermediate copper bond layer would negatively impact the performance of the tubular design. In Figure 67, the interface between the solid stainless and the porous substrate is shown with the 11.0 microns of $\mathrm{Cu}$ coating.

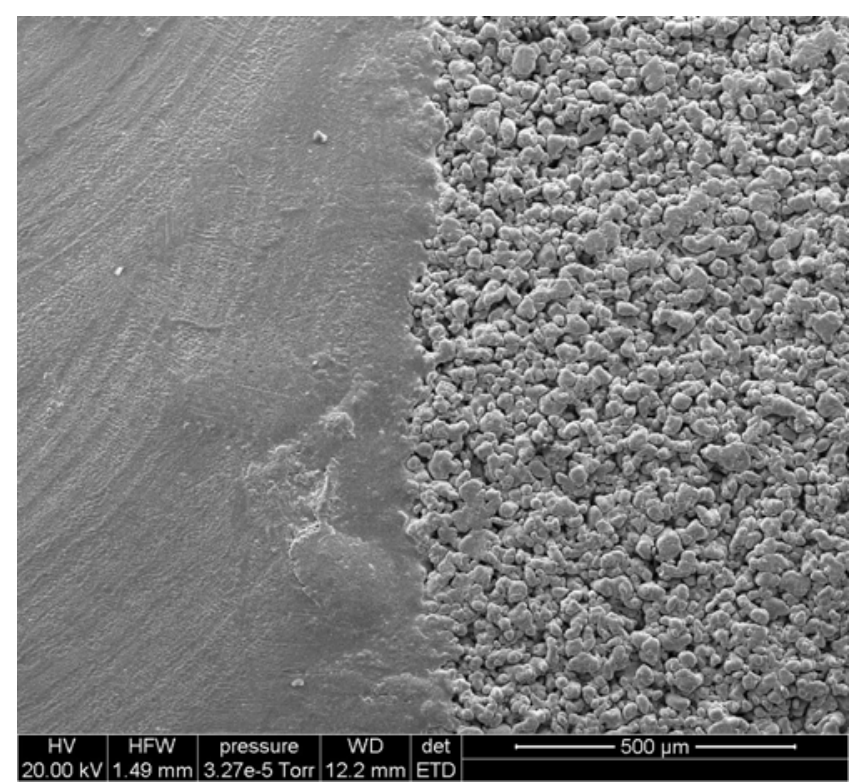

Figure 66: Solid/porous interface on Stainless tube. The tube is coated with $\mathrm{Cu}$.

There is no delineation in the coating from the solid to the porous tube and as shown in Figure 66, an EDS scan of the surface shows the $\mathrm{Cu}$ coating completely covering the underlying stainless.

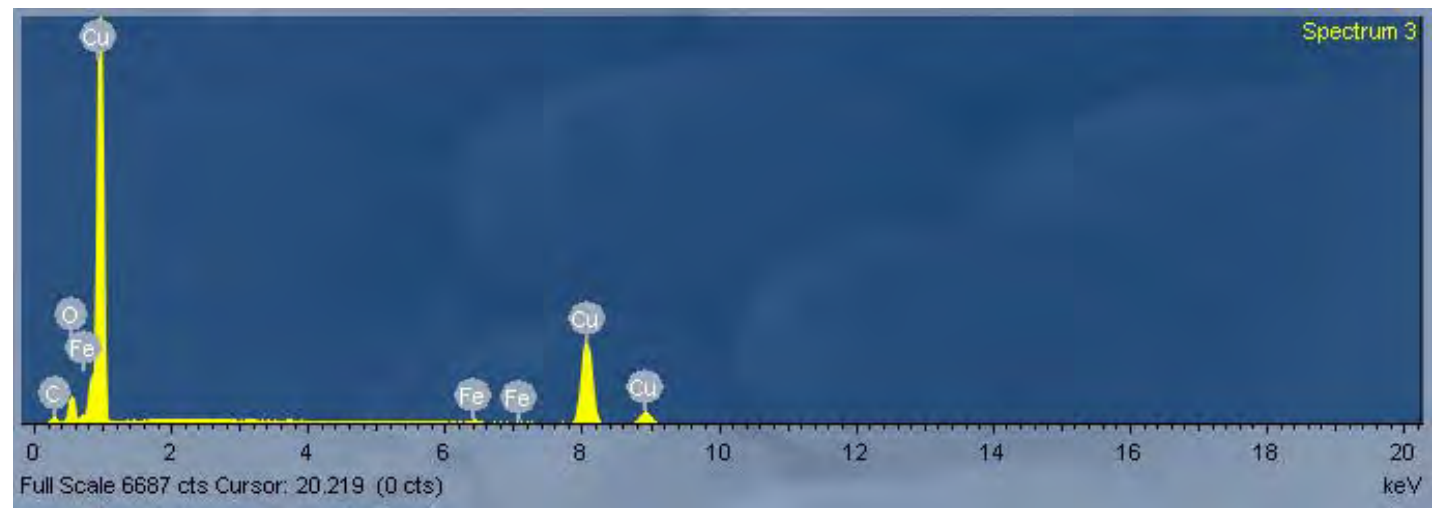

Figure 67. EDS of $\mathrm{Cu}$ Coated tube. 
WRI pressure tested the coated and recoated $\mathrm{ZrCu}$ membranes. Neither held pressure, in fact WRI can freely pull air through the coating. The sample was returned to SwRI for additional coating.

\subsection{Administrative}

A total of 20 conference calls were held over the course of the program with additional collaborative opportunities identified by the team members. On June 14, 2011, Steven Markovich, DOE Program Manager, visited SwRI and was provided a project review and a tour of the facility. On September 3, 2013 Dr. Tom Barton visited SwRI to review the project and identify new opportunities to collaborate.

On March 15, 2011 a joint conference call was held that included the University of Nevada at Reno Team that also is working on Amorphous Alloys for hydrogen separation. In the call, introductions were made and several key findings were exchanged between the teams with a few joint experiments agreed upon. As a result of the call, samples of $\mathrm{Ni}_{30} \mathrm{Zr}_{70}$ and $\mathrm{Ni}_{63.7} \mathrm{Zr}_{36.3}$ prepared by melt spinning for the Nevada Team were provided for inclusion in the thermal stability tests being carried out at WRI. NiZr samples deposited at SwRI were provided to the Nevada Team. In addition to the amorphous alloy membrane development, the University of Nevada team sent several melt spun ribbons that were coated with $100 \mathrm{~nm}$ of Pd as a catalyst layer. These were coated and returned. Dr, Dhanesh Chandra from the University of Nevada at Reno Team visited SwRI on August 9, 2011 and several potential collaborations between their project and this project were discussed. There were multiple individual communications with the Project Team at the University of Nevada at Reno regarding the coating of palladium discussed previously.

A key development was the departure of Shiqiang Hao from Dr. Sholl's group at GT. Shiqiang had led the modeling effort and he took a position as a Senior Research Associate at Northwestern University. A new postdoc, Rongshun Zhu, was hired. Given the departure of Shiqiang, the challenges related to sealing the membranes, and the low spend rate at GT and WRI, the team discussed requesting a no cost time extension to further advance the development of the amorphous alloys. While the deliverables for the project were met in the original duration, the opportunity to better understand some of the fundamental characteristics and make improvements to the amorphous alloys was anticipated. A letter requesting the extension was provided to Steve Markovich on April 11, 2012 and a modified SOPO was provided on May 24, 2012.

A total of four presentations were made at national and international meeting including the U.S. Department of Energy 2010 Hydrogen Program and Vehicle Technologies Program Annual Merit Review and Peer Evaluation Meeting held June 7-11 in Washington, D.C., the North American Membrane Society Meeting in Las Vegas on June 7, 2011, the 2011 American Institute of Chemical Engineers Annual Meeting in Minneapolis on October 16-21, 2011, and the Society of Vacuum Coaters Renewable Energy topical session held April 20-25, 2013. 
Meetings were held at the American Institute of Chemical Engineers Annual Meeting in Minneapolis with substrate suppliers and colleagues in the membrane community on the sealing issue. Meetings were held with Steve Paglieri of TDA Research, Ashok Damle of Pall, James Klein of Savannah River National Laboratories, Tim Ward of the University of New Mexico, and Jamie Davenport of IdaTech LLC.

The following publications resulted from this project.

1. First-principles Models of facilitating $\mathrm{H}_{2}$ Transport Through Metal Films Using Spillover Hao, S. and D. S. Sholl J. Phys. Chem. C. 2013, 117 (3), 1217.

2. Rapid Prediction of Hydrogen Permeation Through Amorphous Metal Membranes: An Efficient Computational Screening Approach Hao, S. and D. S. Sholl, Energy Environ. Sci., 2013, 6, 232.

3. Comparison of first principles calculations and experiments for hydrogen permeation through amorphous $\mathrm{ZrNi}$ and $\mathrm{ZrNiNb}$ films, Hao, S. and D. S. Sholl Journal of Membrane Science 350 (2010) 402-409

4. Computational prediction of durable amorphous metal membranes for $\mathrm{H}-2$ purification, Hao, S. and D. S. Sholl, Journal of Membrane Science 381 (2011) 192-196.

5. GT is preparing one paper that will be submitted to J. Phys. Chem. C.

6. SwRI is preparing a manuscript for submission to J. Vacuum Sci. and Tech.

\subsection{CONCLUSION}

At the beginning of this project, thin film amorphous alloy membranes were considered a nascent but promising new technology for industrial-scale hydrogen gas separations from coal-derived syngas. This project used a combination of theoretical modeling, advanced physical vapor deposition fabricating, and laboratory and gasifier testing to develop amorphous alloy membranes that had the potential to meet Department of Energy (DOE) targets in the testing strategies outlined in the NETL Membrane Test Protocol. The project is complete with Southwest Research Institute ${ }^{\circledR}\left(\mathrm{SwRI}^{\circledR}\right)$, Georgia Institute of Technology (GT), and Western Research Institute (WRI) having all operated independently and concurrently. GT studied the hydrogen transport properties of several amorphous alloys and found that $\mathrm{ZrCu}$ and $\mathrm{ZrCuTi}$ were the most promising candidates. GT also evaluated the hydrogen transport properties of $\mathrm{V}, \mathrm{Nb}$ and Ta membranes coated with different transition-metal carbides (TMCs) $(\mathrm{TM}=\mathrm{Ti}, \mathrm{Hf}, \mathrm{Zr}$ ) catalytic layers by employing first-principles calculations together with statistical mechanics methods and determined that $\mathrm{TiC}$ was the most promising material to provide catalytic hydrogen dissociation. SwRI developed magnetron coating techniques to deposit a range of amorphous alloys onto both porous discs and tubular substrates. Unfortunately none of the amorphous alloys could be deposited without pinhole defects that undermined the selectivity of the membranes. WRI tested the thermal properties of the $\mathrm{ZrCu}$ and $\mathrm{ZrNi}$ alloys and found that under reducing environments the upper temperature limit of operation without recrystallization is $\sim 250^{\circ} \mathrm{C}$. There were four publications generated 
from this project with two additional manuscripts in progress and six presentations were made at national and international technical conferences. The combination of the pinhole defects and the lack of high temperature stability make the theoretically identified most promising candidate amorphous alloys unsuitable for application as hydrogen separation membranes in coal fire systems.

\subsection{REFERENCES}

1. S. Hao, D. S. Sholl, Energy Environ. Sci., 1 (2008) 175; S. Hao, M. Widom, D. S. Sholl, J. Phys.: Condens. Matter, 21 (2009) 115402; S. Hao, D. S. Sholl, J. Chem. Phys. 130 (2009) 244705.

2. S. I. Yamaura, M. Sakurai, M. Hasegawa, K. Wakoh, Y. Shimpo, M. Nishida, H. Kimura, E. Matsubara, A. Inoue, Acta Materialia 53 (2005) 3703; S. Hara, K. Sakaki, N. Itoh, H.-M. Kimura, K. Asami, A. Inoue, J. Membr. Sci. 164 (2000) 289. 